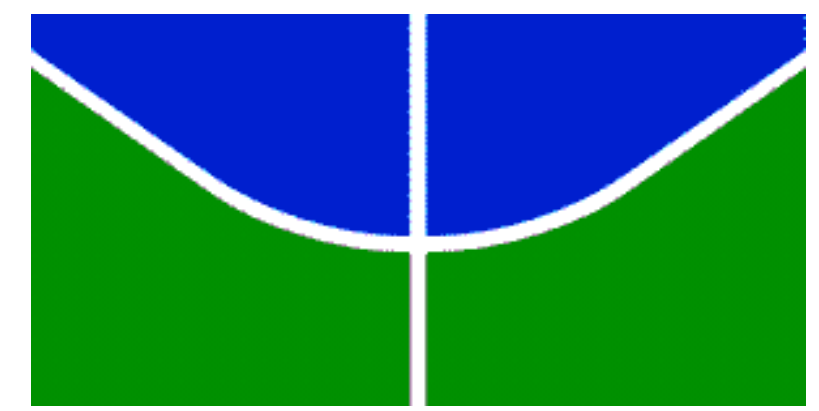

UNIVERSIDADE DE BRASÍLIA

INSTITUTO DE QUÍMICA

\title{
Síntese e Caracterização de Nanocompósitos de Carbon-Dot e Lantanídeos
}

\author{
Daniel de A. Moreira
}

Orientador: Prof. Dr. Marcelo Oliveira Rodrigues Coorientador: Prof. Dr. Brenno Amaro da Silveira Neto

Brasília, dezembro de 2015 
UNIVERSIDADE DE BRASÍLIA

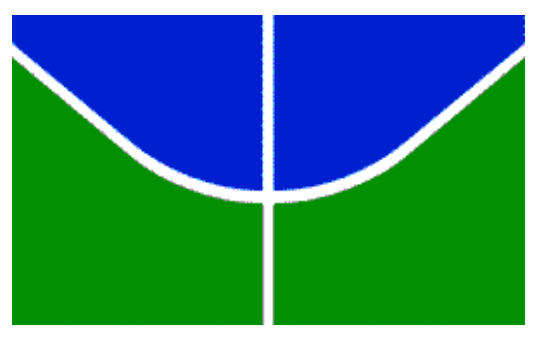

INSTITUTO DE QUÍMICA

Programa de Pós-Graduação

EM QUÍMICA - PPGQ

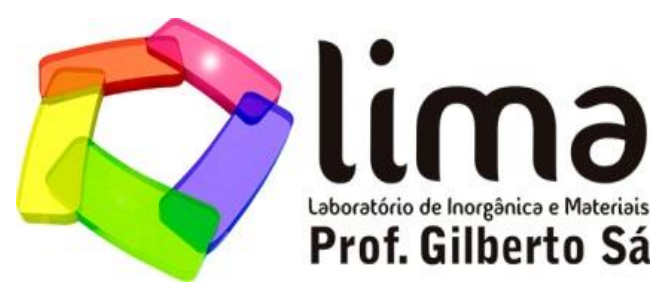

LABORATÓRIO DE INORGÂNICA E MATERIAIS - LIMA

\section{Síntese e Caracterização de Nanocompósitos de Carbon-Dot e Lantanídeos}

Daniel de A. Moreira 
"Não tenho mais nada para Ihe ensinar, não tenho mais nada a dizer.

Exceto que estou muito orgulhoso de você e todo dia eu penso no espírito eternamente reencarnado de meu sensei e nas coisas que ele tentou me ensinar na base da porrada. Rezo para que você se dê melhor neste mundo do que eu. Que encontre a paz onde eu não encontrei nenhuma. Mas quero que saiba que você não estará sozinho." Matt Murdock - Demolidor (Fim Dos Dias, Vol. 8 - Brian M. Bendis e David Mack) 


\section{Agradecimentos}

Agradeço a vida por estar aqui e ao destino por permitir ser alcançado.

Agradeço a minha família e a minha companheira por estarem sempre presentes me tirando ou me colocando no eixo.

Agradeço aos meus tutores por acreditarem em mim e pela paciência.

Agradeço aos meus amigos, por serem meus amigos, perto ou distante.

Agradeço aos meus colegas pelo respeito e pela companhia.

Agradeço a todos que fizeram e fazem parte da minha vida.

Nomes são muitos, uma folha de papel não caberiam todos, mas saibam que serei sempre grato. 


\section{Sumário}

AGRADECIMENTOS ..................................................... II

RESUMO ......................................................................... V

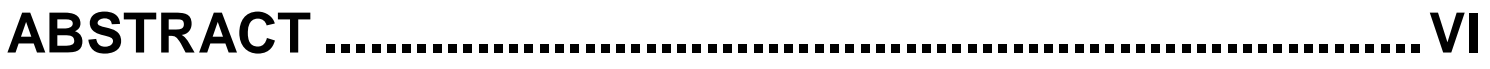

LISTA DE ABREVIAÇÕES E ACRÔNIMOS .................... VII

LISTA DE FIGURAS .................................................. VIII

LISTA DE TABELAS ......................................................

INTRODUÇÃO............................................................ 1

OBJETIVOS ….................................................................. 12

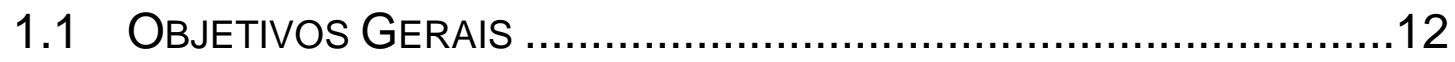

1.2 OBjetIVOS ESPECÍ́FICOS ....................................................12

PARTE EXPERIMENTAL ............................................. 13



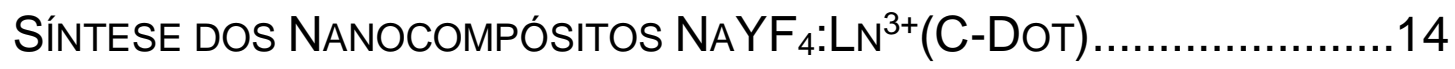

CARACTERIZAÇÃO DOS MATERIAIS ..............................................16

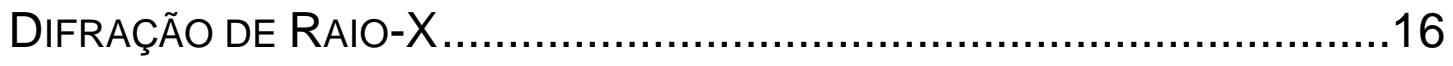

MICROSCOPIA ELETRÔNICA DE VARREDURA ......................................16

Microscopia Eletrônica de Transmissão de Alta ResoluÇão ...16 
ESPECTROSCOPIA DE INFRAVERMELHO COM TRANSFORMADA DE

FOURIER.

ESPECTROSCOPIA DE LUMINESCÊNCIA ..........................................17

RESULTADOS E DISCUSSÃO ..................................... 19

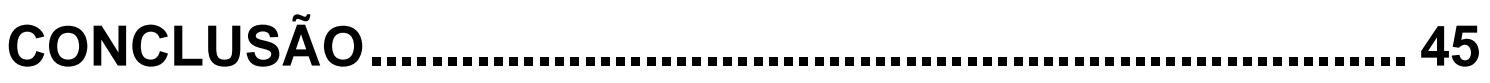

PERSPECTIVAS ........................................................... 46

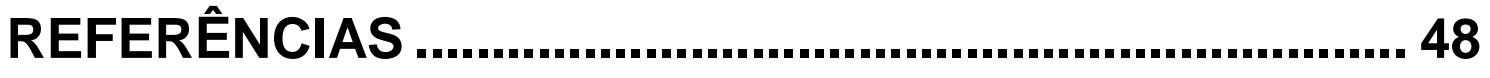

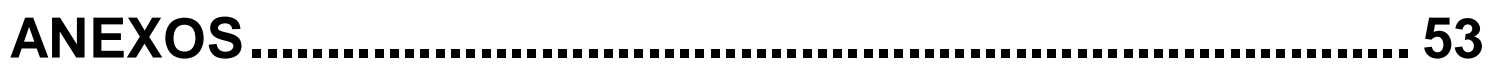




\section{Resumo}

Este trabalho baseia-se na síntese e caracterização de compósitos a partir de nanocristais de NaYF $4: E u$ ou NaYF $4: T b$ e nanopartículas de carbono conhecidas como carbon-dots ou carbon-nanodots, também chamados de CDots, afim de desenvolver e estudar novos materiais luminescentes. Os compósitos são sintetizados por dois métodos, via coprecipitação, onde foram obtidos materiais nanométricos com diâmetros a partir de $25 \mathrm{~nm}$, com baixa cristalinidade, tempos de vida próximos de $1 \mathrm{~ms}$ e rendimentos quânticos abaixo de $1 \%$, para a via hidrotermal, foram obtidos compósitos micrométricos com diâmetro a a partir de $300 \mathrm{~nm}$, cristais de fase hexagonal tempos de vida próximos a $1 \mathrm{~ms}$ e rendimentos quânticos abaixo de 1\%, os compósitos coprecipitados apresentaram luminescência superior aos tratados hidrotermalmente. Houve variação de concentração de C-Dots nas sínteses, visando morfologias e tamanhos distintos e a relação destes com as propriedades luminescentes do material, maiores concentrações de C-Dots indicaram maior agregação dos compósitos, baixa intensidade luminescente e menores tempos de vida, baixas concentrações geraram compósitos dispersos, com intensidade luminescente e tempos de vida superiores as demais concentrações.

Palavras-Chave: Compósitos, Európio, Térbio, Carbon-Dot, C-Dot, Luminescência. 


\section{Abstract}

This work is about the synthesis and characterization of composites from nanocrystals of $\mathrm{NaYF}_{4}: \mathrm{Eu}$ or $\mathrm{NaYF}_{4}: \mathrm{Tb}$ and nanoparticles of carbon, known as carbon-dot or carbon-nanodots, also called of C-Dots to develop and study new luminescent materials. The composites are sintherized by two differents methods co-precipitation and hydrothermal. Using co-precipitation the materials obtained are nanomerics, with diameter from $25 \mathrm{~nm}$, They have low crystallinity and lifetime next to $1 \mathrm{~ms}$ and quantum yeld bellow $1 \%$. Using the hydrothermal method the materials obtained are micrometric composites of hexagonal phase, with diameter from $300 \mathrm{~nm}$, lifetime next to $1 \mathrm{~ms}$ and quantum yeld bellow $1 \%$. The co-precipitates composts shows more luminescence than hydrothermal composts. To obtained sizes and differents morphologies and to determine the relation of this and the luminescence properties the concentration of C-Dots in the sinthezys had been varied. Higher concentrations of C-Dots indicates greater aggregation of composites, low luminescent intensity, shorter lifetime and low concentration produced dispersed composites, with intense luminescence and higher lifetime than with others concentration. 


\section{Lista de Abreviações e Acrônimos}

C-Dots - Carbon-Dots

DE - Operador Dipolo-Elétrico

DM - Operador Dipolo-Magnético

DRX - Difração de Raio-X

FTIR - Espectroscopia de Infravermelho com transformada de Fourier

HRMET - Microscopia Eletrônica de Transmissão de Alta Resolução

HT - Hidrotermal

MEV - Microscopia Eletrônica de Varredura

NIR - Infravermelho Próximo

PEG - Polietilenoglicol

PL - Propriedades Luminescentes

PQ - Ponto Quântico

QD - Quantum Dots

QY - Rendimento Quântico

UV - Radiação Eletromagnética Ultravioleta

Vis - Radiação Eletromagnética do Espectro Visível 


\section{Lista de Figuras}

Figura 1 - Quantum Dot clássico de cádmio, selênio, zinco e enxofre.............. 1

Figura 2 - C-Dot (Passivado - PEG) excitado nos comprimentos de onda indicados na figura. Adaptado da Ref. 12.

Figura 3 - Espectro de emissão, com excitação em $365 \mathrm{~nm}$, de C-Dots sintetizados a partir de oxidação ácida de fibras de carbono com alteração da temperatura, 120, 100 e $80^{\circ} \mathrm{C}$, respectivamente, A, B e C. Adaptado da Ref. 22.

Figura 4 - C-Dot típico de sínteses oxidativas. ............................................. 4

Figura 5 - Ilustração de um C-Dot passivado. Adaptado da Ref. 10................ 4

Figura 6 - a) Imageamento in vivo multicolorido por meio de QDs; b) Imageamento in vivo do câncer de próstata em ratos por meio de QDs.

Adaptado da Ref. 36 ............................................................................ 5

Figura 7 - Diagrama esquemático do funcionamento do efeito antena. ........... 7

Figura 8 - Diagrama esquemático do processo luminescente de downconversion.

Figura 9 - Representação de um Carbon-Dot com lantanídeos suportados em sua superfície. Adaptado das Ref. 71 e 72 .............................................. 11

Figura 10 - Esquema simplificado da síntese de C-Dot .............................. 13

Figura 11 - Esquema simplificado da síntese dos compósitos....................... 15

Figura 12 - Difratograma de Raio-X de pó comparando as fases encontradas nos nanocompósitos com as esperadas em nanocristais convencionais. (-) $\mathrm{NaYF}_{4}:$ Ln Cúbico, (-) NaYF $:$ Ln Cúbico $\rightarrow$ Hexagonal, (-) NaYF $4: \operatorname{Ln}(C-D o t) H T$ e (-) NaYF $4: \operatorname{Ln}(C-D o t)$

Figura 13 - Cristais de NaYF4 em fase a) cúbica e b) hexagonal. Adaptado da referência 75 .

Figura 14 - Imagens de MEV das amostras $\mathrm{Ln}\left(\mathrm{C}_{+}\right)$a) $400 \mu \mathrm{m}$ b) $400 \mathrm{~nm}$ c) 200 nm

Figura 15 - Imagens de MEV das amostras $\operatorname{Ln}(\mathrm{C}+) H T$ a) $40 \mu \mathrm{m}$ b) $5 \mu \mathrm{m}$ c) 3



Figura 16 - Imagens de MEV dos compósitos $\operatorname{Ln}(C)$ a) $400 \mu \mathrm{m}$ b) $40 \mu \mathrm{m}$ c) 400

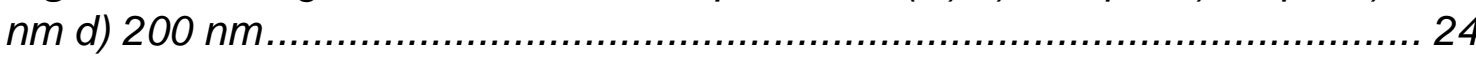

Figura 17 - Imagens de MEV do compósito Ln(C)HT a) $100 \mu \mathrm{m}$ b) $40 \mu \mathrm{m}$ c) 5

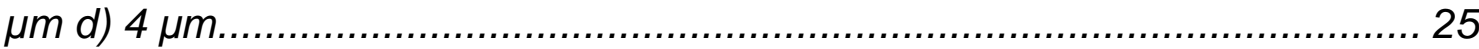

Figura 18 - Imagens de MEV dos compósitos $\operatorname{Ln}(C-)$ a) $400 \mu m$ b) $40 \mu m$ c)

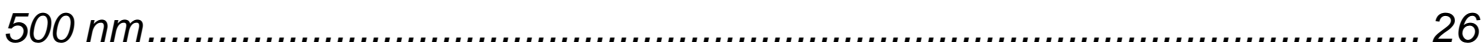

Figura 19 - Imagens de MEV dos compósitos $\operatorname{Ln}(C-) H T$ a) $40 \mu m$ b) $5 \mu m$ c) $1 \mu m$ d) $400 \mathrm{~nm}$....................................................................... 27

Figura 20 - Imagens de HRMET de Compósitos $\operatorname{Ln}(C+)$ a) $100 \mathrm{~nm}$; b) $50 \mathrm{~nm}$;

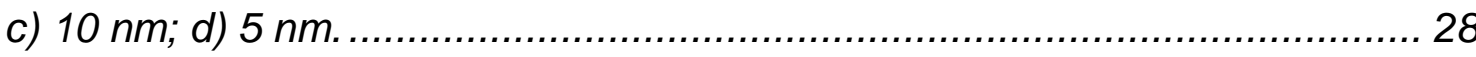

Figura 21 - Imagem de HRMET de Compósito $L n(C$-) com partícula monodispersa com 25,7 nm de diâmetro ................................................ 29

Figura 22 -Imagens de HRMET dos compósitos $\operatorname{Ln}(C-)$ a) $100 \mathrm{~nm}$; b) $10 \mathrm{~nm}$; c)



Figura 23 - Imagens de HRMET dos compósitos $\mathrm{Ln}(\mathrm{C}+) \mathrm{HT}$ a) $100 \mathrm{~nm}$ b) $5 \mathrm{~nm}$

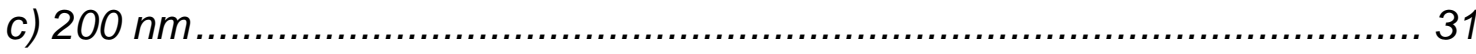


Figura 24 - Espectro de Infravermelho do Carbon-Dot.

Figura 25 - Espectro de Infravermelho das amostras de NaYF4:Eu(C-Dot).

$E u(C+), E u(C)$ e $E u(C-)$, respectivamente, azul, vermelho e preto.

Figura 26 - Espectro de Infravermelho das amostras de $\mathrm{NaYF}_{4}: \mathrm{Tb}(\mathrm{C}-\mathrm{Dot})$.

$\mathrm{Tb}(\mathrm{C}+), \mathrm{Tb}(\mathrm{C})$ e $\mathrm{Tb}(C-)$, respectivamente, azul, vermelho e preto................... 33

Figura 27 - Espectro de Excitação do compósito $\mathrm{Tb}(C$-) .............................. 34

Figura 28 - Espectro de Excitação do compósito $\mathrm{Tb}(C$-) .............................. 35

Figura 29 - Espectro de Excitação do compósito Eu(C-) .............................. 36

Figura 30 - Espectro de Excitação do compósito $E b(C$ - $) H T$........................... 36

Figura 31 - Espectros de Emissão dos compósitos $\mathrm{NaYF}_{4}: \mathrm{Eu}(\mathrm{C}$-) e

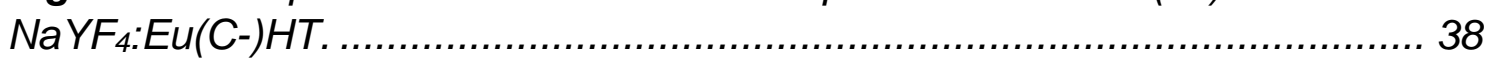

Figura 32 - Gráfico de tempo de vida do compósito NaYF4:Eu(C-) ............... 39

Figura 33 - Espectros de Emissão dos compósitos $\mathrm{NaYF}_{4}: \mathrm{Eu}(\mathrm{C}$-) e

$\mathrm{NaYF}_{4}: \mathrm{Eu}(\mathrm{C}-) \mathrm{HT}$.

Figura 34 - Gráfico de tempo de vida do compósito $\mathrm{NaYF}_{4}: \mathrm{Tb}(\mathrm{C}$-) ................ 42

Figura 35 - Digital recolhida com uso de $\mathrm{NaYF}_{4}$ : $\mathrm{Eu}(\mathrm{C}$-) com imagem

Hiperespectral gerada por meio de emissões na região do NIR.

Figura 36 - Digital recolhida com uso de $\mathrm{NaYF}_{4}: \mathrm{Tb}(\mathrm{C}$-) com imagem

Hiperespectral gerada por meio de emissões na região do NIR.

Figura 37 - Difratograma de Raio-X de pó dos compósitos sintetizados por coprecipitação.

Figura 38 - Difratograma de Raio-X de pó dos compósitos sintetizados por via

hidrotermal

Figura 39 - Espectros de Luminescência dos compósitos NaYF

(-) Excitação e (-) Emissão.

Figura 40 - Espectros de Luminescência dos compósitos NaYF 4 :Eu(C)HT e

(C+)HT; (-) Excitação e (-) Emissão.......................................................... 56

Figura 41 - Espectros de Luminescência dos compósitos $\mathrm{NaYF}_{4}: \mathrm{Tb}(C)$ e (C+);

(-) Excitação e (-) Emissão

Figura 42 - Espectros de Luminescência dos compósitos $\mathrm{NaYF}_{4}: \mathrm{Tb}(\mathrm{C}) \mathrm{HT}$ e $(C+) H T ;(-)$ Excitação e (-) Emissão...................................................... 58

Figura 43 - Tempos de vida dos nanocristais NaYF

Figura 44 - Gráfico de Tempos de Vida dos compósitos NaYF $4: E u(C)$ e (C+).

Figura 45 - Gráficos de Tempos de Vida das Espécies NaYF $4: T b(C)$ e $(C+) . .61$ 


\section{Lista de Tabelas}

Tabela 1 - Configuração eletrônica dos íons Ln(III). Adaptado da Ref. $45 \quad 6$ Tabela 2 - Materiais aferidos para a síntese dos compósitos. 15

Tabela 3 - Parâmetros de análise de emissão e excitação dos compósitos 17

Tabela 4 - Propriedades qualitativas dos compósitos sintetizados 31

Tabela 5 - Tempos de Vida e Rendimento Quântico das espécies

coprecipitadas 


\section{Introdução}

O desenvolvimento de nanomateriais tem se mostrado uma das áreas mais pesquisadas na atualidade por químicos, físicos, engenheiros e diversos outros cientistas de materiais, devido as diversas características atribuídas a esses materiais, propriedades ópticas, eletrônicas e magnéticas; e suas aplicações nas áreas de catálise, bioimageamento e sensores. Suas formas são variadas, nanopartículas, nanotubos, nanoredes, e suas composições podem apresentar, ouro, ferro, carbono, silício, entre outras. Dentre esses materiais existem os Quantum Dots (QDs), também chamados de Pontos Quânticos (PQs), e os nanocristais dopados com íons lantanídeos. ${ }^{1,2}$

Quantum Dots (QDs) tratam-se de estruturas semicondutoras de ordem micrométrica a nanométrica, geralmente entre $1 \mu \mathrm{m}$ a $10 \mathrm{~nm}$, que apresentam mudanças consideráveis em suas características elétricas e ópticas se comparadas a estruturas com a mesma composição química, porém, em volumes maiores. Essas mudanças se devem ao fato de sua superfície confinar elétrons em suas bandas proibidas. ${ }^{3}$

Sua grande eficiência para bioimagens são oriundas de sua estabilidade e sensibilidade o que garante alta qualidade das imagens geradas. A maioria dos QDs caracterizados e utilizados nas pesquisas apresentam uma alta toxidade para organismos vivos devido à presença de metais pesados como, por exemplo, o cádmio, a Figura - 1 exemplifica um QD. Em 2004 surgiu uma nova vertente de QDs que se mostrou eficiente e com baixa toxicidade, se comparadas a outros QDs, são os Carbon-Dots (C-Dots). ${ }^{4,5}$

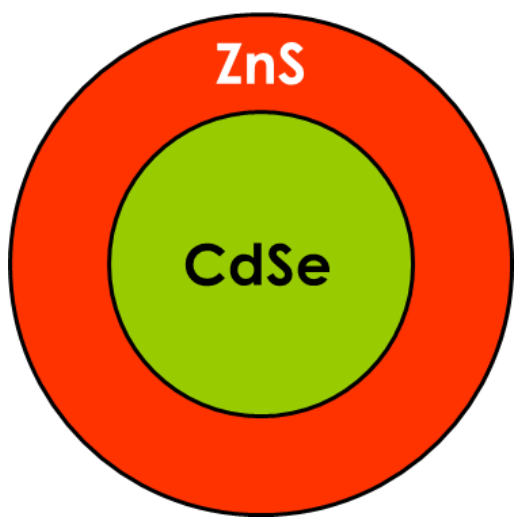

Figura 1 - Quantum Dot clássico de cádmio, selênio, zinco e enxofre. 
Esses C-Dots, são nanomateriais de carbono, com alta dispersão em água, de baixo custo, biocompatíveis, resistentes à fotodegradação, robustez química inerente, facilmente funcionalizado e baixa toxicidade.$^{6-8}$ São compostos basicamente por carbono, oxigênio e nitrogênio, em que a porcentagem de cada um destes átomos varia de acordo com o tipo de síntese e os reagentes utilizados. $^{8}$ Podem apresentar fluorescência nas regiões do espectro ultravioleta, ${ }^{9,10,13}$ visível ${ }^{11,12}$ e infravermelho, ${ }^{13}$ tratam-se de materiais luminescentes do tipo upconversion ou downconversion, ${ }^{14}$ podendo um único material apresentar os dois tipos de sistemas luminescentes ${ }^{15} \mathrm{e}$ ainda podem funcionar como excelentes doadores ou aceptores de elétrons. ${ }^{16} \mathrm{~A}$ Figura -2 apresenta um C-Dot com emissão por todo o espectro visível ao mudar o comprimento de onda excitação. ${ }^{12}$

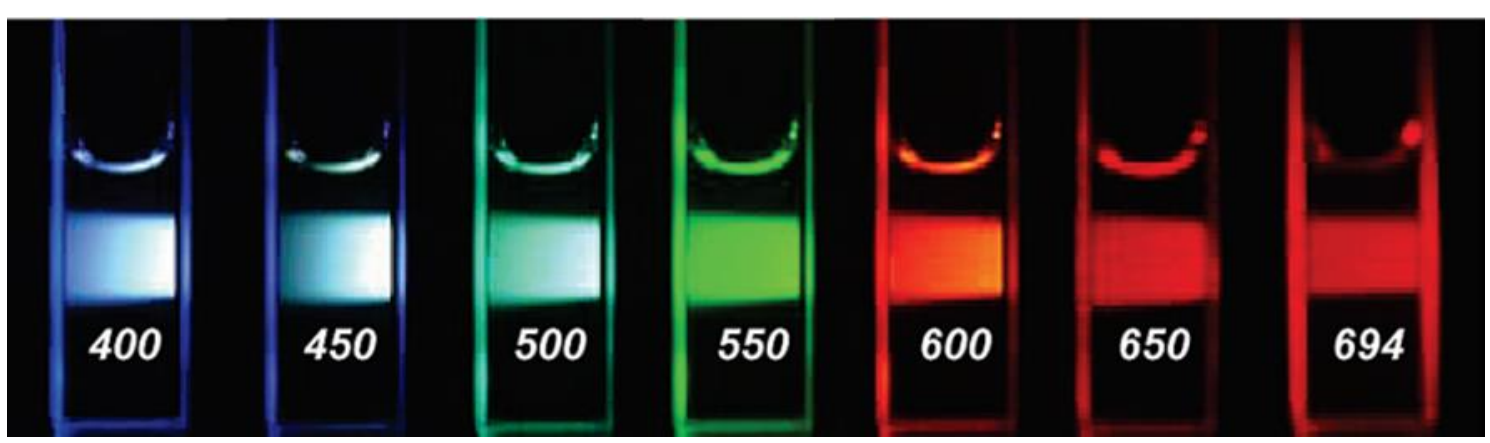

Figura 2 - C-Dot (Passivado - PEG) excitado nos comprimentos de onda indicados na figura. Adaptado da Ref. 12.

Assim como sua composição varia com o tipo de síntese, suas propriedades luminescentes (PL) também variarão, seja pela composição ou estrutura formada. A Figura - 3 mostra o espectro de emissão de C-Dots sintetizados em diferentes temperaturas. ${ }^{22}$ 


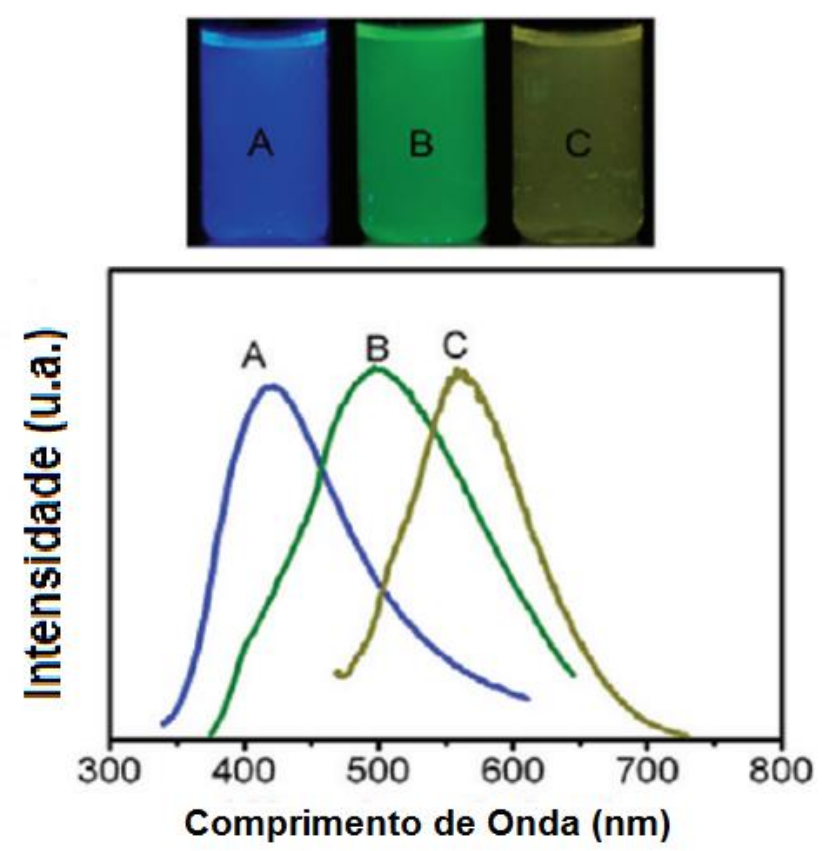

Figura 3 - Espectro de emissão, com excitação em $365 \mathrm{~nm}$, de C-Dots sintetizados a partir de oxidação ácida de fibras de carbono com alteração da temperatura, 120,100 e $80{ }^{\circ} \mathrm{C}$, respectivamente, A, B e C. Adaptado da Ref. 22.

As rotas sintéticas para obtenção de Carbon-Dot podem ser classificadas em métodos químicos ou físicos. ${ }^{8}$ Entre os métodos físicos temos, por exemplo, o arco elétrico ${ }^{5}$, ablação por laser ${ }^{17}$ e tratamento por plasma. ${ }^{18}$ Dentre os métodos químicos mais comuns estão, síntese eletroquímica ${ }^{19}$, por microondas ${ }^{20}$ e diversos métodos de oxidação. ${ }^{11,21-23}$ A oxidação ácida se mostra uma técnica simples, barata, com bons rendimentos e bastante reprodutível. ${ }^{11,23}$

Apesar de não haver um consenso sobre o mecanismo que explique as propriedades luminescentes dos C-Dots, ${ }^{7,8}$ a proposição que vem sendo mais aceita é que o tamanho da partícula e os defeitos superficiais são os responsáveis pela luminescência. ${ }^{24}$ Elétrons confinados na superfície e defeitos superficiais, chamados de buracos, interagem por meio de recombinações radiativas e garantem a luminescência observada no material, a passivação do C-Dot é dita como provável responsável pela estabilização das recombinações radiativas, o que melhora a intensidade da luminescência de um carbon-dot. ${ }^{25}$ 
Passivação trata-se de um processo químico onde são realizadas reações entre a superfície de um material e um outro composto alterando assim sua superfície. Nos C-Dots isso ocorre devido ao fato do nanomaterial comumente apresentar, em sua superfície, grupos carboxílicos que podem ser facilmente funcionalizados com diversas substâncias, como o $\mathrm{PEG}^{12} \mathrm{e}$ a etilenodiamina. ${ }^{11}$ Na Figura - 4 há um exemplo de um C-Dot com diversos grupos carboxílicos em sua superfície. ${ }^{26}$



Figura 4 - C-Dot típico de sínteses oxidativas.

Através desse processo é possível modificar as PL oriundas da síntese do material, modificando os comprimentos de onda de excitação e de emissão e o rendimento quântico. A Figura - 5 apresenta um C-Dot que após ser passivado passou a ser excitado e a emitir em diversos comprimentos de onda por todo 0 espectro visível. ${ }^{12} \mathrm{~A}$ passivação também pode proporcionar outras propriedades como, por exemplo, uma melhora catalítica ${ }^{27}$ e a modificação de solubilidade. ${ }^{28}$

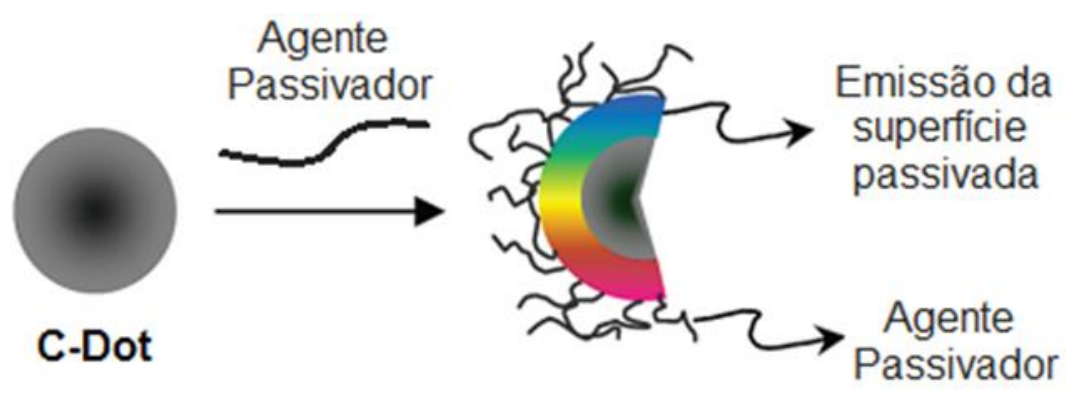

Figura 5 - Ilustração de um C-Dot passivado. Adaptado da Ref. 10.

Tendo em vista todas as características supracitadas, os Carbon-Dots tem sido aplicados nas mais variadas áreas, desde catálise, ${ }^{24,26}$ bioimageamento, ${ }^{9,28,29}$ biosensores, ${ }^{30}$ liberação controlada de fármacos, ${ }^{31}$ dispositivos fotovoltaicos, ${ }^{14}$ sondas para detecção de íons ${ }^{32}$ e até química 
forense ${ }^{35} \mathrm{~A}$ Figura - 6 apresenta a utilização de C-Dot no bioimageamento de ratos. ${ }^{36}$

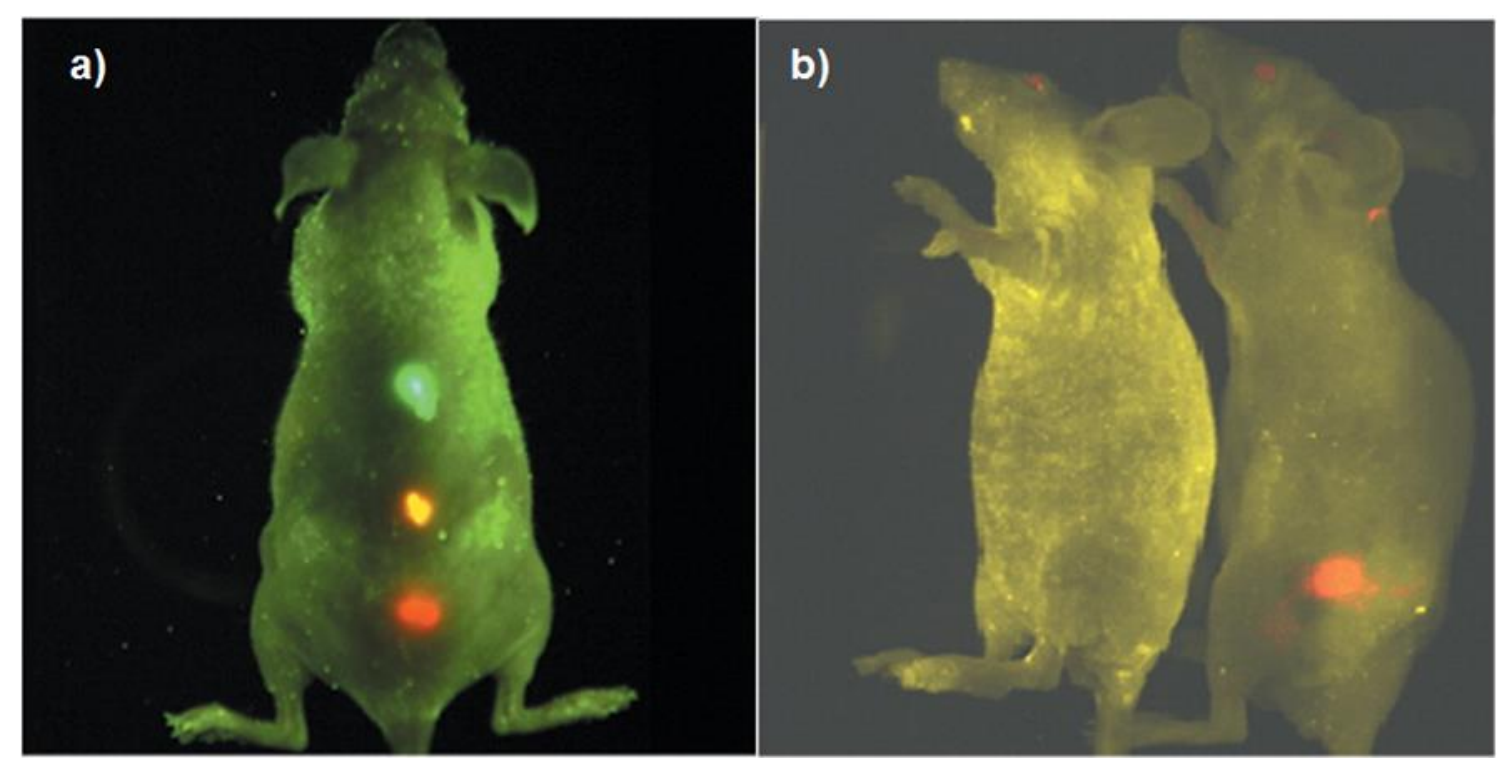

Figura 6 - a) Imageamento in vivo multicolorido por meio de QDs; b) Imageamento in vivo do câncer de próstata em ratos por meio de QDs. Adaptado da Ref. 36

Sua versatilidade não se restringe apenas as técnicas de síntese e aplicabilidade, a fonte de carbono necessária para sua produção é das mais variadas e verdes, sendo utilizado, suco de banana, ${ }^{7}$ suco de laranja, ${ }^{24}$ esterco de ruminantes, ${ }^{11}$ tapioca, ${ }^{37}$ entre outras fontes. ${ }^{38-39}$

Como dito anteriormente a nanociência se faz bastante presente no cenário científico atual, mas não está restrita aos QDs e C-Dots. Outra classe de nanomateriais que também se destaca são os nanocristais dopados com íons lantanídeos. Esse nanocristais apresentam diversas estruturas e aplicações, entretanto suas composições podem ser variadas, fluoretos, ${ }^{40}$ fosfatos $^{41} \mathrm{e}$ vanadatos $^{42}$ são alguns exemplos.

Os íons dopantes lantanídeos são os elementos que se encontram na tabela periódica que vão do Lantânio ao Lutécio são comumente encontrados no estado de oxidação $\mathrm{Ln}(\mathrm{III}) .{ }^{43} \mathrm{~A}$ maioria dos íons lantanídeos são considerados luminescentes por absorverem energia eletromagnética, da região UV/Vis e em alguns casos essa absorção ocorre na região do infravermelho próximo, e emitirem luz. ${ }^{44}$ 
Essas propriedades óticas são oriundas de um efeito de blindagem exercido pelos elétrons de seus orbitais $5 s$ e $5 p$ sobre os elétrons encontrados no orbital $4 f$ essa blindagem resulta em transições proibidas do tipo $f-f$, responsáveis pela luminescência dos lantanídeos, estreitas bandas de emissão, tempos de vida elevados e um baixo coeficiente de absorção molar (1 - $10 \mathrm{M}^{-1}$ $\left.\mathrm{cm}^{-1}\right) .{ }^{45} \mathrm{~A}$ tabela -1 mostra os lantanídeos e a distribuição eletrônica de seus estados Ln(III).

Tabela 1 - Configuração eletrônica dos íons Ln(III). Adaptado da Ref. 45

\begin{tabular}{|c|c|c|c|}
\hline Elemento & Símbolo & Número Atômico (Z) & Configuração Ln(III) \\
\hline Lantânio & $\mathrm{La}$ & 57 & {$[\mathrm{Xe}]$} \\
\hline Cério & $\mathrm{Ce}$ & 58 & {$[\mathrm{Xe}] 4 \mathrm{f}^{1}$} \\
\hline Praseodímio & $\mathrm{Pr}$ & 59 & {$[\mathrm{Xe}] 4 \mathrm{f}^{2}$} \\
\hline Neodímio & $\mathrm{Nd}$ & 60 & {$[\mathrm{Xe}] 4 \mathrm{f}^{4}$} \\
\hline Promécio & $\mathrm{Pm}$ & 61 & {$[\mathrm{Xe}] 4 \mathrm{f}^{5}$} \\
\hline Samário & $\mathrm{Sm}$ & 62 & {$[\mathrm{Xe}] 4 \mathrm{f}^{6}$} \\
\hline Európio & $\mathrm{Eu}$ & 63 & {$[\mathrm{Xe}] 4 \mathrm{f}^{7}$} \\
\hline Gadolínio & $\mathrm{Gd}$ & 64 & {$[\mathrm{Xe}] 4 f^{8}$} \\
\hline Térbio & $\mathrm{Tb}$ & 65 & {$[\mathrm{Xe}] 4 \mathrm{f}^{9}$} \\
\hline Disprósio & $\mathrm{Dy}$ & 66 & {$[\mathrm{Xe}] 4 \mathrm{f}^{10}$} \\
\hline Hólmio & $\mathrm{Ho}$ & 67 & {$[\mathrm{Xe}] 4 \mathrm{f}^{11}$} \\
\hline Érbio & $\mathrm{Er}$ & 68 & {$[\mathrm{Xe}] 4 \mathrm{f}^{12}$} \\
\hline Túlio & $\mathrm{Tm}$ & 69 & {$[\mathrm{Xe}] 4 \mathrm{f}^{13}$} \\
\hline Itérbio & $\mathrm{Yb}$ & 70 & {$[\mathrm{Xe}] 4 \mathrm{f}^{14}$} \\
\hline Lutécio & $\mathrm{Lu}$ & 71 & \\
\hline
\end{tabular}

O baixo coeficiente de absorção molar dos lantanídeos faz com que seus rendimentos quânticos (QY), ou seja, a razão entre fótons emitidos e fótons absorvidos, quando excitados diretamente, também sejam baixos, assim, em 1942, Weissman descobriu um efeito em que era possível aumentar esse coeficiente através da utilização de ligantes e deu a ele o nome de efeito antena ou sensitização. ${ }^{46}$ 
Esse efeito sugere que quando há a excitação do ligante (cromóforo) há uma transferência de energia intersistemas (cruzamento intersistema), onde o ligante transfere energia do seu estado singleto excitado para o próprio estado tripleto e então há a transferência de energia para o metal, ${ }^{47}$ como mostrado na Figura - 7. Entretanto, há diversos casos onde há transferência de energia do estado singleto excitado do ligante diretamente para o metal. ${ }^{43,48}$

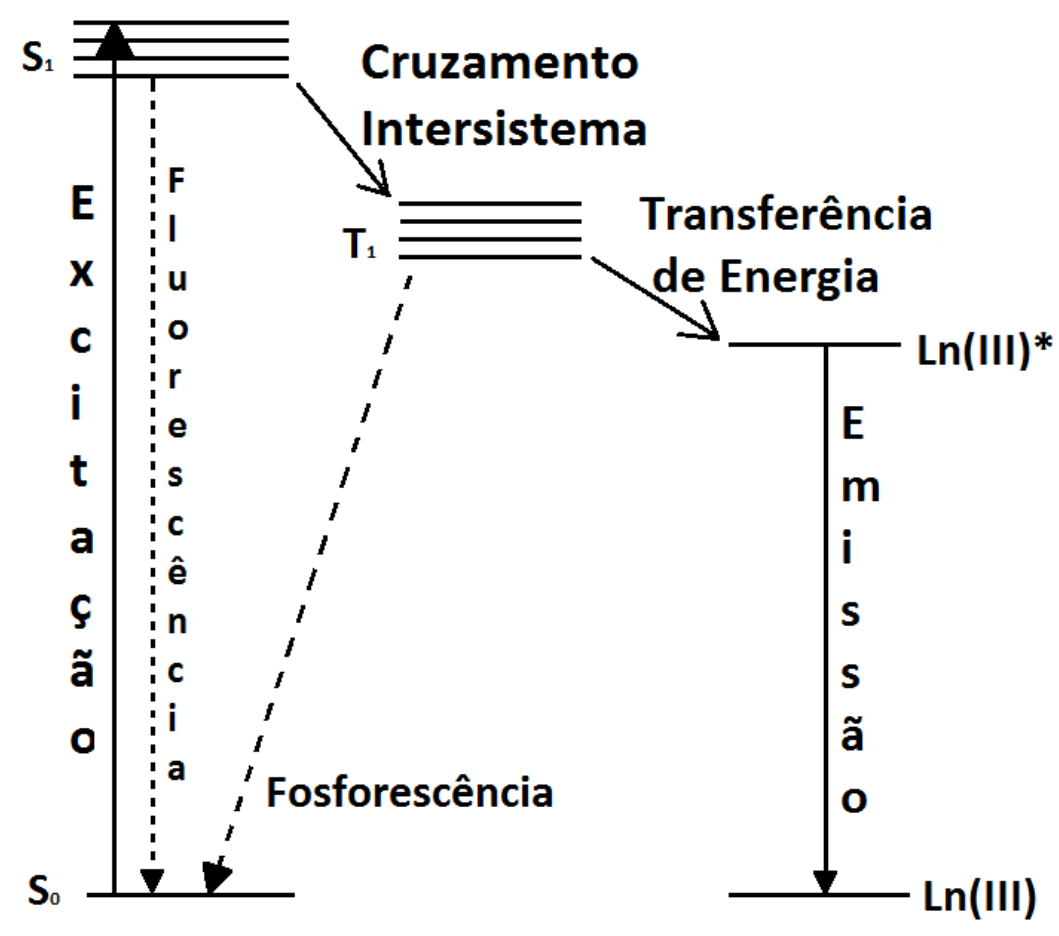

Figura 7 - Diagrama esquemático do funcionamento do efeito antena.

Estudos prévios mostram que a melhor forma de excitação dos lantanídeos se dá através dos estados tripletos dos ligantes ${ }^{48}$ e alguns pesquisadores afirmam ainda que uma maior rigidez do sistema metal-ligante favorece uma maior intensidade de luminescência, pois a rigidez favorece a transferência de energia. ${ }^{43}$

Em se tratando de luminescência de lantanídeos, algumas informações são essenciais, a absorção de luz por seus elétrons ocorrem principalmente pelos operadores dipolo-elétrico (DE) e dipolo-magnético (DM). ${ }^{44}$ Sendo DE extremamente sensível a natureza do ligante e DM independente da natureza do ligante. ${ }^{49}$ Devido a sua sensibilidade ao ambiente químico o operador DE estará envolvido em fenômenos diretamente ligados a luminescência como a hipersensibilidade, que está intrinsecamente ligada a simetria de coordenação 
do metal e dita que um ambiente com baixa simetria tende a ter as transições ligadas ao operador DE muito intensas, ${ }^{44} \mathrm{e}$ a presença de grupos desativadores, que consiste na presença de grupos $\mathrm{N}-\mathrm{H}, \mathrm{C}-\mathrm{H}, \mathrm{C}=\mathrm{O}$ e, principalmente, $\mathrm{O}-\mathrm{H}$ que tendem a favorecer as emissões não-radiativas, diminuindo assim a emissão de fótons. ${ }^{50}$

Existe também a chamada transferência reversa, fenômeno onde os níveis mais altos de energia do metal são populados e não há emissão de fótons pois a energia é transferida de volta ao ligante, esse efeito acarreta em baixos rendimentos quânticos e tempos de vida dependentes de temperatura. ${ }^{48}$

Dois importantes elementos do grupo dos lantanídeos são o európio e o térbio. Esses elementos possuem como característica processos luminescentes do tipo downconversion com emissões mais intensas na região de $614 \mathrm{~nm}$, para o európio, e $545 \mathrm{~nm}$, para o térbio, o que lhes garante uma emissões no vermelho e no verde, respectivamente. ${ }^{51}$ Esse processo, também conhecido como deslocamento Stokes, consiste na conversão de fótons de maior energia, como radiação UV, em fótons de menor energia, como luz visível. ${ }^{52} \mathrm{~A}$ Figura -8 demonstra de maneira simplificada o processo downconversion. 


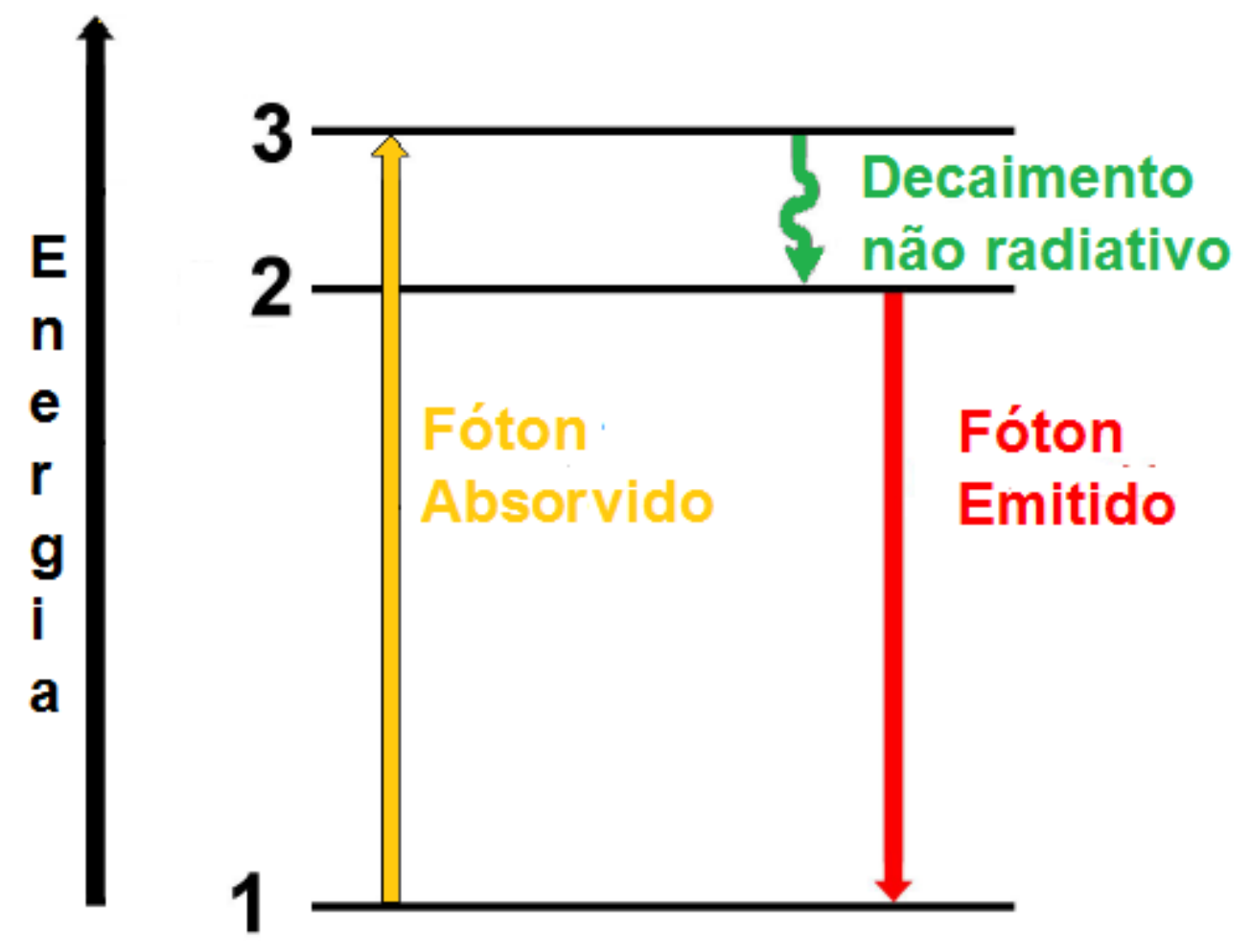

Figura 8- Diagrama esquemático do processo luminescente de downconversion.

O európio possui as linhas de emissão ${ }^{5} \mathrm{D}_{0} \rightarrow{ }^{7} \mathrm{~F}_{1}$ como uma transição de $\mathrm{DM}$ e ${ }^{5} \mathrm{D}_{0} \rightarrow{ }^{7} \mathrm{~F}_{2}$ como uma transição de $\mathrm{DE}$, a razão dessas duas transições $\left({ }^{7} \mathrm{~F}_{2} /{ }^{7} \mathrm{~F}_{1}\right)$ indicam a simetria de coordenação do $\mathrm{Eu}^{3+}$, valores elevados indicam um ambiente assimétrico, enquanto baixos valores indicam um ambiente com alto grau de simetria. ${ }^{53}$

O térbio, por sua vez, possui as linhas de emissão ${ }^{5} \mathrm{D}_{4} \rightarrow{ }^{7} \mathrm{~F}_{5}$ como uma transição de $\mathrm{DM}$ e as ${ }^{5} \mathrm{D}_{4} \rightarrow{ }^{7} \mathrm{~F}_{6}$ e ${ }^{5} \mathrm{D}_{4} \rightarrow{ }^{7} \mathrm{~F}_{4}$ como uma transição de $\mathrm{DE}$, mas ao contrário do Európio essas emissões são ditas como mistas, tendo contribuição de outros dipolos sendo esses apresentados os que mais contribuem. ${ }^{49}$ Uma de suas peculiaridades é sua transferência reversa quando a diferença de energia entre os estados tripletos de menor energia (Tb-Ligante) é menor que $1850 \mathrm{~cm}^{-}$ 1.48

Os nanocristais de fluoretos dopados com esses íons têm se destacado na nanotecnologia, por sua baixa energia de fônons e transparência óptica em um amplo comprimento de onda. Um desses fluoretos é o $\mathrm{NaYF}_{4}$, uma das matrizes mais eficientes para íons Ln(III). ${ }^{54} \mathrm{~A}$ união entre esses nanocristais e $\mathrm{o}$ lantanídeos tem sido aplicada nas mais variadas áreas e seus métodos de 
síntese tem inovado tanto quanto suas aplicações, a fim de encontrar uma forma de controlar seus tamanhos e morfologias. ${ }^{55}$

Essas características são imprescindíveis, uma vez que o tamanho do material irá determinar a estabilidade do mesmo em solução e a morfologia, por sua vez, tende a influenciar na PL do material. Há diversos métodos de síntese, coprecipitação, decomposição térmica, hidrotérmico, combustão, entre outros. ${ }^{56}$

Dois métodos possuem bastante destaque, a coprecipitação, possui baixo custo e consiste na precipitação de duas substâncias em conjunto e o hidrotérmico, que apesar de necessitar de reatores apropriados possui a versatilidade de preparar nanocristais de vanadatos, fosfatos, óxidos e fluoretos com custo reduzido. ${ }^{56.57}$ Quando aplicados à síntese dos nanocristais de $\mathrm{NaYF}_{4}$ tendem a formar cristais na fase cúbica $(\alpha)$ e hexagonal $(\beta)$, respectivamente. ${ }^{58}$

Visando a aplicação desses nanocristais na área biológica a passivação foi empregada desejando modificações que Ihes rendessem biocompatibilidade, estabilidade coloidal e química e ainda abrisse a possibilidade para bioconjugação. ${ }^{56,59}$ Para obter materiais com essas características diversas técnicas foram desenvolvidas, as principais foram a silanização, ${ }^{59}$ recobrimento dos cristais com silício, e os recobrimentos com polímeros ${ }^{60}$, como 0 polietilenoglicol (PEG), ou agentes eletrostáticos ${ }^{61}$, como o ácido tartárico.

As características apresentadas, como propriedades luminescentes, controle de estrutura e modificação superficial, dos Carbon-Dots e nanocristais aproximam esses dois materiais, aproximação que abre precedente para a criação de um novo material empregando-os: os compósitos. Compósitos são materiais, produzidos a partir da íntima mistura entre dois ou mais compostos com propriedades físico-químicas distintas. ${ }^{62}$ As propriedades do material formado poderão ser únicas do novo material ou serem uma acentuação de alguma propriedade já existente em algum dos compostos de partida. ${ }^{63}$

Ao contrário de outros materiais carbonáceos, os C-Dots ainda são relativamente inexplorados e uma área que vem sendo desenvolvida com o intuito de aproveitar todo o potencial dos C-Dots trata-se dos compósitos metálicos, área esta que tem demonstrado grande versatilidade tecnológica. ${ }^{64}$ 
Esses compósitos têm sido produzidos com diversos metais como prata, paládio, ouro, titânio, entre outros, e aplicados em catálise, sensores e dispositivos. ${ }^{64-70}$

Compósitos de C-Dots e lantanídeos são ainda mais escassos e recentes, sendo encontrados os materiais com európio, ${ }^{71,72}$ térbio, ${ }^{73}$ e gadolínio ${ }^{74}$ voltados para aplicação em bioimagens, sensores e estudos luminescentes. Esses materiais têm como princípio melhorar as propriedades luminescentes dos compostos envolvidos e garantir a manutenção de algumas outras propriedades individuais, como a solubilidade e dispersão em água dos C-Dots e os longos tempos de vida e as finas linhas de emissão dos lantanídeos. A Figura -9 demonstra um C-Dot com lantanídeos suportados em sua superfície.



Figura 9 - Representação de um Carbon-Dot com lantanídeos suportados em sua superfície. Adaptado das Ref. 71 e 72.

O desenvolvimento de compósitos de C-Dot e nanocristais dopados com lantanídeos, apresenta-se como uma área desconhecida e potencialmente vantajosa necessitando, portanto, de um estudo profundo de suas sínteses e características para aplica-los de maneira ideal na nanociência. 


\section{Objetivos}

\subsection{Objetivos Gerais}

Esse trabalho tem como objetivo o desenvolvimento por síntese por coprecipitação e hidrotermal e a caracterização de compósitos $\mathrm{NaYF}_{4}: \mathrm{Eu}^{3+}(\mathrm{C}$ Dot) e NaYF $: \mathrm{Tb}^{3+}$ (C-Dot), utilizando os Carbon-Dots como agentes passivadores e cromóforos para os nanocristais, desenvolvendo assim novos materiais luminescentes.

\subsection{Objetivos Específicos}

- Sintetizar compósitos de NaYF4:Eu(C-Dot) e NaYF4:Tb(C-Dot) que sejam luminescentes via síntese hidrotermal e por coprecipitação.

- Caracterizar o material por diferentes técnicas. DR-X, MEV, HRMET, FTIR e analises luminescentes.

- Estudar o efeito da concentração de Carbon-Dot no compósito em questão. 


\section{Parte Experimental}

\section{Síntese do Carbon-Dot}

Para a síntese do C-Dot foi utilizado como matéria prima esterco bovino. ${ }^{11}$ Inicialmente $35 \mathrm{~g}$ de esterco foram lavados com água destilada e em seguida seco em estufa a $110^{\circ} \mathrm{C}$, o material seco foi então calcinado em uma mufla à $300{ }^{\circ} \mathrm{C}$ durante $12 \mathrm{~h}$. O pó obtido é então deixado por 30 minutos em banho ultrassônico e em seguida foi colocado em um balão de fundo redondo com 250 $\mathrm{mL}$ de solução ácida de $\mathrm{HNO}_{3}(5 \mathrm{~mol} / \mathrm{L})$ a $100^{\circ} \mathrm{C}$, por $24 \mathrm{~h}$. Após esse período neutraliza-se o conteúdo do balão volumétrico com solução saturada de $\mathrm{NaOH}$ e realiza-se duas filtragens, a primeira em papel filtro qualitativo onde o filtrado é retirado e levado à centrifuga por 30 minutos a 6000 RPM, o sobrenadante é então filtrado uma segunda vez em um filtro de membrana com porosidade de $0,22 \mu \mathrm{m}$. O produto final do processo é levado a estufa à $110^{\circ} \mathrm{C}$ para evaporação da água. Foi obtido cerca de $20 \mathrm{~g}$ de produto final C-Dot. A Figura - 10 possui um esquema simplificado da síntese de Carbon-Dot.

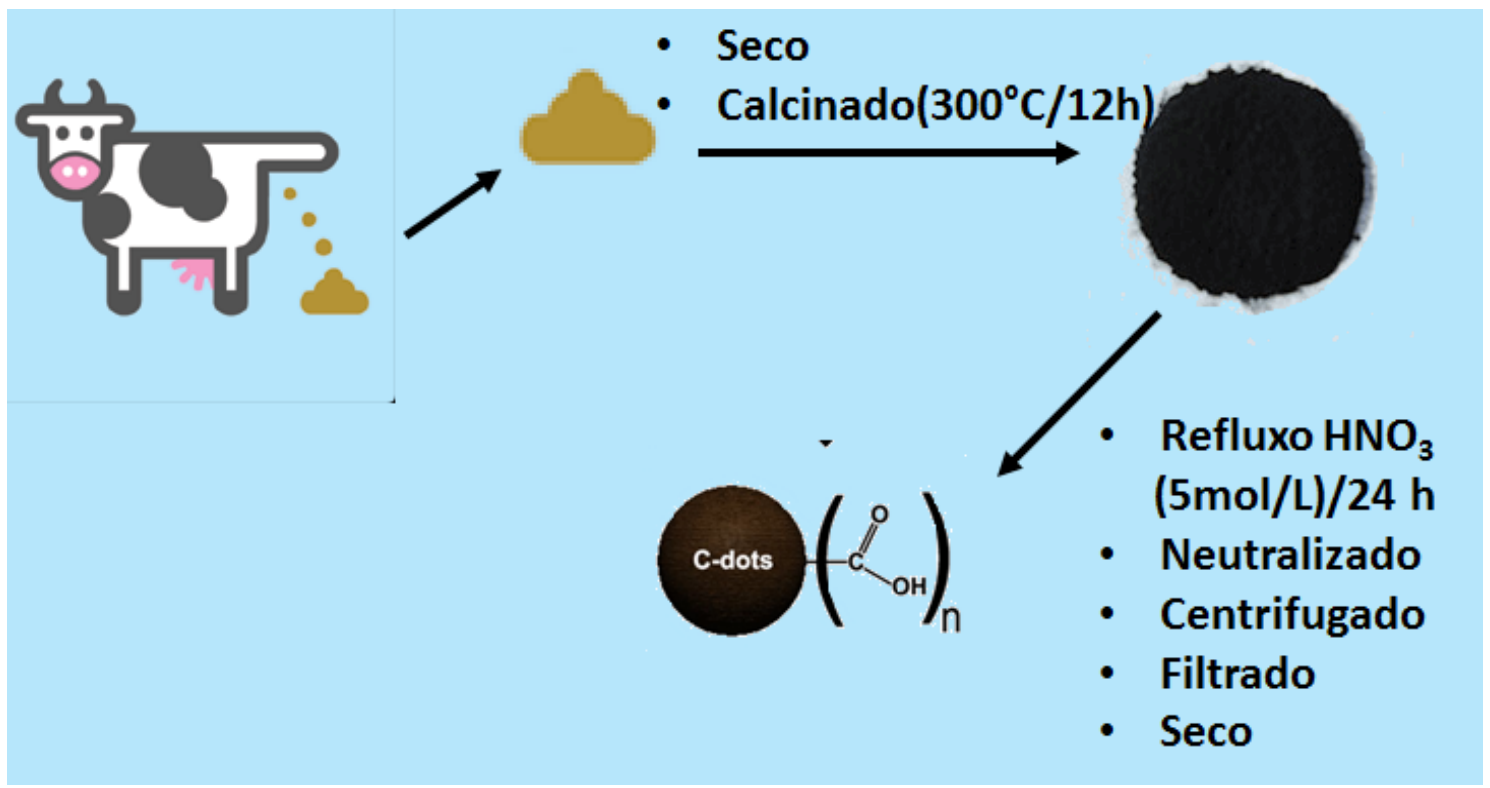

Figura 10 - Esquema simplificado da síntese de C-Dot 


\section{Síntese dos Nanocompósitos $\mathrm{NaYF}_{4}: \mathrm{Ln}^{3+}$ (C-Dot)}

Os nanocompósitos foram sintetizados sob dois métodos onde houve a variação da concentração de C-Dot. Essa variação de concentração foi realizada buscando melhores propriedades luminescentes do material, elas foram denominadas $\mathrm{C}+(0,7 \mathrm{~g}), \mathrm{C}(0,05 \mathrm{~g})$ e $\mathrm{C}-(0,003 \mathrm{~g})$

Fora escolhido para síntese os métodos de coprecipitação e hidrotermal de nanocristais de $\mathrm{NaYF}_{4},{ }^{62}$ por se tratarem de métodos práticos e simples, assim, para a coprecipitação em um béquer é colocado sob vigorosa agitação uma solução contendo 0,35 g de $\mathrm{NaOH}$ (8,75 mmol), 0,101g de $\mathrm{NaF}$ (2,4 mmol), e o Carbon-Dot na quantidade adequada ao produto desejado. Em seguida são adicionados $1,5 \mathrm{~mL}$ de uma solução contendo $0,168 \mathrm{~g}$ de $\mathrm{Y}\left(\mathrm{NO}_{3}\right)_{3}(0,44 \mathrm{mmol}) \mathrm{e}$ $0,0372 \mathrm{~g}$ de $\mathrm{Eu}\left(\mathrm{NO}_{3}\right)_{3}(0,11 \mathrm{mmol})$ e mantida sob agitação durante 20 minutos, após esse período o conteúdo do béquer é colocado em tubos falcon e levado a centrifuga durante 30 minutos à 6000 RPM. Retira-se o sobrenadante, adicionase água destilada e mantem sob agitação mecânica até que o precitado despregue do fundo do tubo, após isso, o tubo é levado ao banho ultrassônico por 30 minutos, novamente é centrifugado por 30 minutos à 6000 RPM, esse processo é repetido 3 vezes. Após a última centrifugação retira-se o sobrenadante e adiciona-se $5 \mathrm{~mL}$ de metanol, o tubo falcon é novamente colocado sob agitação mecânica até que o precipitado disperse do fundo do tubo, feito isso o material é colocado em uma placa de Petri e levado a estufa a $60^{\circ} \mathrm{C}$ até que seque. Ao final se obtém um pó. Para as amostras de Tb o mesmo procedimento é utilizado, porém o nitrato de európio é substituído por 0,0498 g de nitrato de $\mathrm{Tb}(0,11 \mathrm{mmol})$.

Para a síntese hidrotermal utiliza-se a mesma metodologia de coprecipitação, porém, após os 20 minutos de reação a solução dos béqueres são colocadas em reatores do tipo autoclave, lacrados e levados a estufa de reação por $24 \mathrm{~h}$ à $200^{\circ} \mathrm{C}$. Passado esse tempo, a metodologia por coprecipitação volta a ser implementada. A figura - 11 apresenta um esquema simplificado da síntese dos compósitos. 


\section{Coprecipitação}

\begin{tabular}{|c|c|c|c|c|c|}
\hline \multirow{3}{*}{$\begin{array}{c}\mathrm{NaOH} \\
\mathrm{NaF} \\
\text { Carbon-Dot } \\
\mathrm{H}_{2} \mathrm{O}\end{array}$} & \multirow{3}{*}{$+\begin{array}{c}\mathrm{Y}\left(\mathrm{NO}_{3}\right)_{3} \\
\mathrm{Eu}\left(\mathrm{NO}_{3}\right)_{3} \mathrm{OU} \\
\mathrm{Tb}\left(\mathrm{NO}_{3}\right)_{3}\end{array}$} & & \multirow{3}{*}{$\begin{array}{c}3 x \\
\text { Centrífuga } \\
\text { e Lavagem }\end{array}$} & & \multirow{3}{*}{ Compósito } \\
\hline & & & & Evaporaçao & \\
\hline & & $\begin{array}{l}\text { Agitação } \\
20 \text { min }\end{array}$ & & & \\
\hline
\end{tabular}

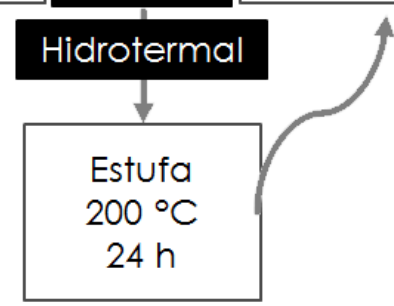

Figura 11 - Esquema simplificado da síntese dos compósitos

A Tabela - 2 apresenta o material sintetizado com as massas de todos os materiais utilizados na síntese. A fim de simplificar os compósitos foram nomeados de acordo com o lantanídeo dopado (Eu e Tb), as concentrações de Carbon-Dot ( $\mathrm{C}+$, mais concentrado; $\mathrm{C}$, concentração média; C- menos concentrado) e o tipo de síntese realizada (ausência para a coprecipitação e HT para hidrotermal).

Tabela 2 - Materiais aferidos para a síntese dos compósitos.

\begin{tabular}{|c|c|c|c|c|c|c|}
\hline Material & $\begin{array}{c}\mathbf{C}-D o t \\
(\mathbf{g})\end{array}$ & $\begin{array}{c}\mathbf{H}_{2} \mathbf{O} \\
(\mathbf{m L})\end{array}$ & $\begin{array}{c}\mathrm{NaOH} \\
(\mathbf{g})\end{array}$ & $\begin{array}{c}\mathbf{N a F} \\
(\mathbf{g})\end{array}$ & $\mathbf{Y}\left(\mathrm{NO}_{3}\right)_{3}(\mathbf{g})$ & $\begin{array}{c}\mathbf{L n}\left(\mathrm{NO}_{3}\right)_{3} \\
(\mathbf{g})\end{array}$ \\
\hline $\mathbf{E u}(\mathbf{C}-)$ & 0,0036 & 11,5 & 0,3562 & 0,1011 & 0,1690 & 0,0371 \\
\hline $\mathbf{E u}(\mathbf{C})$ & 0,0515 & 11,5 & 0,3526 & 0,1012 & 0,1690 & 0,0372 \\
\hline $\mathbf{E u}(\mathbf{C}+)$ & 0,7141 & 11,5 & 0,3577 & 0,1012 & 0,1688 & 0,0374 \\
\hline $\mathbf{T b}(\mathbf{C}-)$ & 0,0031 & 11,5 & 0,3509 & 0,1009 & 0,1687 & 0,0496 \\
\hline $\mathbf{T b}(\mathbf{C})$ & 0,0506 & 11,5 & 0,3561 & 0,1010 & 0,1684 & 0,0497 \\
\hline $\mathbf{T b}(\mathbf{C}+)$ & 0,7126 & 11,5 & 0,3502 & 0,1012 & 0,1678 & 0,0498 \\
\hline $\mathbf{E u}(\mathbf{C}-\mathbf{)} \mathbf{H T}$ & 0,0034 & 11,5 & 0,3495 & 0,1009 & 0,1710 & 0,0374 \\
\hline $\mathbf{E u}(\mathbf{C}) \mathbf{H T}$ & 0,0503 & 11,5 & 0,3479 & 0,0995 & 0,1697 & 0,0371 \\
\hline $\mathbf{E u}(\mathbf{C +}) \mathbf{H T}$ & 0,7161 & 11,5 & 0,3523 & 0,1016 & 0,1690 & 0,0372 \\
\hline $\mathbf{T b}(\mathbf{C}-\mathbf{)} \mathbf{H T}$ & 0,0033 & 11,5 & 0,3563 & 0,1014 & 0,1743 & 0,0497 \\
\hline $\mathbf{T b}(\mathbf{C}) \mathbf{H T}$ & 0,0515 & 11,5 & 0,3579 & 0,1018 & 0,1710 & 0,0498 \\
\hline $\mathbf{T b}(\mathbf{C +}) \mathbf{H T}$ & 0,7125 & 11,5 & 0,3515 & 0,1093 & 0,1691 & 0,0490 \\
\hline
\end{tabular}




\section{Caracterização dos Materiais}

Foram utilizadas diversas técnicas para a análise dos compósitos, tais como difração de Raios X (DRX), microscopia eletrônica de varredura (MEV), microscopia eletrônica de transmissão de alta resolução (HRMET), espectroscopia de infravermelho com transformada e Fourier (FTIR) e espectroscopia de luminescência.

Os Carbon-Dots sintetizados foram caracterizados e seus resultados são em conformidade com os encontrados por Barbosa e colaboradores ${ }^{11}$, devido a isso esses resultados não são apresentados nesse trabalho.

\section{Difração de Raio X}

As análises de DR-X foram realizadas em um Difratômetro X-Ray Rigaku, utilizando radiação $\mathrm{Cu} \mathrm{Ka}(\lambda=1,54 \AA)$, em uma velocidade de varredura de $1,5^{\circ} /$ min com incremento de 1,0 e ampliando o ângulo de $2 \Theta$ de $15^{\circ}$ à $80^{\circ}$.

\section{Microscopia Eletrônica de Varredura}

As imagens de MEV foram obtidas por um microscópio de varredura da marca FEI modelo Quanta FEG 250. As amostras foram secas a vácuo e depois colocadas em um dessecador durante uma semana, após esse processo foram metalizadas em banho de ouro.

\section{Microscopia Eletrônica de Transmissão de Alta Resolução}

As imagens de HRMET foram realizadas utilizando um microscópio de alta resolução Jeol JEM-2100. As amostras foram dispersas em etanol, deixadas sob banho de ultrassom durante 30 minutos. Em seguida, adicionou-se 1 gota de cada amostra sob grids de cobre recobertos com uma fina camada de carbono. 


\section{Espectroscopia de Infravermelho com Transformada de Fourier}

Os espectros de FTIR foram adquiridos em um espectrômetro Jasco FT/IR-4100, com pastilhas de $\mathrm{KBr}$, com resolução espectral de $4 \mathrm{~cm}^{-1}$, na faixa de 4000 a $400 \mathrm{~cm}^{-1}$.

\section{Espectroscopia de Luminescência}

As medidas de emissão e excitação foram realizadas em estado sólido por um espectrofluorímetro Fluorolog-3 Horiba FL3-22 iHr320. Considerando as condições variadas que foram necessárias para as análises as configurações encontram-se na Tabela - 3. Essas variações nas condições ocorreram afim de encontrar um espectro adequado.

Tabela 3 - Parâmetros de análise de emissão e excitação dos compósitos

\begin{tabular}{|c|c|c|c|c|c|}
\hline Material & $\begin{array}{c}\text { Velocidade } \\
\text { de } \\
\text { Varredura } \\
(\mathrm{nm} / \mathrm{s})\end{array}$ & $\begin{array}{c}\text { Tempo de } \\
\text { integração } \\
\text { (ms) }\end{array}$ & $\begin{array}{l}\text { Potência } \\
\text { (V) }\end{array}$ & $\begin{array}{c}\text { Fenda de } \\
\text { emissão } \\
(n m)\end{array}$ & $\begin{array}{c}\text { Fenda de } \\
\text { excitação } \\
(n m)\end{array}$ \\
\hline $\mathrm{Eu}\left(\mathrm{C}_{+}\right)$ & 0.5 & 0.5 & 900 & 3 & 3 \\
\hline $\mathrm{Eu}(\mathrm{C})$ & 0.5 & 0.5 & 900 & 2 & 2 \\
\hline $\mathrm{Eu}(\mathrm{C}-)$ & 0.5 & 0.5 & 900 & 2 & 2 \\
\hline $\mathrm{Tb}(\mathrm{C}+)$ & 0.5 & 0.5 & 900 & 4 & 4 \\
\hline $\mathrm{Tb}(\mathrm{C})$ & 0.5 & 0.5 & 900 & 3 & 3 \\
\hline $\mathrm{Tb}(\mathrm{C}-)$ & 0.5 & 0.5 & 900 & 2 & 2 \\
\hline $\mathrm{Eu}\left(\mathrm{C}_{+}\right) \mathrm{HT}$ & 0.5 & 0.5 & 900 & 4 & 4 \\
\hline $\mathrm{Eu}(\mathrm{C}) \mathrm{HT}$ & 0.5 & 0.5 & 900 & 3 & 3 \\
\hline $\mathrm{Eu}(\mathrm{C}-) \mathrm{HT}$ & 0.5 & 0.5 & 900 & 2 & 2 \\
\hline $\mathrm{Tb}(\mathrm{C}+) \mathrm{HT}$ & 0.5 & 0.5 & 900 & 4 & 4 \\
\hline $\mathrm{Tb}(\mathrm{C}) \mathrm{HT}$ & 0.5 & 0.5 & 900 & 4 & 4 \\
\hline $\mathrm{Tb}(\mathrm{C}-) \mathrm{HT}$ & 0.5 & 0.5 & 900 & 3 & 3 \\
\hline
\end{tabular}

Os valores de rendimento quântico foram obtidos para as amostras em estado sólido em uma esfera de integração Quanta- $\phi$ Horiba F-309 acoplada ao espectrofluorímetro Fluorolog-3 Horiba FL3-22 iHr320 utilizando conjunto de fibras ópticas, as medidas de rendimento quântico foram realizadas apenas para os materiais sintetizados por coprecipitação. 
As medidas de tempo de vida de emissão foram realizadas em estado sólido em um espectrofluorímetro Fluorolog-3 Horiba FL3-22 iHr320, com excitação na banda do ligante utilizando uma lâmpada de xenônio pulsada de $150 \mathrm{~W}$.

Para as análises de DR-X e MEV houve a colaboração do professor Juliano A. Chaker (FCE - UnB), de HRMET da doutora Tatiane O. dos Santos (IF - UFG), de FTIR do professor Jez W. B. Braga (IQ - UnB) e as medidas de rendimento quântico e tempos de vida do professor Fernando A. Sigoli (IQ UniCamp) 


\section{Resultados e Discussão}

O difratograma de Raios $\mathrm{X}$ da Figura - 12 trata-se de um comparativo entre as fases cristalinas encontradas para os compósitos com nanocristais de $\mathrm{NaYF}_{4}$ :Ln constituintes isolados nas fases $\alpha$ (cúbica) e $\alpha \rightarrow \beta$ (transição entre cúbica e hexagonal), importante lembrar que a mudança de fase ocorre quando o cristal formado por coprecipitação, fase cúbica $(\alpha)$, passa por tratamento hidrotermal transitando para a fase hexagonal $(\beta) .{ }^{75}$ Como pode ser observado o compósito que recebe tratamento hidrotermal apresenta-se na fase esperada, hexagonal, entretanto o compósito sintetizado por coprecipitação não apresenta fase cristalina definida, caracterizando o material com baixa cristalinidade, não se comportando como o nanocristal que nessas condições sintéticas se encontraria em fase cúbica, esse tipo de propriedade já foi observada em outros compósitos onde há presença de carbono. ${ }^{76,77}$

Vale ressaltar que a imagem apresentada se trata de um difratograma representativo para íons $\mathrm{Eu}$ (III) e $\mathrm{Tb}$ (III) e em diferentes sínteses, a variação da concentração de carbono no compósito não influencia de maneira significativa nos resultados, os demais espectros se encontram nos anexos. 


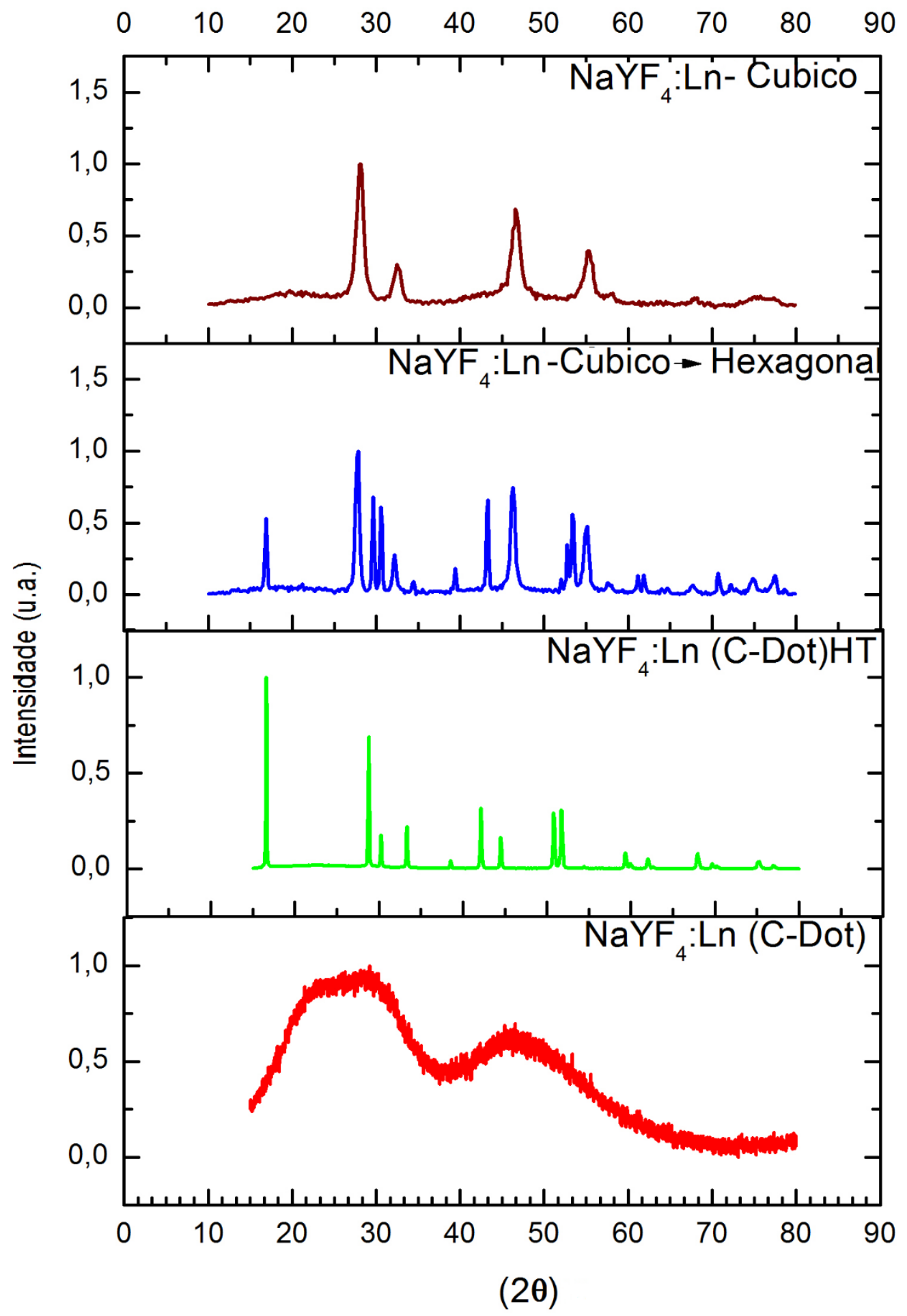

Figura 12 - Difratograma de Raio-X de pó comparando as fases encontradas nos nanocompósitos com as esperadas em nanocristais convencionais. (-) NaYF4:Ln Cúbico, (-) $\mathrm{NaYF}_{4}: \mathrm{Ln}$ Cúbico $\rightarrow$ Hexagonal, (-) NaYF $4: \operatorname{Ln}(C-D o t) H T$ e (-) NaYF $4: L n(C-D o t)$ 
A Figura - 13 trata-se de imagens de microscopia dos cristais de $\mathrm{NaYF}_{4}$ nas fases a) cúbicas e b) hexagonais, essas imagens são importantes para visualizar a diferença de comportamento entre as fases esperadas e as encontradas neste trabalho.
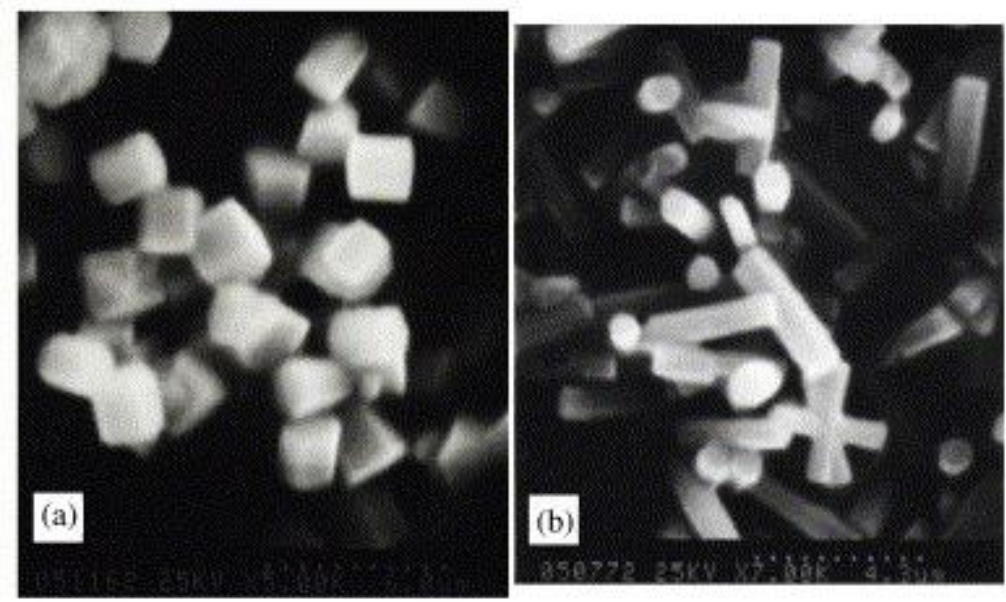

Figura 13 - Cristais de NaYF4 em fase a) cúbica e b) hexagonal. Adaptado da referência 75.

A Figura - 14 mostra as imagens de MEV para os compósitos $\mathrm{NaYF}_{4}: \mathrm{Eu}$ com concentração $\mathrm{C}+$ sem tratamento hidrotérmico, observa-se a formação de pequenas placas do material com vários flóculos sobre as mesmas na imagem a) e com uma maior aproximação observa-se partículas muito pequenas em formas variadas que não demonstram uma organização clara, como observados nas imagens b) e c). 



Figura 14 - Imagens de MEV das amostras $\operatorname{Ln}(C+)$ a) $400 \mu \mathrm{m}$ b) $400 \mathrm{~nm}$ c) $200 \mathrm{~nm}$

Em contrapartida a Figura - 15, mostra o compósito $\mathrm{NaYF}_{4}: \mathrm{Tb}$ com a mesma concentração anterior, $\mathrm{C}_{+}$, sobre a síntese hidrotermal, observa-se um comportamento muito distinto onde há a formação de bastonetes característicos da fase $\beta$, entretanto esses bastonetes apresentam um formato arredondado, que se associa a alta concentração de C-Dot, e aglomeram-se em pequenos grupos de forma bastante organizada, como evidenciado pelas imagens b) e c). O tipo de aglomeração e a forma arredondada dos bastonetes são distintas das apresentadas na Figura - 13 b), indicando a influência dos C-Dots na composição. 

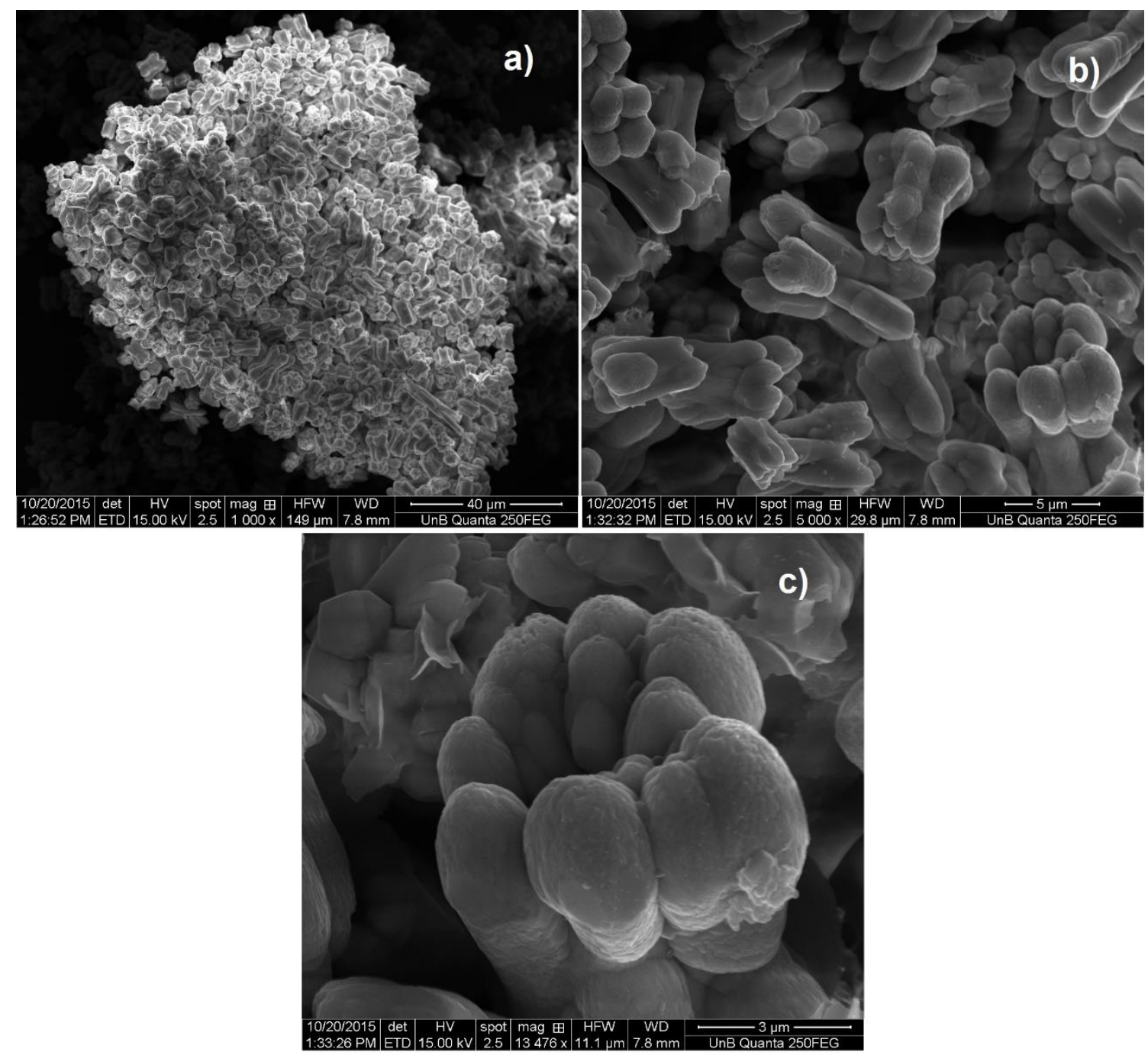

Figura 15 - Imagens de MEV das amostras $\operatorname{Ln}\left(C_{+}\right) H T$ a) $40 \mu m$ b) $5 \mu m$ c) $3 \mu m$

As imagens da Figura - 16 apresentam os compósitos $\mathrm{NaYF}_{4}: \mathrm{Eu}$ com concentração intermediária, C, as imagens a) e b) mostram a formação de placas enquanto c) e d) demonstram pequenos aglomerados de morfologia irregular e variável. 

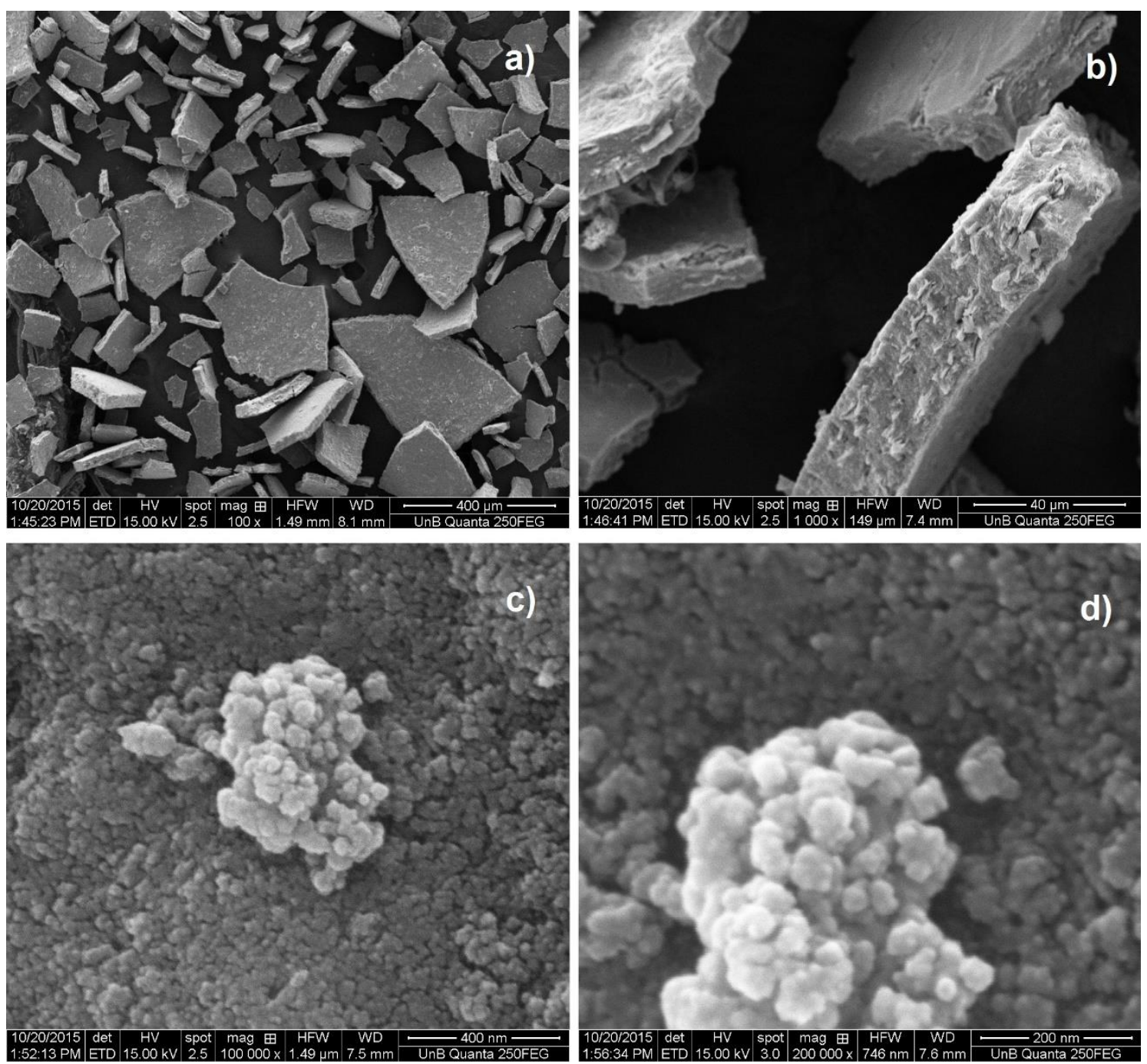

Figura 16 - Imagens de MEV dos compósitos Ln(C) a) $400 \mu \mathrm{m}$ b) $40 \mu \mathrm{m}$ c) $400 \mathrm{~nm}$ d) $200 \mathrm{~nm}$

A Figura - 17 trata-se do material $\mathrm{NaYF}_{4}: \mathrm{Tb}$ com concentração de Carbon-Dot $\mathrm{C}$ e tratamento hidrotermal, nas imagens a) e b) fica evidente um aglomerado de pequenas "agulhas", enquanto c) demonstra bastonetes semelhantes aos encontrados na Figura - 14 a figura d) evidencia uma estrutura poligonal, aproximando o material da estrutura presente na Figura $-13 \mathrm{~b}$ ). 

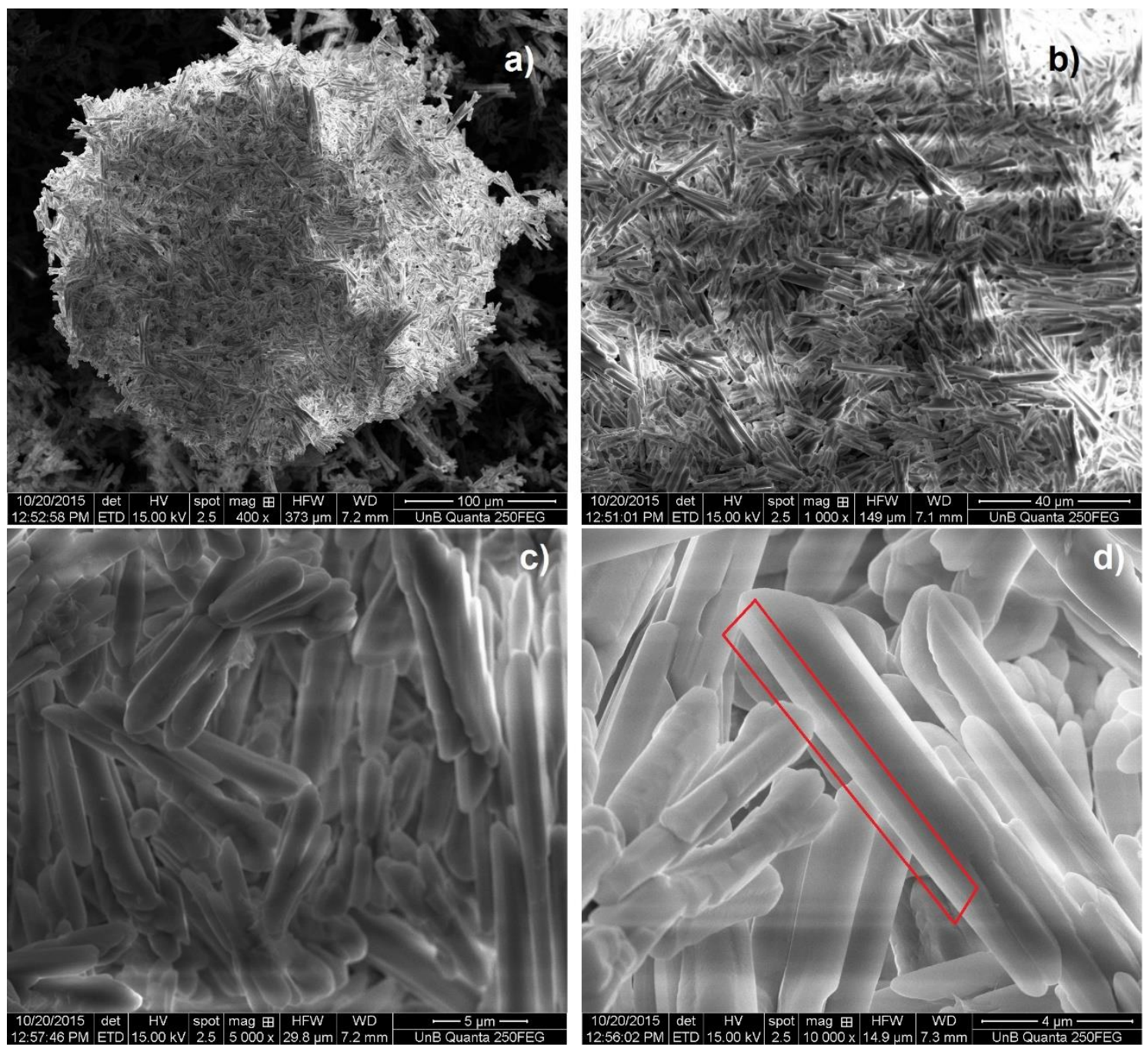

Figura 17 - Imagens de MEV do compósito Ln(C)HT a) $100 \mu \mathrm{m}$ b) $40 \mu \mathrm{m}$ c) $5 \mu \mathrm{m}$ d) $4 \mu \mathrm{m}$

As imagens de MEV dos compósitos $\mathrm{NaYF}_{4}: E u$ com concentração de Carbon-Dot C- estão representadas pela Figura - 18, a imagem a) mostra os mesmos tipos de placas encontradas nos outros compósitos sem tratamento hidrotérmico na imagem b) é possível observar uma maior quantidade de partes pequenas compondo esta placa, diferente das outras imagens onde ela aparentava uma maior solidez, por fim, a imagem c) mostra as mesmas pequenas estruturas sem morfologia definida e agregadas de maneira aleatória. 

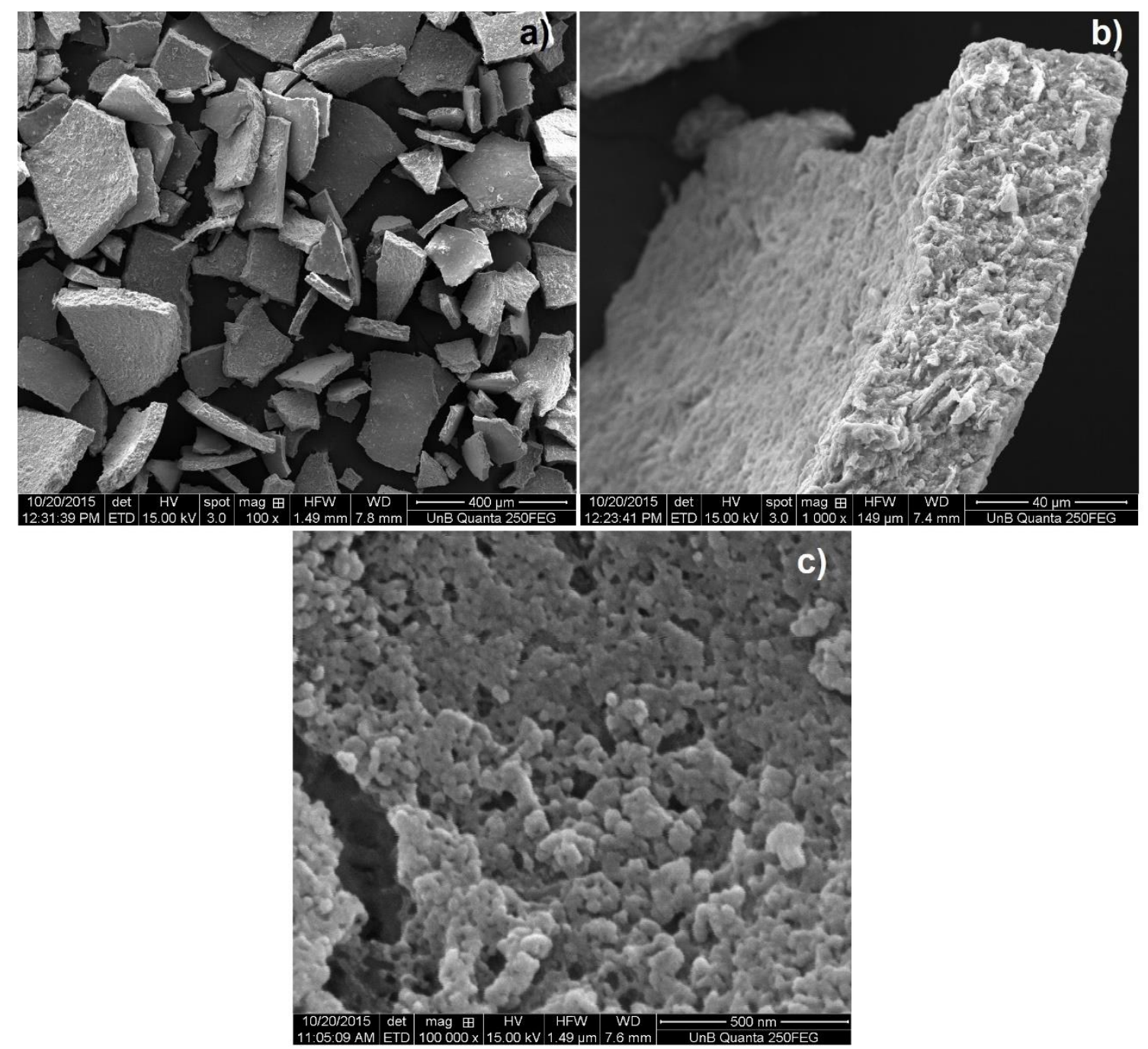

Figura 18 - Imagens de MEV dos compósitos $\operatorname{Ln}(C-)$ a) $400 \mu \mathrm{m}$ b) $40 \mu \mathrm{m}$ c) $500 \mathrm{~nm}$

Apresentando a Figura - 19, pode-se observar as finas "agulhas" formadas pelo compósito $\mathrm{NaYF}_{4}$ :Eu com concentração C- sintetizados por método hidrotermal, como visto na figura a) e b), nelas, fica evidente a diferença de espessura dos bastonetes quando comparadas aos outros materiais hidrotermais nas imagens c) e d) pode-se observar com clareza a estrutura poligonal, diferentemente das abaloadas encontradas nos outros compósitos que possuem a mesma rota sintética, material muito semelhante ao encontrado na Figura - 13 b). 



Figura 19 - Imagens de MEV dos compósitos Ln(C-)HT a) $40 \mu \mathrm{m}$ b) $5 \mu \mathrm{m}$ c) $1 \mu \mathrm{m}$ d) $400 \mathrm{~nm}$

É importante ressaltar que os nanocompósitos sintetizados via coprecipitação deveriam apresentar estrutura cúbica e os por via hidrotermal, hexagonal, como os da Figura - 13 a) e 13 b), respectivamente. ${ }^{58,75}$ Entretanto os compósitos por coprecipitação não se comportam como os nanocristais estabilizados por outras substâncias orgânicas, a aglomeração e espessura dos bastonetes hidrotermais deixa claro que há uma interação diferenciada entre os nanocristais e os Carbon-Dots. Esses efeitos podem ser associados as forças de Van der Waals e a uma possível diferença de carga gerada pela síntese levemente básica dos cristais e os grupos carboxílicos da superfície dos C-Dots.

As análises de MEV foram realizadas com amostras representativas para os compósitos $\mathrm{NaYF}_{4}: \mathrm{Ln}(\mathrm{C}-\mathrm{Dot})$, com variação nas concentrações. 
A Figura - 20 apresenta uma imagem gerada por HRMET dos compósitos $\mathrm{NaYF}_{4}$ :Eu com concentração de carbono $\mathrm{C}_{+}$, as partículas não apresentam orientação clara, formando diversos aglomerados. As imagens c) e d) apresentam círculos vermelhos onde é observado várias pequenas fases cristalinas em diversas orientações, característica evidenciada em compósitos de C-Dot. ${ }^{69}$

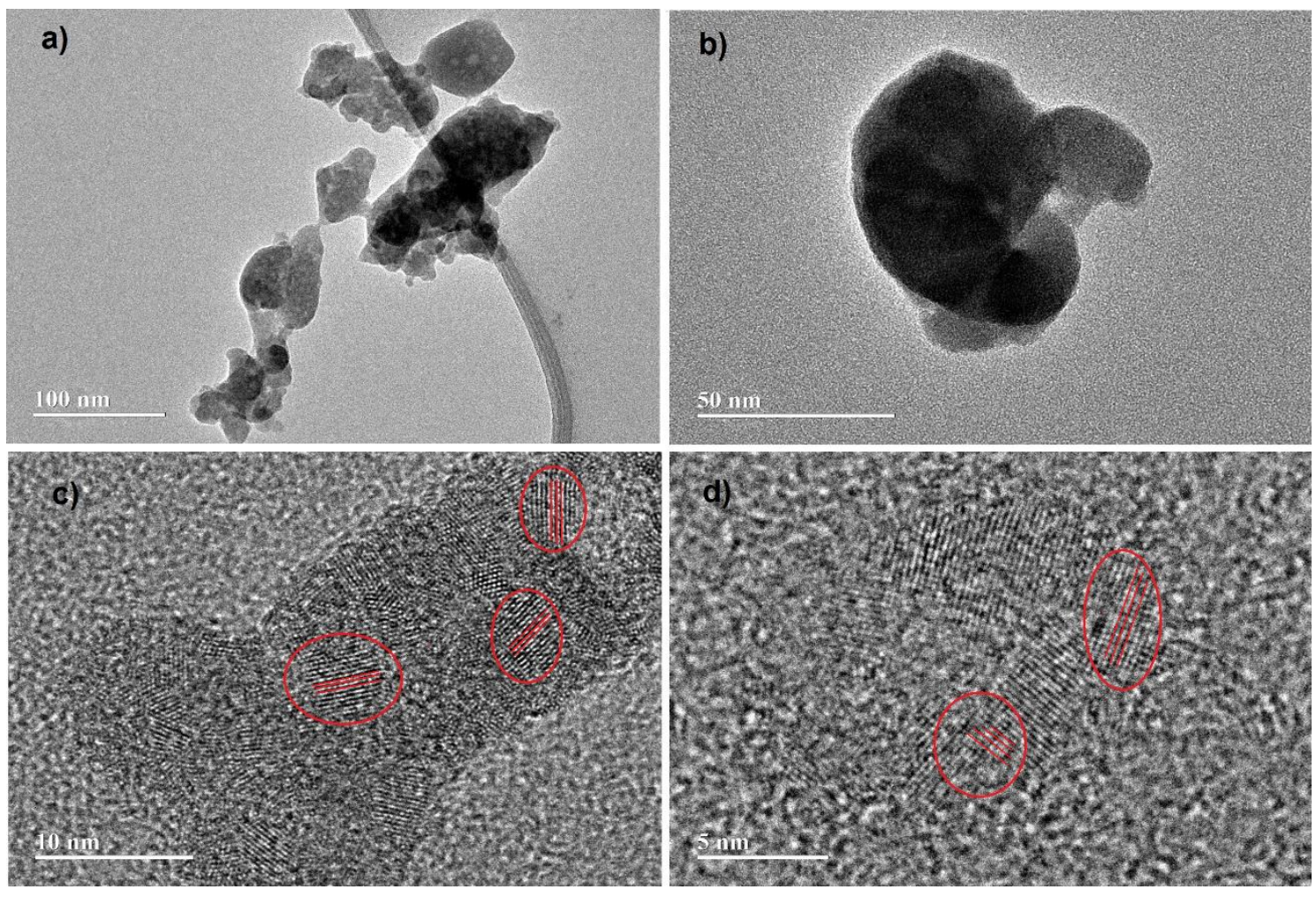

Figura 20 - Imagens de HRMET de Compósitos Ln(C+) a) $100 \mathrm{~nm}$; b) $50 \mathrm{~nm}$; c) $10 \mathrm{~nm}$; d) 5 $n m$.

A Figura - 21 apresenta os compósitos com concentração de carbono C, nessa concentração foi possível observar partículas monodispersas com cerca de $25 \mathrm{~nm}$, porém com a alteração da concentração observou-se o mesmo comportamento citado na concentração anterior, como pode ser observado na Figura - 22. A imagem b) apresenta círculos vermelhos onde também é possível identificar fases cristalinas com orientações distintas. 


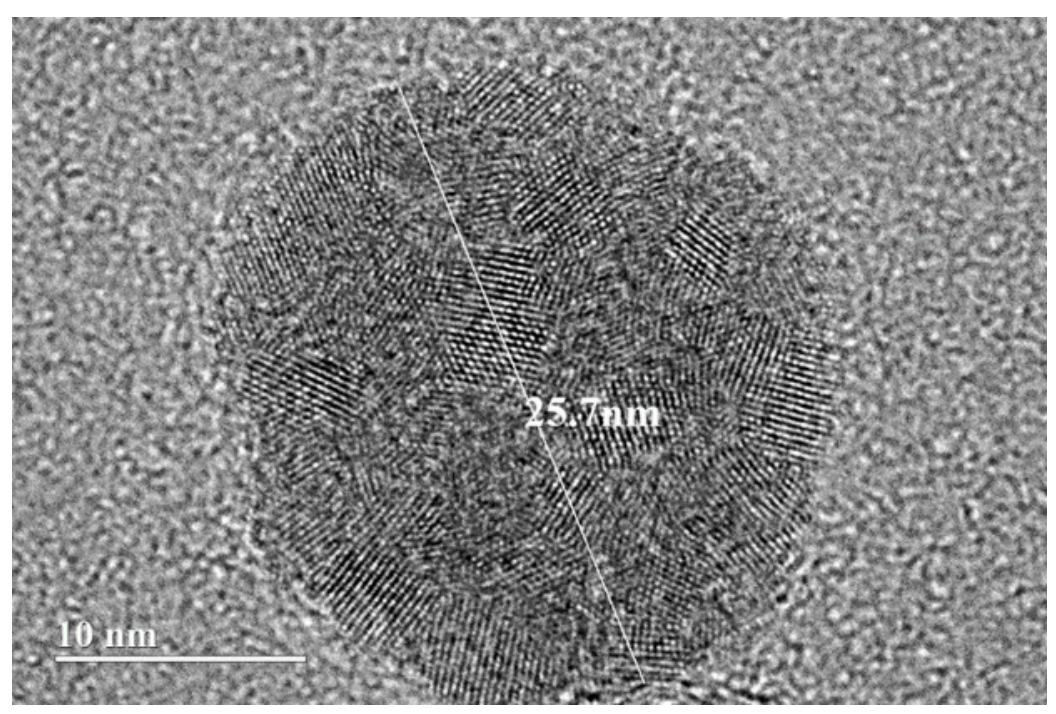

Figura 21 - Imagem de HRMET de Compósito Ln(C-) com partícula monodispersa com 25,7 nm de diâmetro

Esse comportamento evidencia a cobertura da matriz $\mathrm{NaYF}_{4}: \mathrm{Ln}$ pelos CDots, isolando os nanocristais inorgânicos e gerando as fases cristalinas isoladas. ${ }^{66}$ 

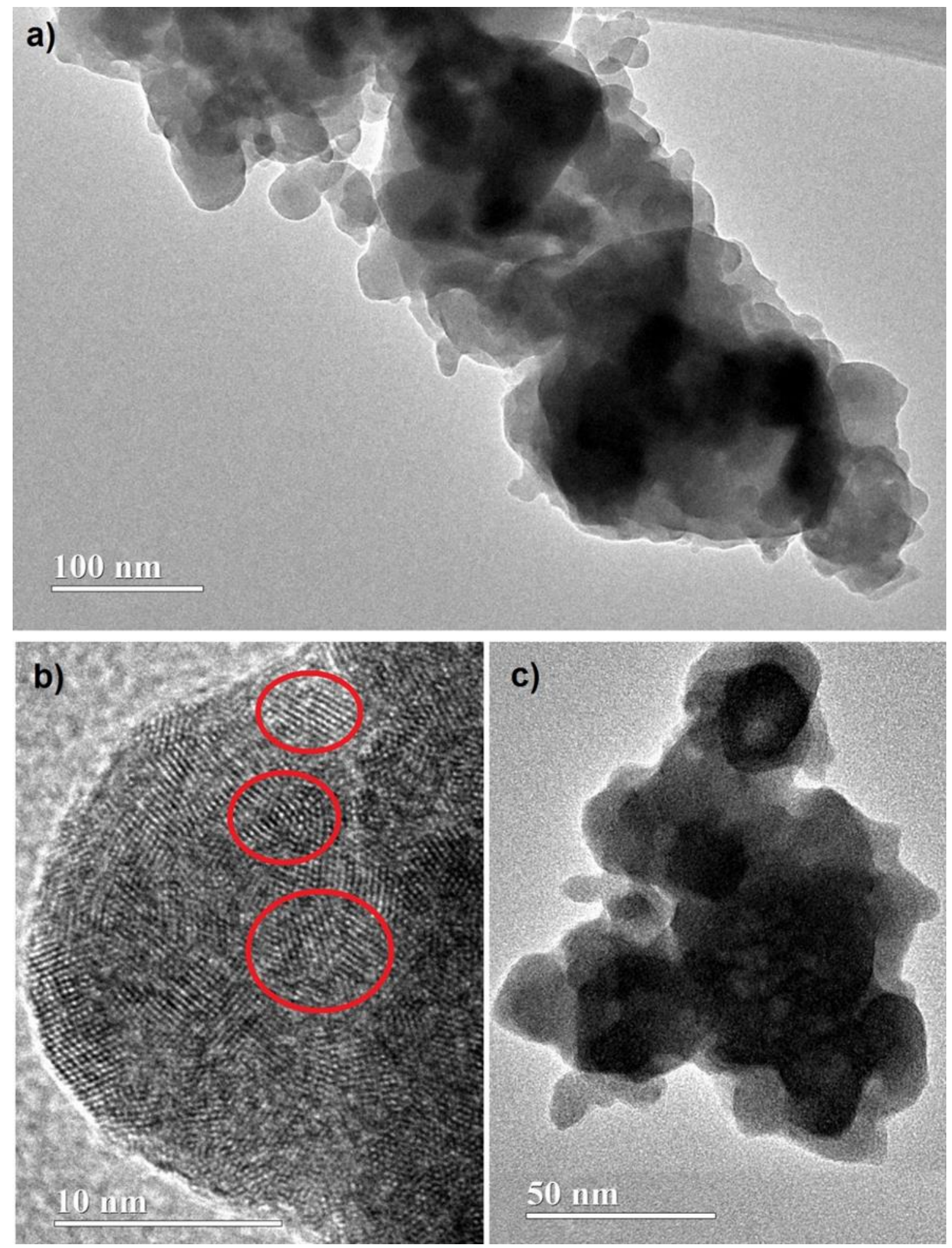

Figura 22 -Imagens de HRMET dos compósitos Ln(C-) a) $100 \mathrm{~nm}$; b) $10 \mathrm{~nm}$; c) $50 \mathrm{~nm}$.

A Figura - 23 apresenta os compósitos sintetizados via método hidrotermal com concentração $\mathrm{C}+$ de Carbon-Dot, as partículas apresentadas podem ser encontradas dispersas como visto na imagem a), a imagem b) mostra os planos cristalinos bem orientados e c) demonstra um tamanho de partícula bastante superior ao da síntese por coprecipitação de aproximadamente $300 \mathrm{~nm}$. 

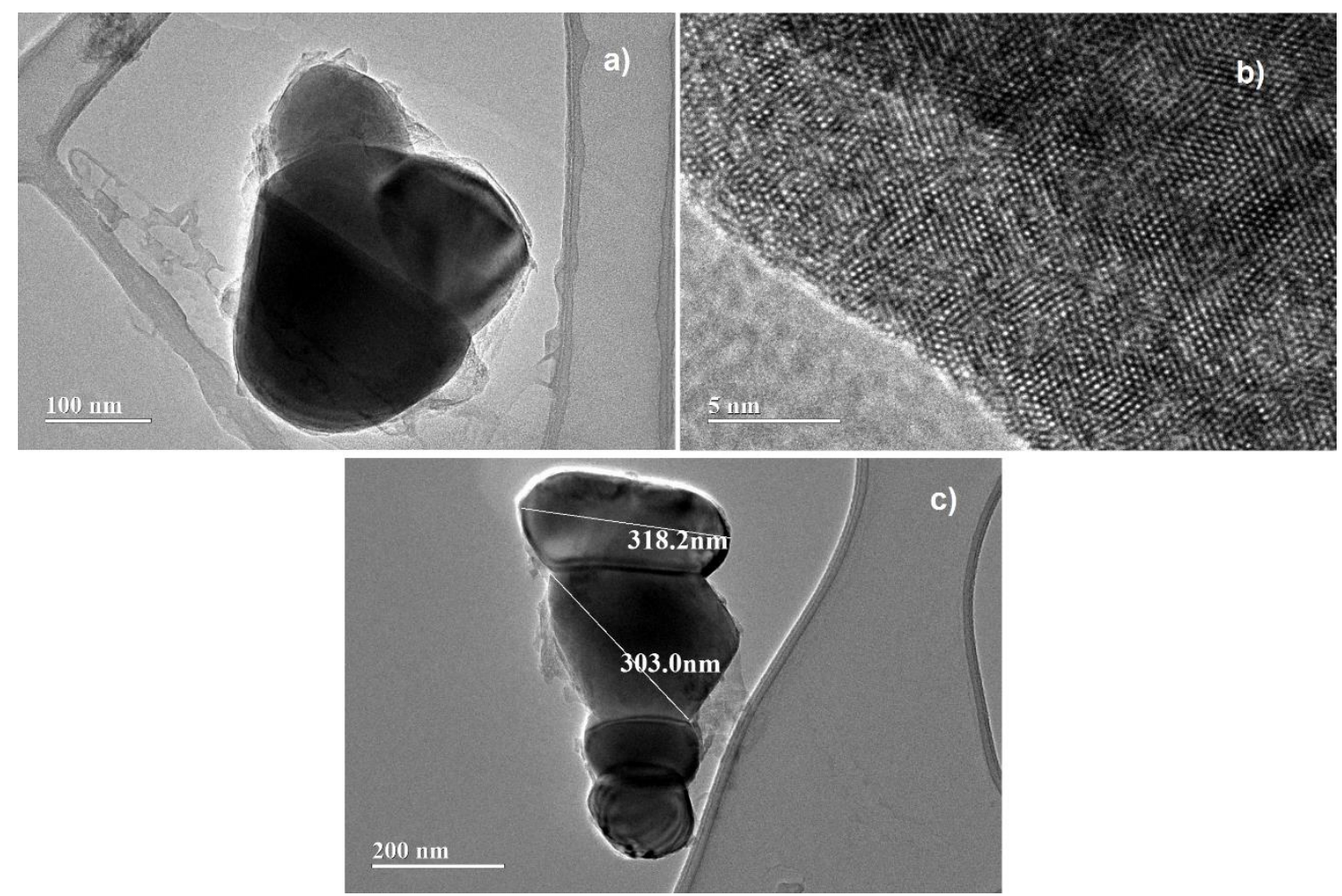

Figura 23 - Imagens de HRMET dos compósitos Ln(C+)HT a) $100 \mathrm{~nm}$ b) $5 \mathrm{~nm}$ c) $200 \mathrm{~nm}$

A Tabela - 4 apresenta de maneira simplificada as propriedades observadas nos materiais sintetizados.

Tabela 4 - Propriedades qualitativas dos compósitos sintetizados

\begin{tabular}{|c|c|l|l|l|l|l|l|l|}
\cline { 2 - 9 } \multicolumn{1}{c|}{} & Ln(C-) & Ln(C) & Ln(C+) & $\begin{array}{l}\text { Ln(C-) } \\
\text { HT }\end{array}$ & $\begin{array}{l}\text { Ln(C) } \\
\text { HT }\end{array}$ & $\begin{array}{l}\text { Ln(C+) } \\
\text { HT }\end{array}$ & $\begin{array}{l}\text { NaYF4: } \\
\text { Ln }\end{array}$ & $\begin{array}{l}\text { NaYF4: } \\
\text { Ln (HT) }\end{array}$ \\
\hline Fase & Amorfa & Amorfa & Amorfa & Hexagonal & Hexagonal & Hexagonal & Cúbica & Hexagonal \\
\hline Dispersão & Mono & Aglomerada & Aglomerada & Mono & Aglomerada & Aglomerada & Mono & Mono \\
\hline Dimensão & Nano & Nano & Nano & Micro & Micro & Micro & Nano & Micro \\
\hline
\end{tabular}

O espectro de infravermelho apresentado na Figura - 24 indica o C-Dot antes de sua aplicação na síntese do compósito a Figura - 25 e a Figura - 26, tratam-se de espectros representativos dos compósitos afim de identificar possíveis grupos funcionais, eles apresentam picos de absorção em números de onda próximos em todos os espectros. O pico na região de $3400 \mathrm{~cm}^{-1}$ é atribuído ao estiramento da ligação $\mathrm{O}-\mathrm{H}$, um pico de difícil percepção nos compósitos e claro no C-Dot pode ser observado na região $2950 \mathrm{~cm}^{-1}$ é atribuído ao estiramento da ligação $-\mathrm{CH}_{3}$, em $1630 \mathrm{~cm}^{-1}$ encontramos estiramento da ligação 
$\mathrm{C}=\mathrm{O}$, em $1519 \mathrm{~cm}^{-1}$ indica deformação da ligação $-\mathrm{NH}, 1380 \mathrm{~cm}^{-1}$ evidencia deformação simétrica da ligação $-\mathrm{CH}_{3}$, em $1080 \mathrm{~cm}^{-1}$ assinala estiramento da ligação $\mathrm{C}-\mathrm{O}$.

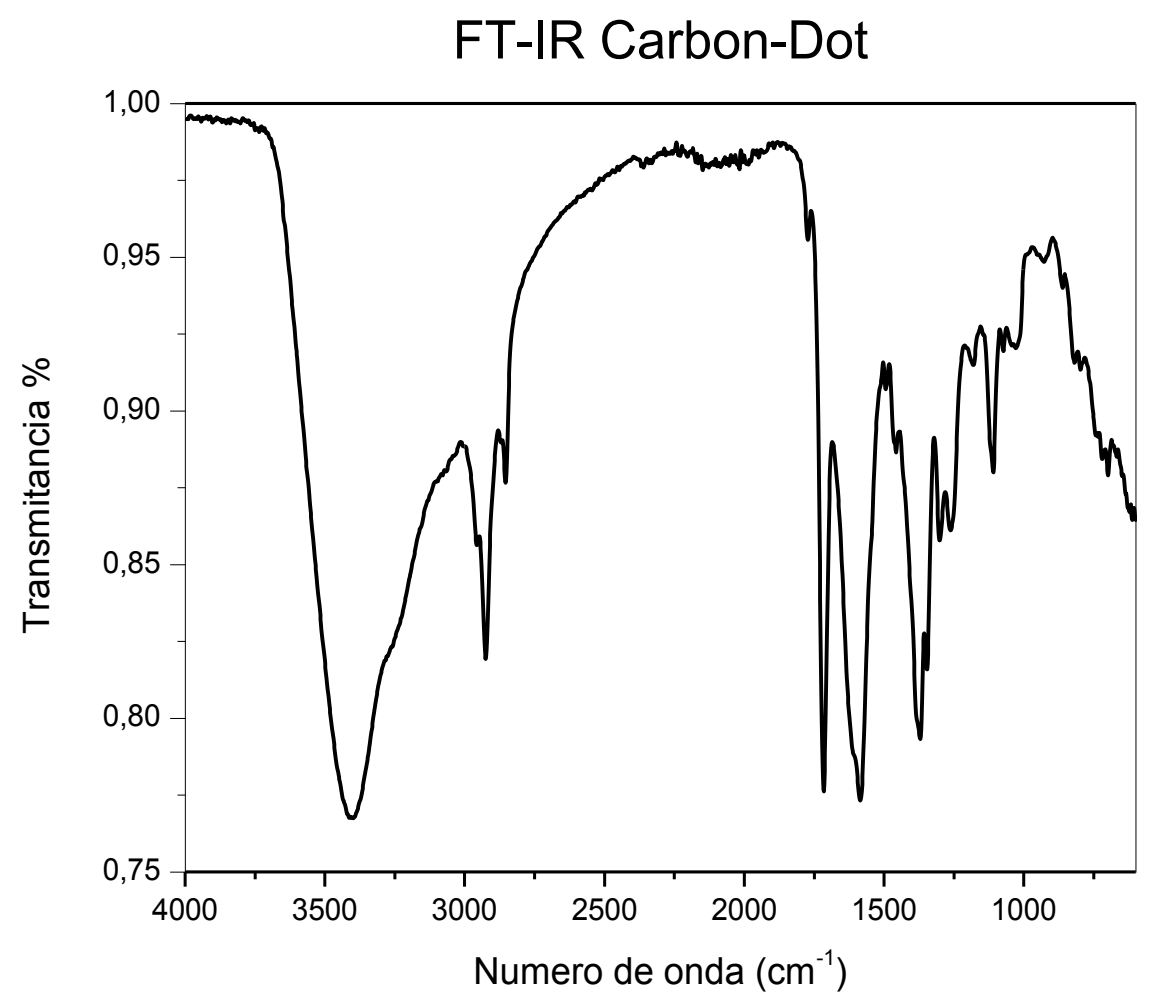

Figura 24 - Espectro de Infravermelho do Carbon-Dot. 




Figura 25 - Espectro de Infravermelho das amostras de NaYF4:Eu(C-Dot). Eu(C+), Eu(C) e Eu(C-), respectivamente, azul, vermelho e preto.

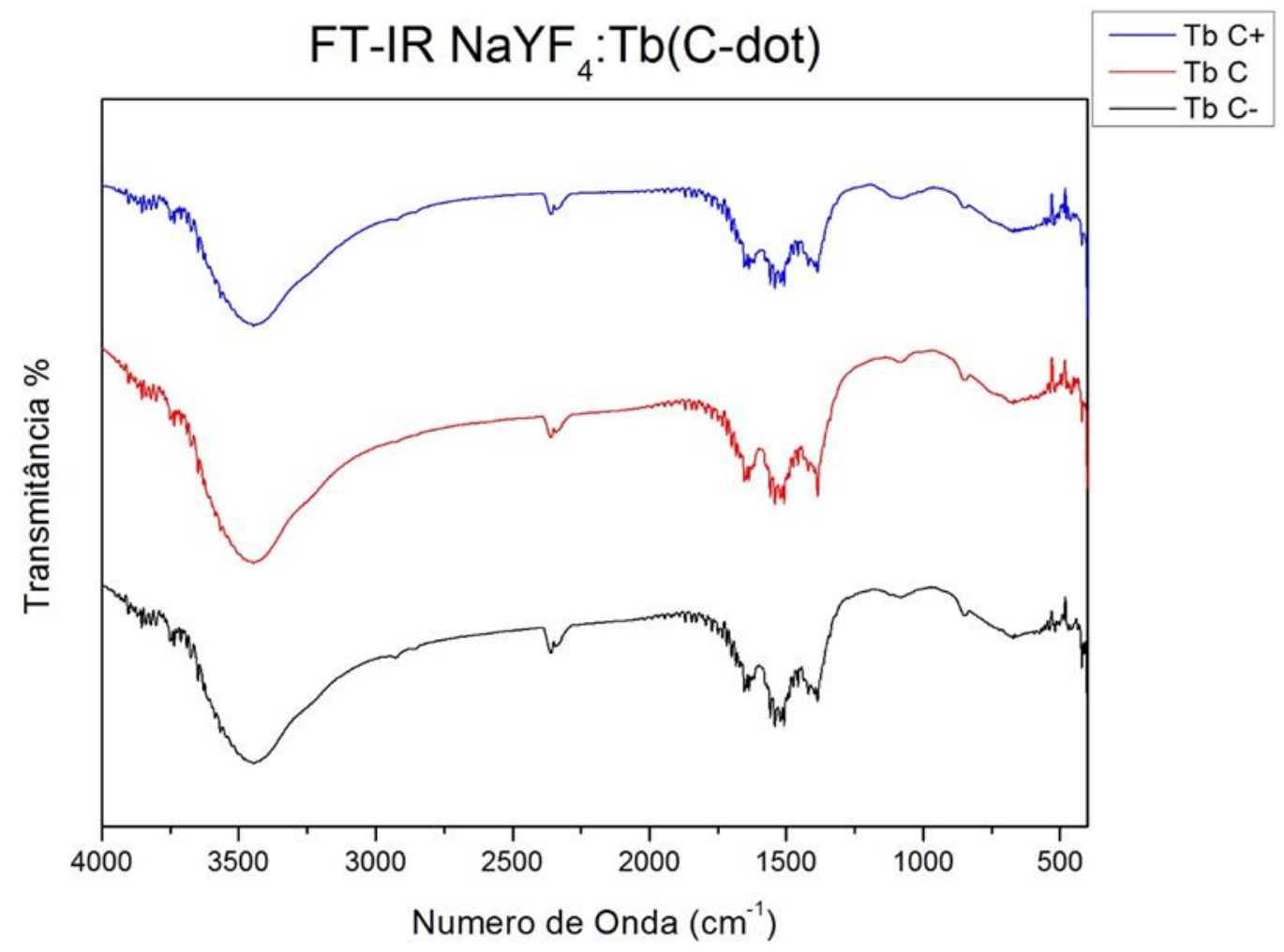

Figura 26 - Espectro de Infravermelho das amostras de $\mathrm{NaYF}_{4}: \mathrm{Tb}(\mathrm{C}-\mathrm{Dot}) . \mathrm{Tb}(\mathrm{C}+), \mathrm{Tb}(\mathrm{C})$ e $\mathrm{Tb}(\mathrm{C}$ ), respectivamente, azul, vermelho e preto. 
Esses resultados corroboram com a presença de grupos $-\mathrm{COOH}$ e $-\mathrm{COH}$ que a síntese oxidativa propõe que estarão na superfície no C-Dot. O grupo -NH pode ser explicado devido a origem da matéria prima para síntese do material. ${ }^{8}$

$\mathrm{O}$ espectro de excitação da espécie $\mathrm{NaYF}_{4}: \mathrm{Tb}(\mathrm{C}$-Dot), apresentado na Figura -27 , foi realizado a temperatura ambiente com $\lambda_{\mathrm{em}}=545 \mathrm{~nm}$, devido a esse comprimento de onda representar a principal emissão do térbio responsável pela coloração verde. É possível observar as transições do tipo $f-f$, entretanto elas não se apresentam finas e definidas como o esperado dos lantanídeos. Seguindo as mesmas condições a Figura - 28, representa 0 espectro de excitação da espécie $\mathrm{NaYF}_{4}: \mathrm{Tb}(\mathrm{C}-) \mathrm{HT}$, é possível observar que apesar das mudanças estruturais do espectro o material se comporta de maneira muito semelhante à espécie coprecipitada.



Figura 27 - Espectro de Excitação do compósito $T b(C$-) 


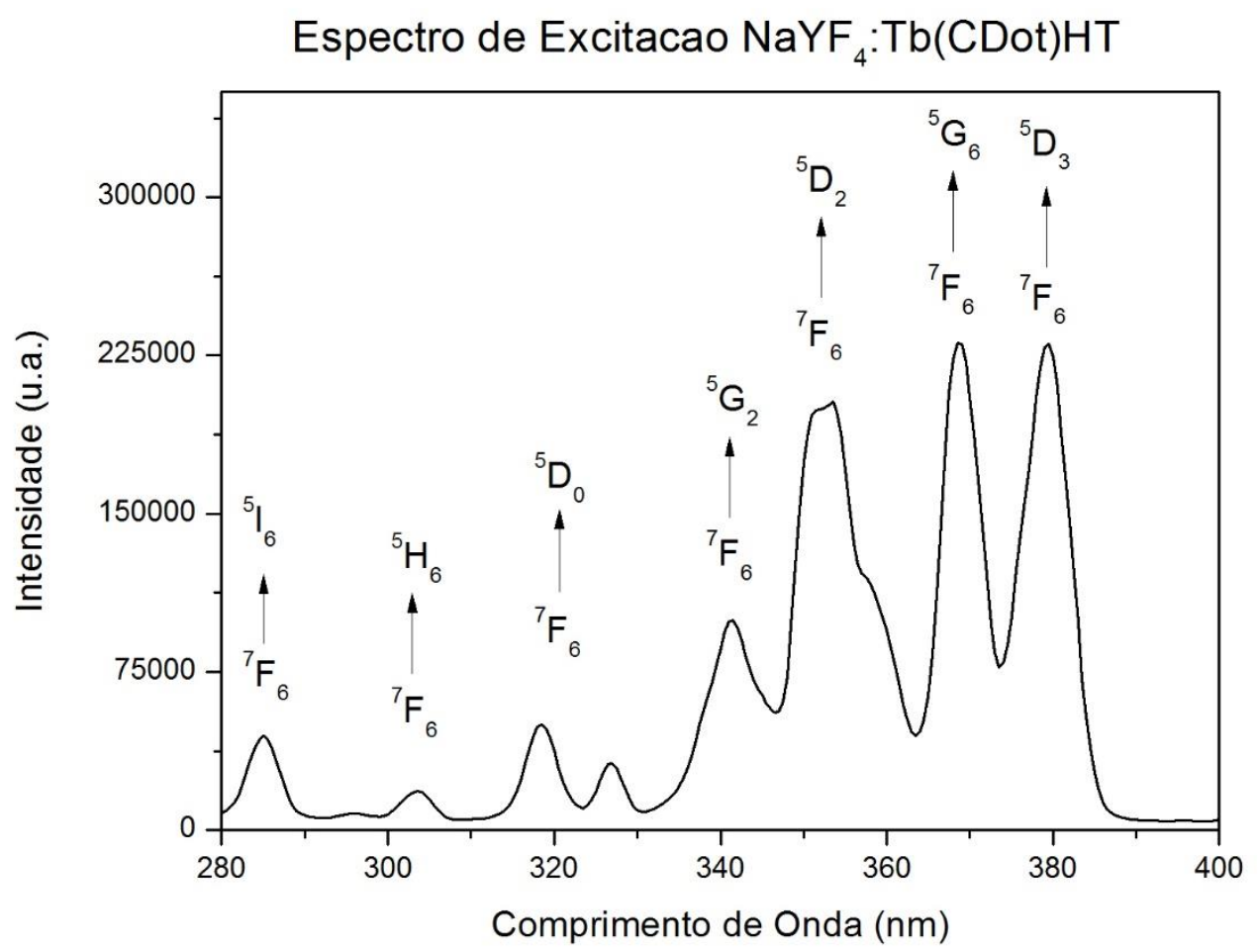

Figura 28 - Espectro de Excitação do compósito $T b(C$-)

A Figura - 29, trata-se do espectro de excitação da espécie $\mathrm{NaYF}_{4}: \mathrm{Eu}(\mathrm{C}$ ), eles foram realizados em temperatura ambiente com $\lambda_{\mathrm{EM}}=614 \mathrm{~nm}$, uma vez que esse comprimento de onda representa a principal emissão do európio responsável pela coloração vermelha. Como evidenciado a grande maioria das linhas de maior intensidade tratam-se de transições do tipo $f$ - $f$, o que indica um baixo nível de sensitização do metal pelo C-Dot, entretanto a banda observada entre 250 e $300 \mathrm{~nm}$ indica a transferência de energia pelo efeito antena. Por sua vez a Figura - 30, demonstra o espectro de espectro de excitação da espécie $\mathrm{NaYF}_{4}: \mathrm{Eu}(\mathrm{C}-\mathrm{Dot}) \mathrm{HT}$, linhas menos definidas e alargadas são visíveis nesse material, o que sugere uma maior participação do C-Dot em suas PL, a banda formada entre 270 e 360 indica uma transferência de energia pelo efeito antena, no mais o material se comporta de maneira semelhante ao adquirido via coprecipitação. 


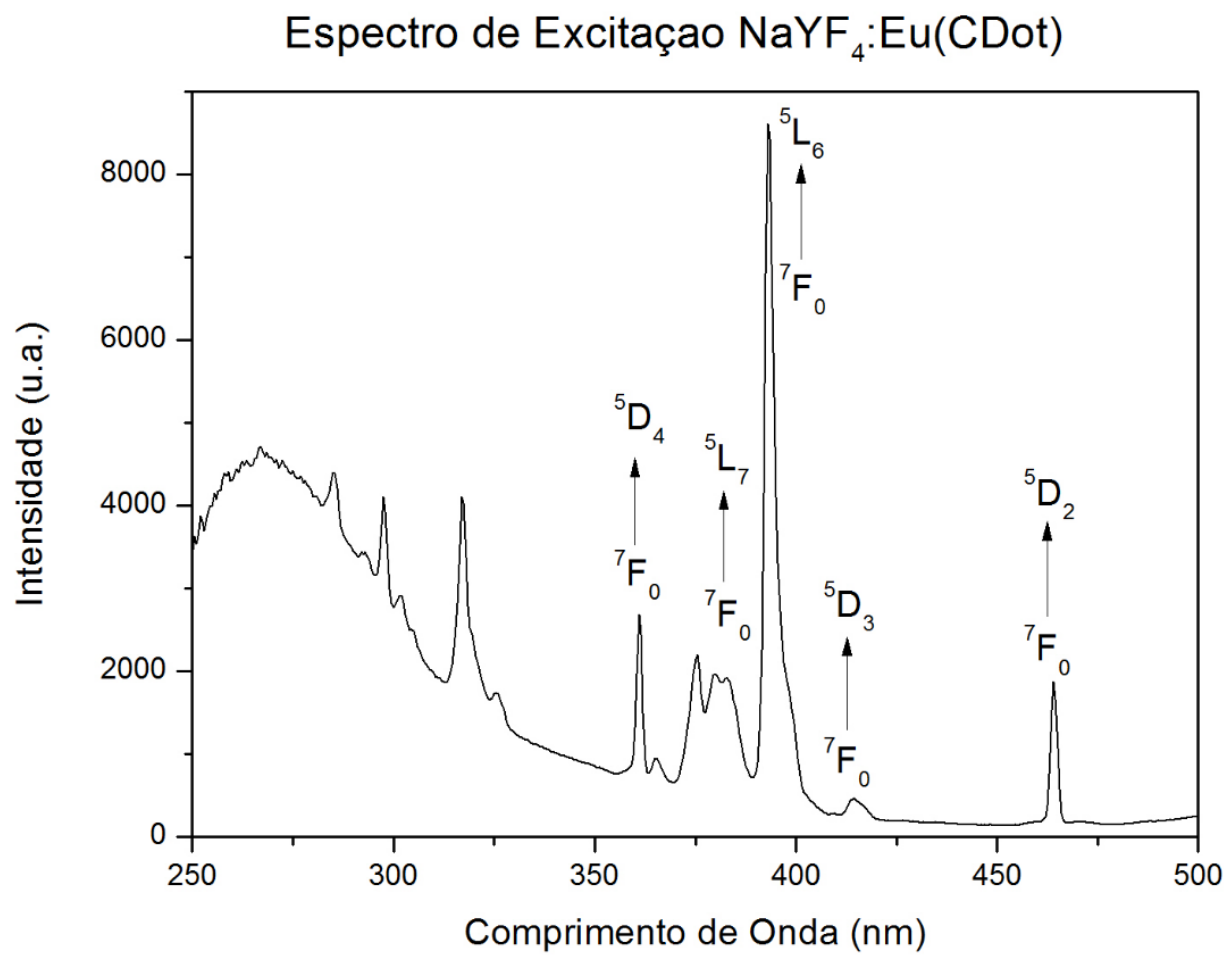

Figura 29 - Espectro de Excitação do compósito Eu(C-)

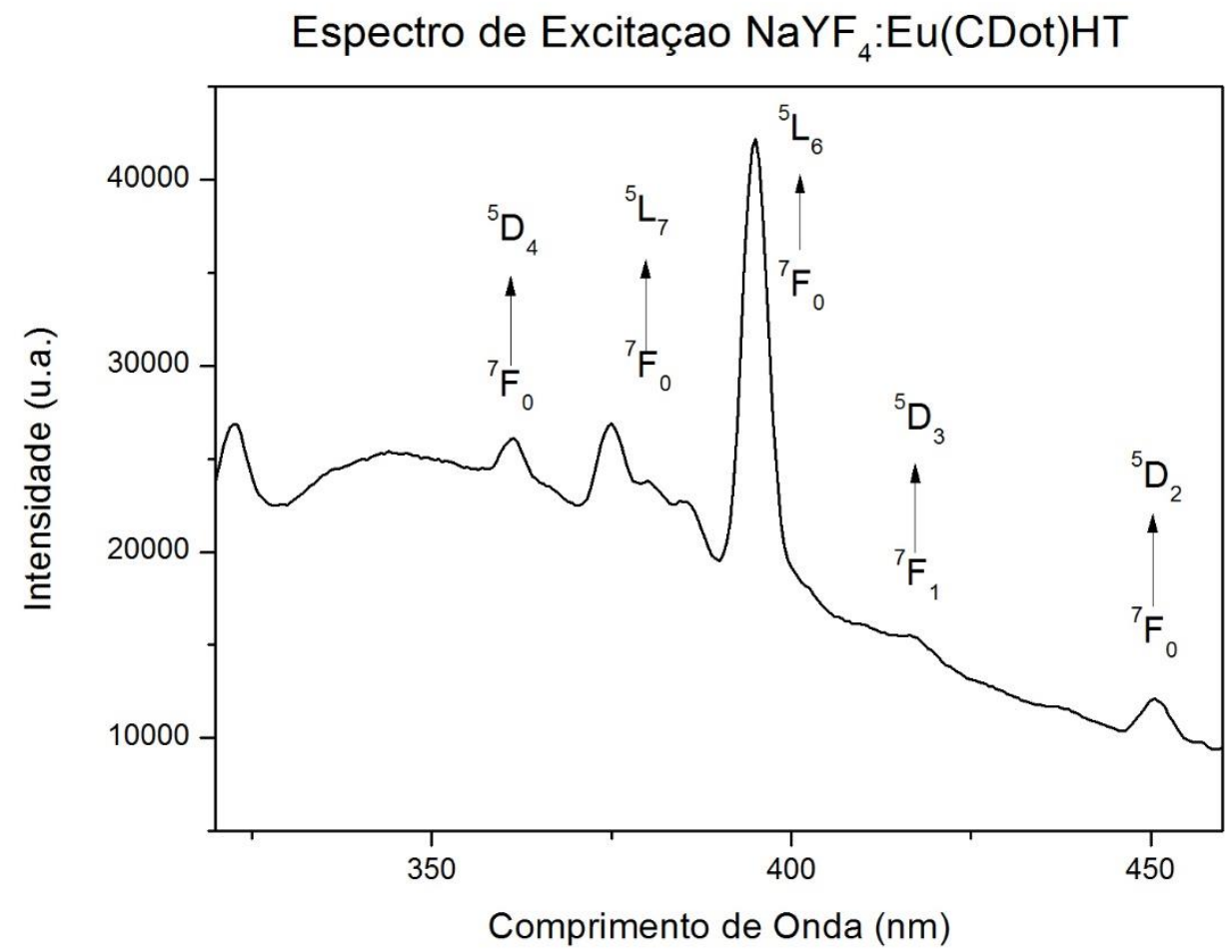

Figura 30 - Espectro de Excitação do compósito Eu(C-)HT 
Os espectros de emissão apresentados na Figura - 31, foram obtidos em temperatura ambiente com excitação direta no íon lantanídeo, ou seja, a excitação direta sem a participação do efeito antena. Optou-se por esse tipo de análise tendo em vista a baixa sensitização dos C-Dots, excitando na transição ${ }^{7} \mathrm{~F}_{0} \rightarrow{ }^{5} \mathrm{~L}_{6}$ foi utilizado um $\lambda_{\text {ex }}$ entre 390 e $397 \mathrm{~nm}$, apresentam as transições ${ }^{5} \mathrm{D}_{0} \rightarrow{ }^{7} \mathrm{~F}_{1},{ }^{5} \mathrm{D}_{0} \rightarrow{ }^{7} \mathrm{~F}_{2},{ }^{5} \mathrm{D}_{0} \rightarrow{ }^{7} \mathrm{~F}_{3}$ e ${ }^{5} \mathrm{D}_{0} \rightarrow{ }^{7} \mathrm{~F}_{4}$ do íon $\mathrm{Eu}^{3+}$, nos comprimentos de onda de 590, 614, 648 e $698 \mathrm{~nm}$, respectivamente. Sendo a emissão de $614 \mathrm{~nm}$ a responsável pela coloração avermelhada do material sob luz UV. Se comparadas as emissões entre as espécies coprecipitadas e hidrotermais fica claro a diferença das propriedades luminescentes, diferenças oriundas da diferença de ambiente químico devido a simetria diferenciada das espécies coprecipitadas e hidrotermais. 


\section{Espectro de Emissao $\mathrm{NaYF}_{4}: \mathrm{Eu}(\mathrm{C}-)$}
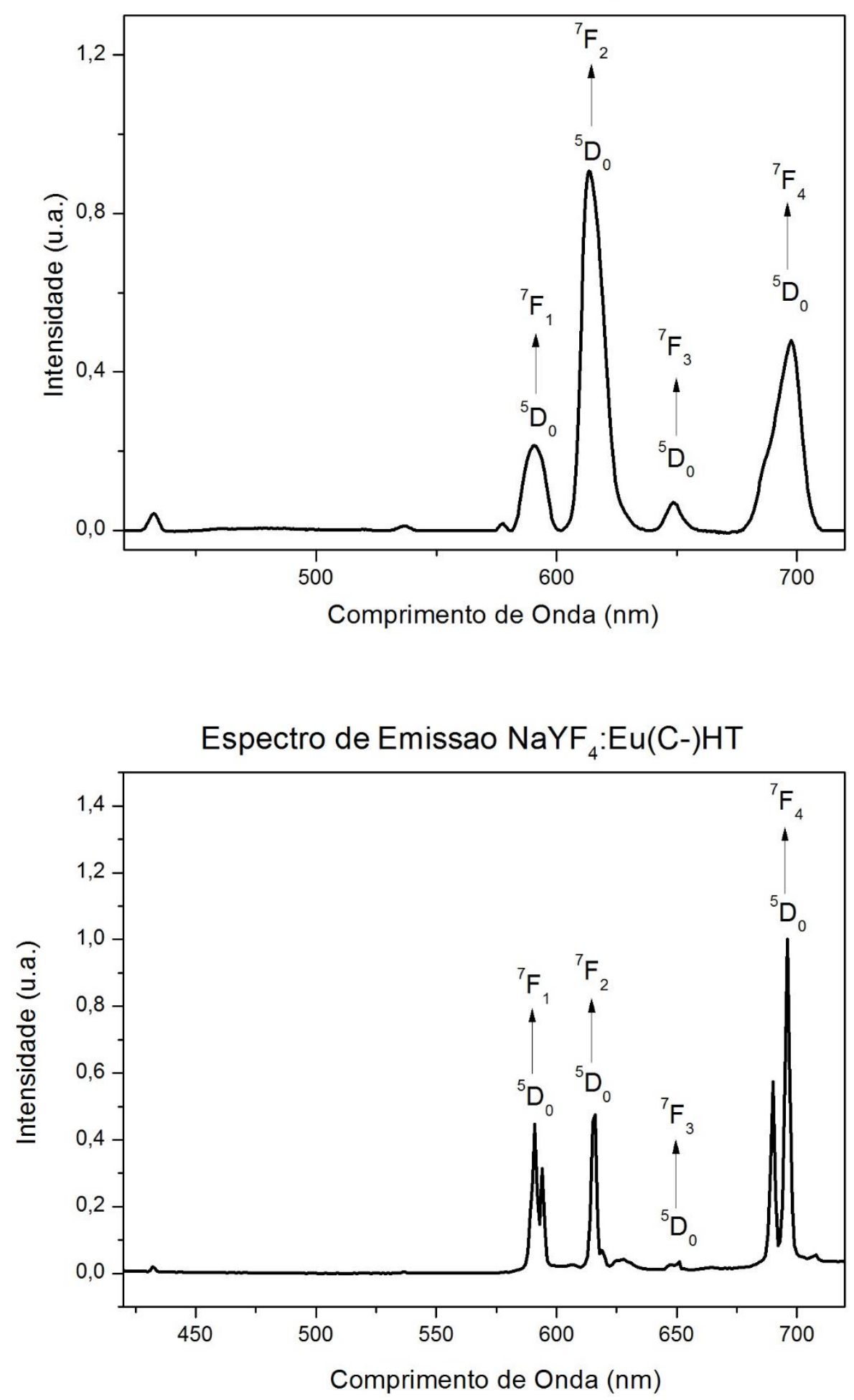

Figura 31 - Espectros de Emissão dos compósitos NaYF4:Eu(C-) e NaYF4:Eu(C-)HT.

$\mathrm{Na}$ amostra HT a emissão hipersensitiva é de baixa intensidade indicando um ambiente altamente simétrico ${ }^{53}$ o que condiz com os espectros de DRX, as 
amostras de coprecipitação se mostram muito mais luminescentes na região do vermelho característico das emissões de Európio.

Considerando as três concentrações de C-Dot para a síntese por coprecipitação, todas as amostras tiveram rendimento quântico menor que $1 \%$ e a perda de luminescência é inversamente proporcional a concentração de C-Dot, não foram realizadas medidas de rendimento quântico para as espécies HT, uma vez que a luminescência das mesmas é inferior à de coprecipitação.

Os tempos de vida das amostras por coprecipitação para a transição ${ }^{5} \mathrm{D}_{0} \rightarrow{ }^{7} \mathrm{~F}_{2}$ se mostraram inversamente proporcionais à concentração de C-Dot no material, na figura - 32 pode-se observar o decaimento da amostra C-. Importante ressaltar que a amostra $\mathrm{C}+$ apresentou dois tempos de vida, devido a isso é possível associar a alta concentração de C-Dot com a formação de mais de uma fase. Observando o decaimento nas amostras $C+$ também é possível observar um rápido decaimento inicial e em seguida um decaimento mais lento. As amostras HT não tiveram seus tempos de vida monitorados devido à baixa luminescência apresentada.



Figura 32 - Gráfico de tempo de vida do compósito NaYF4:Eu(C-) 
A Figura - 33 trata-se dos espectros de emissão das espécies $\mathrm{NaYF}_{4}: \mathrm{Tb}$ (C-Dot), eles foram realizados a temperatura ambiente com excitação direta no íon lantanídeo por conta da baixa sensitização que o C-Dot proporciona, como visto nos espectros de excitação, a transição escolhida para essa excitação foi a ${ }^{7} \mathrm{~F}_{6} \rightarrow{ }^{5} \mathrm{D}_{2}$ com um $\lambda_{\text {ex }}$ entre 349 e $354 \mathrm{~nm}$. Nesses espectros é possível observar nas três concentrações de C-Dot as transições ${ }^{5} \mathrm{D}_{4} \rightarrow^{7} \mathrm{~F}_{6}$, ${ }^{5} \mathrm{D}_{4} \rightarrow{ }^{7} \mathrm{~F}_{5},{ }^{5} \mathrm{D}_{4} \rightarrow{ }^{7} \mathrm{~F}_{4},{ }^{5} \mathrm{D}_{4} \rightarrow{ }^{7} \mathrm{~F}_{3}$ e ${ }^{5} \mathrm{D}_{4} \rightarrow{ }^{7} \mathrm{~F}_{2}$ encontradas representadas pelos picos em 489, 545, 584, 620 e $668 \mathrm{~nm}$, respectivamente. Sendo o pico de $545 \mathrm{~nm}$ o mais intenso, que proporciona a coloração verde ao material sob luz UV. Todas as concentrações de C-Dot tiveram rendimento quântico inferior a $1 \%$ e a perda de luminescência é inversamente proporcional a concentração do nanomaterial de carbono utilizado na síntese, não foram realizadas medidas de rendimento quântico para as espécies HT, uma vez que a luminescência das mesmas é inferior à de coprecipitação. 

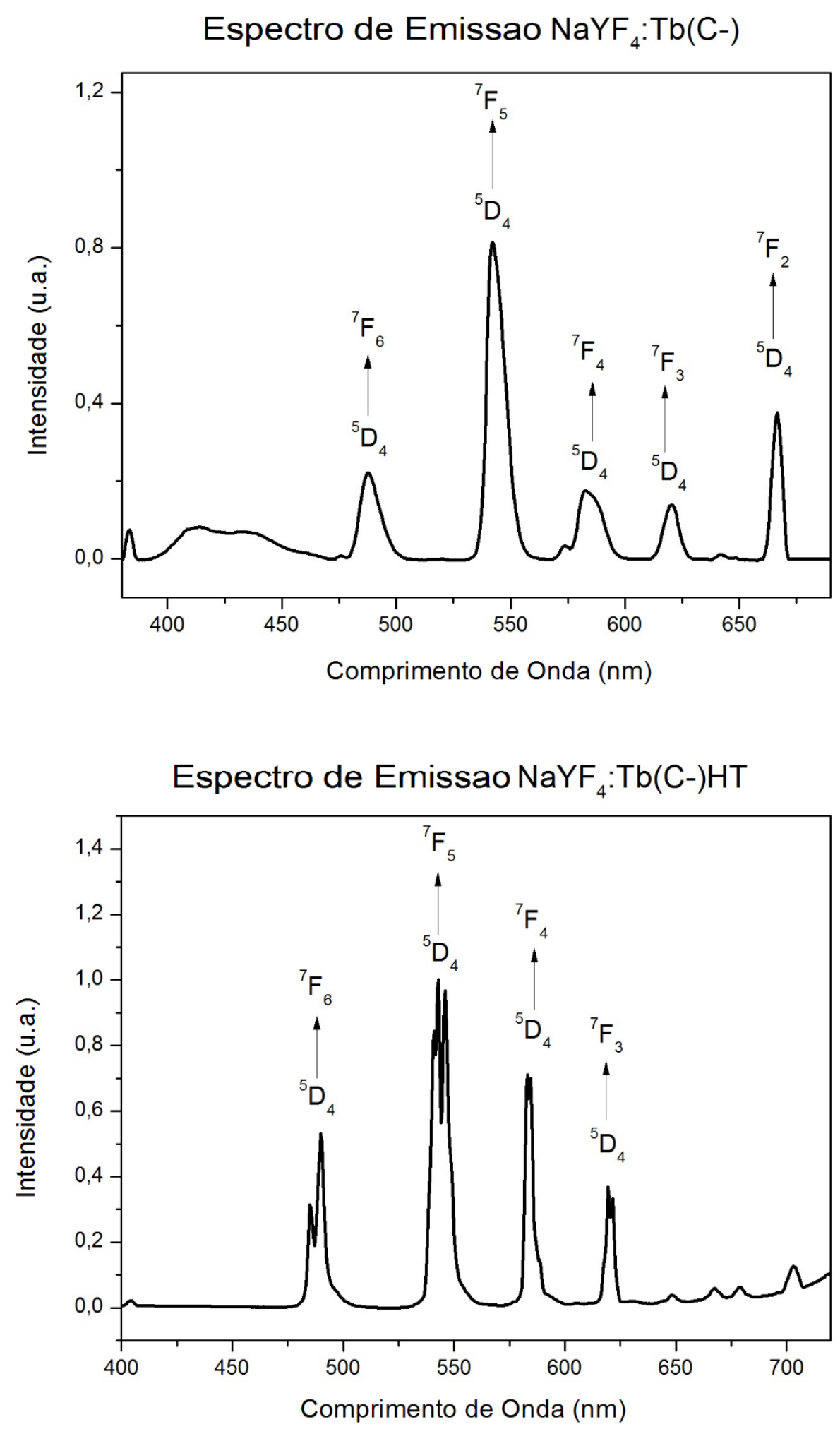

Figura 33 - Espectros de Emissão dos compósitos $\mathrm{NaYF}_{4}: \mathrm{Eu}\left(\mathrm{C}\right.$-) e NaYF$F_{4}: \mathrm{Eu}(\mathrm{C}$-)HT. 
A emissão ${ }^{5} D_{4} \rightarrow{ }^{7} F_{2}$, pode ser observada em todos os espectros e é valido notar que sua intensidade aumenta com a quantidade de Carbon-Dot utilizado na síntese, esse fenômeno pode ser decorrente de uma transferência de energia da emissão ${ }^{5} D_{4} \rightarrow{ }^{7} F_{6}$, promovida pela interação Tb-C-Dot. ${ }^{81}$

O tempo de vida para a concentrações C- está presente na Figura - 34, eles foram obtidos monitorando a emissão em $545 \mathrm{~nm}$ referente a transição ${ }^{5} D_{4} \rightarrow^{7} F_{5}$. Os tempos de vida, assim como a luminescência diminuem com 0 aumento da concentração de C-Dot na síntese. As amostras C e C+ apresentaram mais de um tempo de vida, que pode ser observado pelo decaimento exponencial presentes nos gráficos.

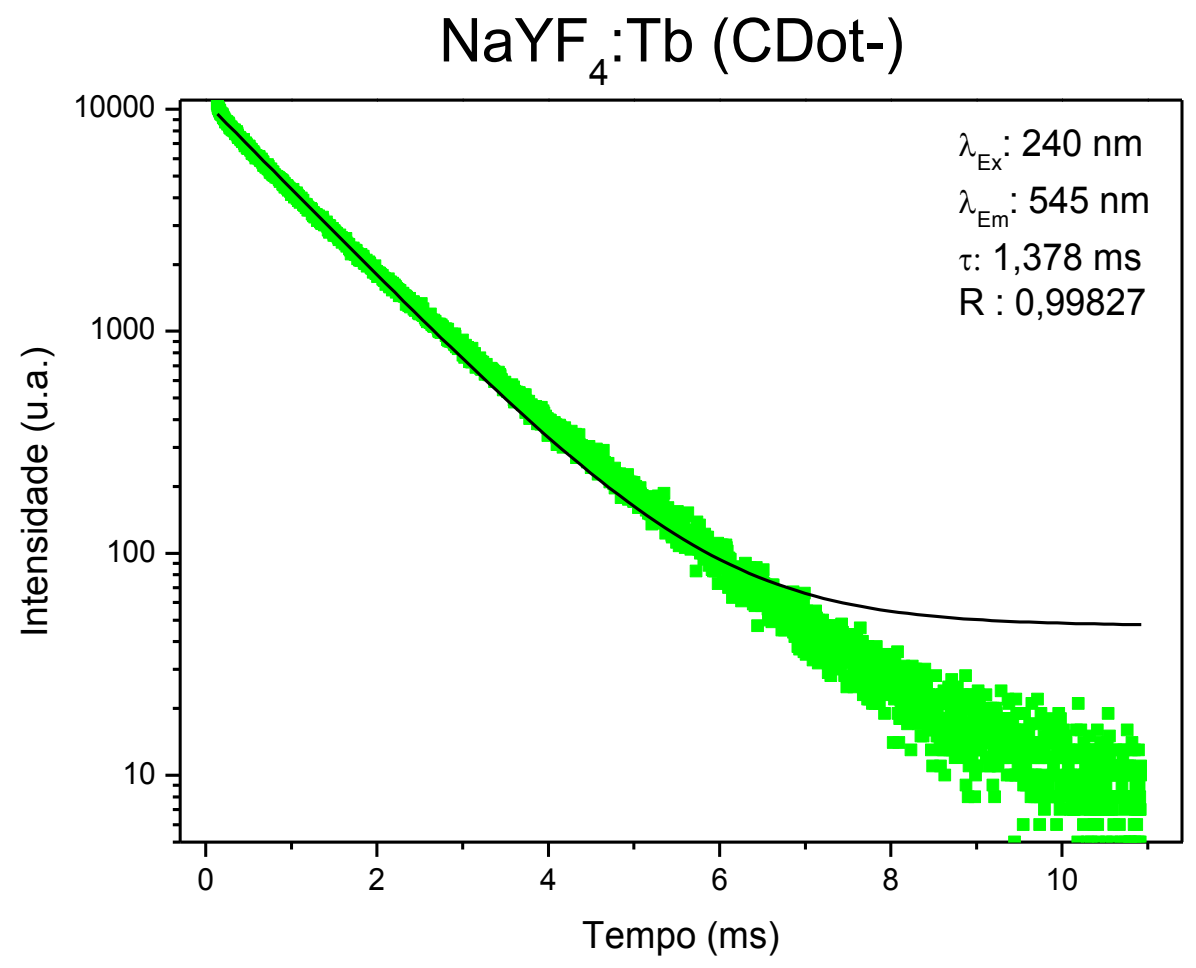

Figura 34 - Gráfico de tempo de vida do compósito $\mathrm{NaYF}_{4}: \mathrm{Tb}(\mathrm{C}$-)

Como visto as amostras com Tb possuem melhor sensitização que as amostras com Eu, isso é demonstrado pelos tempos de vida, uma vez que a amostras $\mathrm{Tb}\left(\mathrm{C}_{-}\right)$apresentou $\mathrm{T}=1,378 \mathrm{~ms}$, enquanto $\mathrm{Eu}(\mathrm{C}-)$ possui $\mathrm{T}=0,8890$ ms. $A$ análise do efeito antena por meio dos rendimentos quânticos $(Q Y)$ tornase inconclusiva uma vez que todas amostras apresentaram $Q Y<1 \%$. A Tabela 5 nos mostra os valores de Tempos de vida e QY para os compósitos 
sintetizados por coprecipitação e para os nanocristais puros, todos os tempos de vida foram calculados pela equação (1) a seguir82

$$
<\tau>=\frac{\int_{t_{0}}^{\infty} I(t) \cdot d t}{\int_{t_{0}}^{\infty} I_{0} \cdot d t}
$$

onde $I$ é a intensidade de fotoluminescência e $t$ é o tempo. Como pode ser observado os valores de QY quando comparados com as amostras de nanocristais não possuem uma diferença de valores considerável, entretanto os valores de tempos de vida são bem inferiores quando comparados.

Tabela 5 - Tempos de Vida e Rendimento Quântico das espécies coprecipitadas

\begin{tabular}{|c|c|c|}
\hline Material & Tempo de vida (ms) & $\mathbf{Q Y}(\%)$ \\
\hline $\mathrm{NaYF}$ :Eu & 6,215 & 1,24 \\
\hline $\mathrm{Eu}(\mathrm{C}-)$ & 0,8890 & 0,64 \\
\hline $\mathrm{Eu}(\mathrm{C})$ & 0,4257 & 0,11 \\
\hline $\mathrm{Eu}(\mathrm{C}+)$ & 0,2531 & - \\
\hline $\mathrm{NaYF}: \mathrm{Tb}$ & 5,329 & 0,38 \\
\hline $\mathrm{Tb}(\mathrm{C}-)$ & 1,378 & 0,30 \\
\hline $\mathrm{Tb}(\mathrm{C})$ & 0,9216 & 0,40 \\
\hline $\mathrm{Tb}(\mathrm{C}+)$ & 0,3919 & - \\
\hline
\end{tabular}

A tabela não indica o QY das espécies $\operatorname{Ln}(\mathrm{C}+)$, uma vez que os números apresentados pelas medidas realizadas foram resultados negativos.

A visível absorção de umidade por parte do C-Dot poderia ser a responsável pelo quenching das emissões dos lantanídeos empregados ${ }^{50}$ e essa teoria poderia se valer da relação entre o aumento da concentração de C-Dot na síntese e a perda de luminescência do material. Entretanto, outros exemplos de nanocompósitos presentes na literatura indicam a presença de grupos desativadores do tipo $\mathrm{O}-\mathrm{H}$, mas com excelentes $\mathrm{PL}$ dos materiais. ${ }^{73,74}$ Todos os demais espectros de luminescência encontram-se nos anexos.

Sendo assim, com base no mecanismo luminescente proposto para os Carbon-Dot, é possível supor que a aglomeração das partículas, observadas nas imagens de MEV e HRMET, tenha suprimido os buracos quânticos responsáveis por suas PL e dificultado a transferência de energia necessária para a 
sensitização dos lantanídeos, além da correção dos defeitos superficiais dos próprios nanocristais diminuindo a emissão dos mesmos. A maior concentração de C-Dots também está diretamente ligada a intensidade das emissões, quanto maior a concentração maiores são os aglomerados favorecendo a absorção da luz emitida pelos lantanídeos. ${ }^{80} \mathrm{O}$ fato da concentração $\mathrm{C}$ - apresentar melhores tempos de vida, maior intensidade luminescente e partículas monodispersas fortalece essa suposição.

Em se tratando dos materiais com európio a razão entre as emissões ${ }^{7} \mathrm{~F}_{2} /{ }^{7} \mathrm{~F}_{1}$, para todas as concentrações de Carbon-Dot obtiveram valor de aproximadamente 1,0 para as amostras $\mathrm{HT}$ e 4,1 para as coprecipitadas, ambos os valores indicam considerável grau de simetria do ambiente químico do metal, ${ }^{53}$ entretanto a análise de DR-X não indicou qualquer fase cristalográfica para as coprecipitadas.

A partir dos dados obtidos no trabalho e comparando-os com a literatura ${ }^{79}$ é possível afirmar que as fases cristalinas isoladas das espécies coprecipitadas tratam-se de a-NaYF4:Ln, ou seja, cristais cúbicos, apesar de as análises morfológicas e cristalográficas não indicarem isso, pelos estudos luminescentes é possível chegar a essa conclusão, uma vez que as espécies cúbicas apresentam melhores propriedades que as encontradas na fase hexagonal. $\mathrm{E}$ devido a perca de luminescência do material sintetizado via hidrotermal pode-se afirmar que a fase em que se encontram é $\beta-\mathrm{NaYF}_{4}: \mathrm{Ln}$, uma vez que se apresentasse a fase transitória $\alpha \rightarrow \beta-\mathrm{NaYF}_{4}: \mathrm{Ln}$ sua luminescência seria maior devido à baixa simetria e uma maior quantidade de defeitos na matriz.

Essa comparação corrobora o fato da aglomeração das partículas serem responsáveis pela supressão da luminescência dos C-Dots, uma vez que os compósitos apresentaram comportamento muito semelhante ao dos nanocristais inorgânicos separados. 


\section{Conclusão}

O método por coprecipitação e hidrotermal se mostraram eficientes nas síntese dos compósitos de C-Dot e $\mathrm{NaYF}_{4}$, sejam eles dopados com európio ou térbio, entretanto as análises evidenciaram morfologias e propriedades luminescente destoantes se comparadas aos outros compósitos de lantanídeos e C-Dots encontrados na literatura, uma vez que os adquiridos por coprecipitação não apresentaram fase cristalográfica definida e seus rendimentos quânticos foram muito aquém do esperado, e os via síntese hidrotermal apesar de apresentarem fase cristalográfica possui PL inferiores aos coprecipitados.

Os compósitos coprecipitados, menores e com uma melhor dispersão apresentaram melhor luminescência que os hidrotermais, maiores e mais agregados. A concentração de C-Dot influencia diretamente no tamanho, morfologia e agregação dos compósitos, logo, influencia diretamente em suas propriedades luminescentes.

Uma passivação prévia do C-Dot ou uma outra rota sintética que controle a morfologia para uma fase transitória $\alpha \rightarrow \beta$, ou ainda evite a agregação de CDot, provavelmente garantiria ao compósito as condições ideais para o desenvolvimento de PLs superiores as encontradas, tendo em vista que as PL dos nanocristais e dos C-Dots são muito influenciados pelo tamanho e estrutura dos mesmos.

Considerando a influência das cargas entre dos C-Dots e dos nanocristais de NaYF 4:Ln a alteração de pH do C-Dots antes de introduzi-lo na síntese dos compósitos pode favorecer estruturas distintas e possíveis alterações nas PLs.

O trabalho apresentado trata-se de um material extremamente inovador, tendo em vista que existem poucos trabalhos desenvolvidos na área de compósitos de Carbon-Dot e lantanídeos e nenhum trabalho envolvendo Carbon-Dot e nanocristais dopados com íons lantanídeos, tornando essa caracterização pioneira. 


\section{Perspectivas}

Os materiais sintetizados e apresentados possuem diversas possibilidades de aplicação, geração de bioimagens, estudos catalíticos, sensores químicos, química forense e diversas outras áreas onde C-Dots e complexos de lantanídeos podem ser aplicados, uma vez que se apresenta em pó, de manuseio fácil e prático, e mantém as propriedades de solubilidade do Carbon-Dot e as finas linhas de emissão dos lantanídeos.

Trabalhos desenvolvidos recentemente já mostram as capacidades desse material em bioimageamento e química forense. A aplicação em química forense chamou a atenção para outro detalhe não estudado nesse trabalho, as emissões na região do NIR (infravermelho próximo), as Figuras - 35 e 36, mostram imagens de digitais recolhidas pelo uso dos compósitos $\mathrm{NaYF}_{4}: \mathrm{Eu}(\mathrm{C}-)$ e $\mathrm{NaYF}_{4}: \mathrm{Tb}(\mathrm{C}+)$, são imagens do tipo Hiperespectral na Região do Infravermelho Próximo (HSI-NIR) e foram obtidas utilizando uma faixa espectral compreendida entre 928 e $2524 \mathrm{~nm}$.

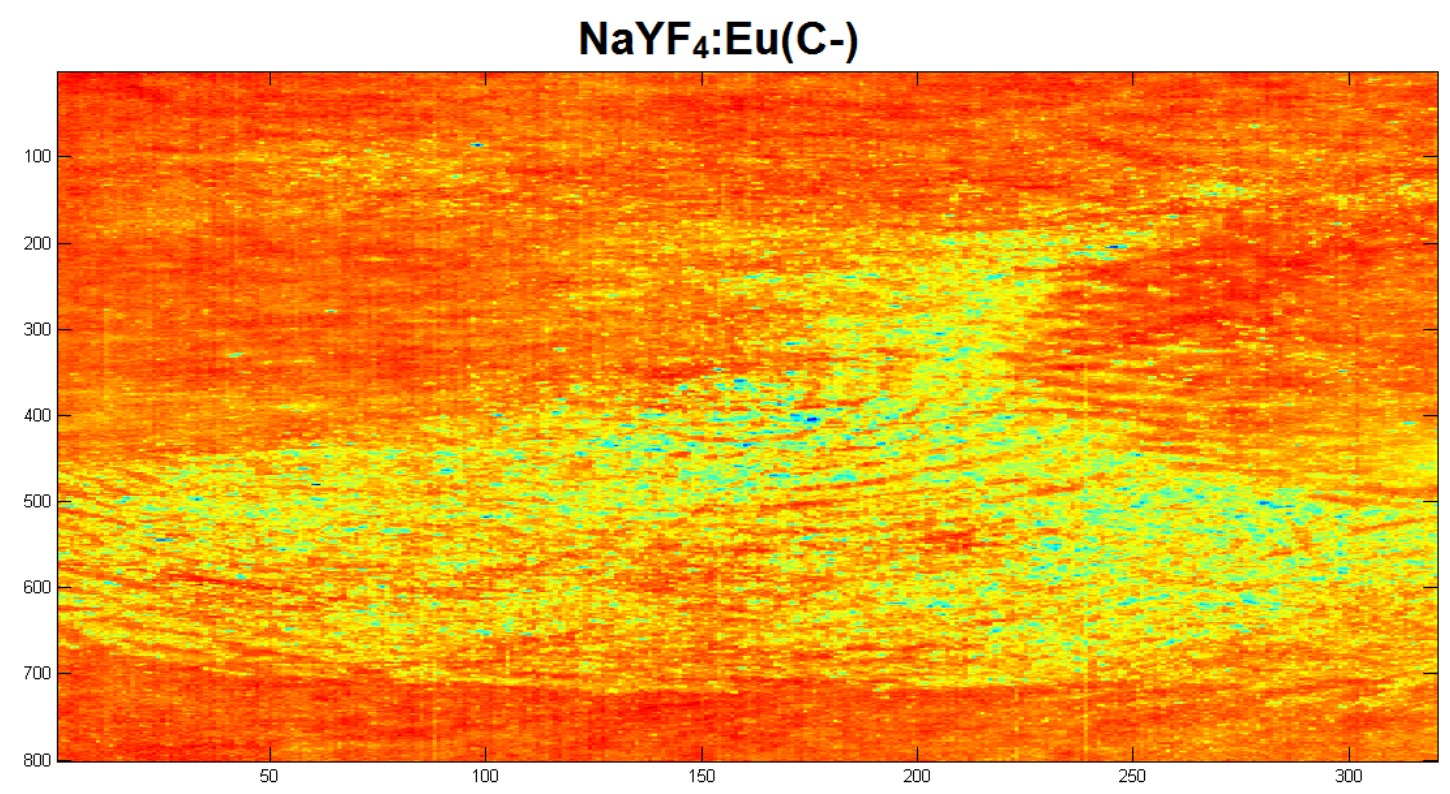

Figura 35 - Digital recolhida com uso de $\mathrm{NaYF}_{4} \mathrm{Eu}(\mathrm{C}$-) com imagem Hiperespectral gerada por meio de emissões na região do NIR. 


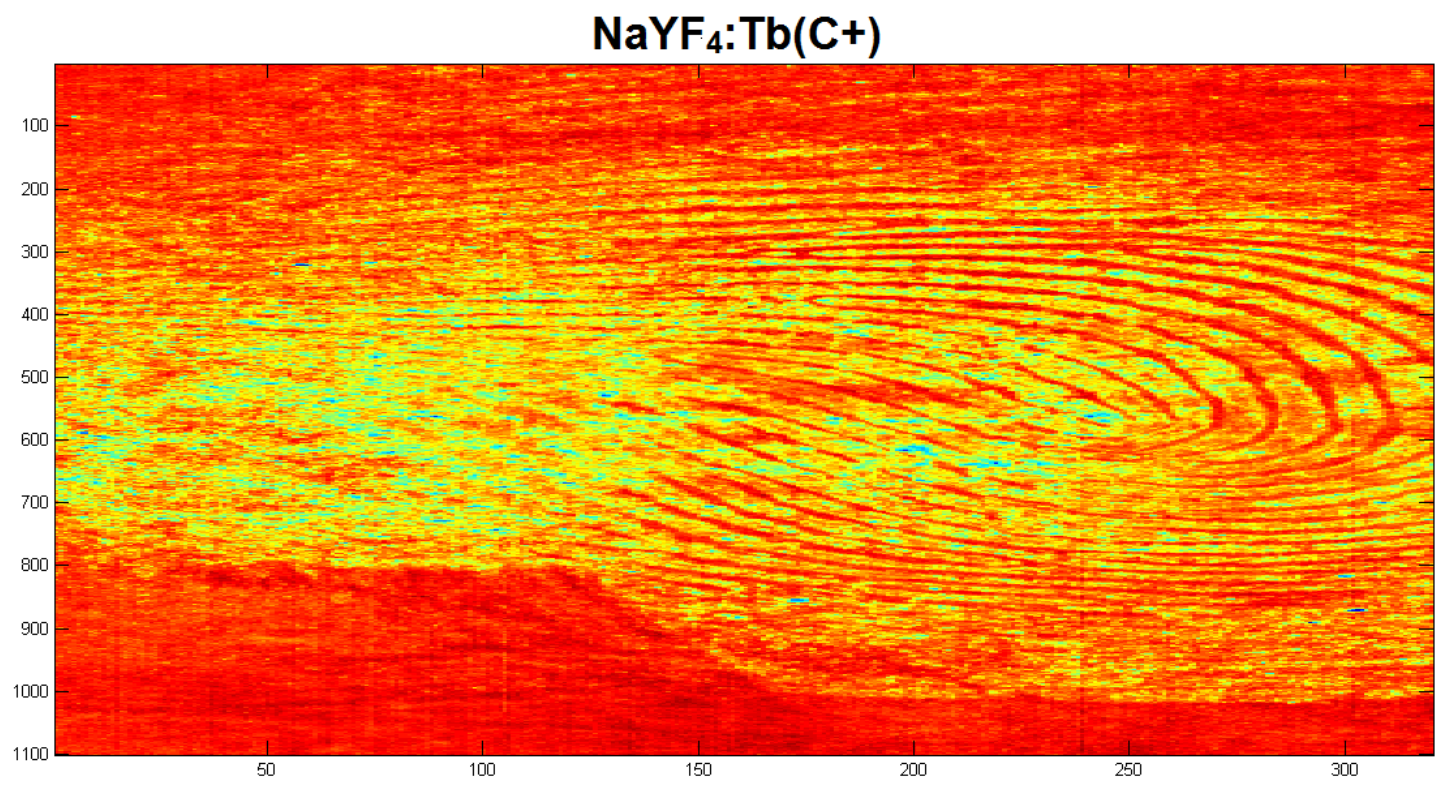

Figura 36 - Digital recolhida com uso de $\mathrm{NaYF}_{4}: \mathrm{Tb}(\mathrm{C}$-) com imagem Hiperespectral gerada por meio de emissões na região do NIR.

Os compósitos desenvolvidos merecem um estudo mais profundo aplicado à essa área, tendo em vista que suas propriedades luminescentes na região do visível e NIR, e sua variação de coloração a olho nu, branco para

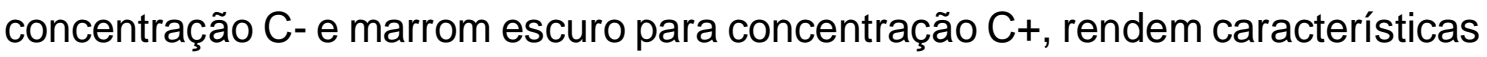
ótimas para essa aplicação como citado por Fernandes e colaboradores. ${ }^{35}$

Vale ressaltar que a união entre C-Dots e lantanídeos possa vir a ser uma forma efetiva de solucionar o mecanismo de luminescência dos Carbon-Dots uma vez que os estudos de transferência de energia e luminescência dos lantanídeos são bastante conclusivos. 


\section{Referências}

1. Wang, Y., Hu, A., J. Mater. Chem. C, 2014, 2, 6921.

2. Deng, M., Ma, Y., Huang, S., Hu, G., Wang, Nano Res., 2011, 4(7): 685.

3. Alivisatos, P. A., Science, 1996, 5251, 933.

4. Yang, S.-T., Wang, X., Wang, H., Lu, F., Luo, P. G., Cao, L., Meziani, M. J., Liu, J.-H., Liu, Y., Chen, M., Huang, Y., Sun, Y.-P., 'J. Phys. Chem. C, 2009, 113, 18110.

5. Xu, X. Y., Ray, R., Gu, Y. L., Ploehn, H. J., Gearheart, L., Raker, K., Scrivens, W. A., J. Am. Chem. Soc., 2004, 126, 12736.

6. Goh, E. J., Kim, K. S., Kim, Y. R., Jung, H. S., Beack, S., Kong, W. H., Scarcelli, G., Yun, S. H., Hahn, S. K., Biomacromolecules, 2012, 13, 2554.

7. De, B., Karak, N., RSC Adv., 2013, 3, 8286.

8. Li, H., Kang, Z., Liu, Y., Lee, S.-T., J. Mater. Chem., 2012, 22, 24230.

9. Liu, Y., Kim, D. Y., Chem. Commun., 2015, 51, 4176.

10. Tang, L. B., Ji, R. B., Cao, X. K., Lin, J. Y., Jiang, H. X., Li, X. M., Teng, K. S., Luk, C. M., Zeng, S. J., Hao, J. H., Lau, S. P., ACS Nano, 2012, 6, 5102.

11.Barbosa, C. D. E. S., Corrêa, J. R., Medeiros, G. A., Barreto, G., Magalhães, K. Ç., Oliveira, A. L., Spencer, J., Rodrigues, M. O., Neto, B. A. D., Chem. Eur. J., 2015, 21, 5055.

12.Sun, Y.-P., Zhou, B., Lin, Y., Wang, W., Fernando, K. A. S., Pathak, P., Meziani, M. J., Harruff, B. A., Wang, X., Wang, H., Luo, P. G., Yang, H., Kose, M. E., Chen, B., Veca, L. M., Xie, S.-Y., J. Am. Chem. Soc., 2006, $128,7756$.

13. Tang, L., Ji, R., Li, X., Bai, G., Liu, C. P., Hao, J., Lin J., Jiang, H., Teng, K. S., Yang, Z., Lau, S. P., ACS Nano, 2014, 8, 6312.

14. Yin, B., Deng, J., Peng, X., Long, Q., Zhao, J., Lu, Q., Chen, Q., Li, H., Tang, H., Zhang, Y., Yao, S., Analyst, 2013, 138, 6551.

15.Wang, F., Xie, Z., Zhang, B., Liu, Y., Yang, W., Liu, C.-Y., Nanoscale, 2014, 6, 3818.

16. Wang, X., Cao, L., Lu, F., Meziani, M. J., Li, H., Qi, G., Zhou, B., Harruf, B. A., Kermarrec, F., Sun, Y.-P., Chem. Commun. (Camb), 2009, 25, 3774. 
17. Li, X., Wang, H., Shimizu, Y., Pyatenko, A., Kawaguchi, K., Koshizaki, N., Chem. Commun., 2011, 47, 932.

18. Jiang, H., Chen, F., Lagally, M. G., Denes, F. S., Langmuir, 2010, 26 , 1991.

19.Zhou, J., Booker, C., Li, R., Zhou, X., Sham, T.-K., Sun, Z., Ding, Z., J. Am. Chem. Soc., 2007, 129, 744.

20.Zhu, H., Wang, X., Li, Y., Wang, Z., Yang, F., Yang, X., Chem. Commun., 2009, 5118.

21. Liu, H., Ye, T., Mao, C., Angew. Chem. Int., 2007, 46, 6473.

22. Peng, J., Gao, W., Gupta, B. K., Liu, Z., Romero-Aburto, R., Ge, L., Song, L., Alemany, L. B., Zhan, X., Gao, G., Vithayathil, S. A., Kaipparettu, B. A., Marti, A. A., Hayashi, T., Zhun, J.-J., Ajayan, P. M., Nano Lett., 2012, 12, 844.

23. Pan, D., Zhang, J., Li, Z., Wu, M., Adv. Mater., 2010, 22, 734.

24. Sahu, S., Behera, B., Maiti, T. K., Mohapatra, S., Chem. Commun., 2012, 48, 8835.

25. Anilkumar, P., Wang, X., Cao, L., Sahu, S., Liu, J.-H., Wang, P., Korch, K., Tackett II, K. N., Parenzan, A., Sun, Y.-P., Nanoscale, 2011, 3, 2023.

26. Wang, K., Gao Z., Gao, G., Wo, Y., Wang, Y., Shen, G., Cui, D., Nanoscale Res. Lett., 2013, 8, 122.

27. Cao, L., Sahu, S., Anilkumar, P., Bunker, C. E., Xu, J., Fernando, K. A. S., Wang, P., Guliants, E. A., Tackett II, K. N., Sun, Y.-P., J. Am. Chem. Soc., 2011, 133, 4754.

28. Cao, L. Anilkumar, P., Wang, X., Liu, J.-H., Sahu, S., Meziani, M. J., Myers, E., Sun, Y.-P., Can. J. Chem., 2011, 89, 104.

29. Li, Y., Zhao, Y., Cheng, H., Hu, Y., Shi, G., Dai, L., Qu, L., J. Am. Chem. Soc., 2012, 134, 15.

30. Luo, P. G., Sahu, S., Yang, S.-T., Sonkar, S. K., Wang, J., Wang, H., LeCroy, G. E., Cao, L., Sun, Y.-P., J. Mater. Chem. B, 2013, 1, 2116.

31. Luo, P. G., Yang, F., Yang, S.-T., Sonkar, S. K., Yang, L., Broglie, J. J., Liu, Y., Sun, Y.-P., RSC Adv., 2014, 4, 10791.

32. Posthuma-Trumpie, G. A., Wichers, J. H., Koets, M., Berendsen, B. J. M., van Amerongen, A., Anal. Bioanal. Chem., 2012, 402, 593.

33. Zhou, L., Li, Z., Liu, Z., Ren, J., Qu., Langmuir, 2013, 29, 6396. 
34. Yu, J., Song, N., Zhang, Y.-K., Zhong, S.-X., Wang, A.-J., Chen, J., Sens. Actuators B, 2015, 214, 29.

35. Fernandes, D., Krysmann, M. J., Kelarakis, A., Chem. Commun., 2015, $51,4902$.

36. Gao, X., Yang, L., Petros, J. A., Marshall, F. F., Simons, J. W., Nie, S., Curr. Opin. Biotechnol., 2005, 16, 63.

37. Basu, A., Suryawanshi, A., Kumawat, B., Dandia, A., Gui, D., Ogale, S. B., Analyst, 2015, 140, 1837.

38. Liu, S.-S.; Wang, C.-F.; Li, C.-X.; Wang, J.; Mao, L.-H.; Chen, S.; J. Mater. Chem. C, 2014, 2, 6477.

39. Rodrigues, C. V., Correa, J. R., Aiube, C. M., Andrade, L. P., Galvão, P. M., Costa, P. A., Campos, A. L., Pereira, A. J., Ghesti, G. F., Felix, J. F., Weber, I. T., Neto, B. A., Rodrigues, M. O., J. Braz. Chem. Soc., 2015, 00, 1.

40. Lorbeer, C.; Mudring, A.-V. 'J. Phys. Chem. C, 2013, 117, 12229.

41. Zhang, F.; Wong, S. S. ACS Nano, 2009, 4, 99.

42. Kimani, M. M.; McMillen, C. D.; Kolis, J. W. Inorg. Chem., 2012, 51, 3588.

43. Binnemans, K., Chem. Rev., 2009, 109, 4283.

44. Eliseevaa, S. V., Bünzli, J. G., Chem. Soc. Rev., 2010, 39, 189.

45. Räsänen, M., Takalo, H., Rosenberg, J., Mäkela, J., Haapakka, K., Kakare, J., J. Lumin., 2014, 146, 211.

46. D'Aléo, A., Pointillart, F., Ouahab, L., Andraud, C., Maury, O., Coord. Chem. Rev., 2012, 256, 1604.

47. Neto, N. M. B., Oliveira, S. L., Guedes, I., Dinelli, L. R., Misoguti, L., Mendonça, C. R., Batista, A. A., Zílio, S. C., J. Braz. Chem. Soc., 2006, 17, 1377.

48. Latva, M., Takalo, H., Mukkala, V., Matachesu, C., Rodriguez-Ubis, J. C., Kankare, J., J. Lumin., 1997, 75, 149.

49. Richardson, F. S., Chem. Rev., 1982, 82, 541.

50. Beeby, A., Clarkson, I. M., Dickins, R. S., Faulkner, S., Parker, D., Royle, L., Sousa, A. S., Williams, J. A. G., Woods, M., J. Chem. Soc. Perkin Trans., 1999, 2, 493.

51. Wang, G., Peng, Q., J. Solid State Chem., 2011, 184, 59. 
52. Wang, Q., Liu, Y., Liu, B., Chai, Z., Xu, G., Yu, S., Zhang, J., CrystEngComm, 2013, 15, 8262.

53. Klink, S. I., Grave, L., Reinhoudt, D. N., van Veggel, F. C. J. M., Werts, M. H. V., Geurts, F. A. J., Hofstraat, J. W., 'J. Phys. Chem. A, 2000, 104, 5457.

54. Syamchand, S. S., Sony, G., J. Lumin., 2015, 165, 190.

55. van der Ende, B. M., Aarts, L., Meijerink, A., Phys. Chem. Chem. Phys., 2009, 11, 11081.

56. Wang, F., Liu, X., Chem. Soc. Rev., 2009, 38, 976.

57. Assaaoudi, H., Shan, G.-B., Dyck, N., Demopoulos, G. P., CrystEngComm, 2013, 15, 4739.

58. Sui, Y., Tao, K., Tian, Q., Sun, K., 'J. Phys. Chem. C, 2011, 116, 1732.

59. Stöber, W., Fink, A., Bohn, E., J. Colloid Interface Sci., 1968, 26, 62.

60. Wong, H.-T., Vetrone, F., Naccache, R., Chan, H. L. W., Hao, J., Capobianco, J. A., J. Mater. Chem., 2011, 21, 16589

61. Yang, J., Shen, D., Li, X., Li, W., Fang, Y., Wei, Y., Yao, C., Tu, B., Zhang, F., Zhao, D., Chem. Eur. J., 2012, 18, 13642.

62. Sanchez, C., Julián, B., Belleville, P., Popall, M., J. Mater. Chem., 2005, 15, 3559.

63. Hatchett, D. W., Josowicz, M., Chem. Rev., 2008, 108, 746.

64. Dey, D., Bhattacharya, T., Majumdar, B., Mandani, S., Sharma, B., Sarma, T. K., Dalton Trans., 2013, 42, 13821.

65. Wang, Z.-X., Zheng, C.-L., Li, Q.-L., Ding, S.-N., Analyst, 2014, 139, 1751.

66. Liu, N. Liu, J., Yang, Y., Qiao, S., Huang, H., Liu, Y., Kang, Z., Dalton Trans., 2015, 44, 7318.

67. Wang, J., Gao, M., Ho, G. W., J. Mater. Chem. A, 2014, 2, 5703.

68. Luo, P., Li, C., Shi, G., Phys. Chem. Chem. Phys., 2012, 14, 7360.

69. Li, X., Zhang, S., Kulinich, S. A., Liu, Y., Zeng, H., Sci. Rep., 2014, 4:4976.

70. Tang, D., Liu, J., Wu, X., Liu, R., Han, X., Han, Y., Huang, H., Liu, Y., Kang, Z., ACS Appl. Mater. Interfaces, 2014, 6, 7918.

71. Samanta, T., Hazra, C., Mahalingam, V., New J. Chem., 2015, 39, 106.

72. Zhou, Z., Wang, Q., Wang, J., Zhang, C. C., Carbon, 2015, 93, 671.

73. Chen, H., Xie, Y., Kirillov, A. M., Liu, L., Yu, M., Liu, W., Tang, Y., Chem. Commun., 2015, 51, 5036. 
74. Shi, Y., Pan, Y., Zhong, J., Yang, J., Zheng, J., Cheng, J., Song, R., Yi, C., Carbon, 2015, 93, 742.

75. Wang, Z., Tao, F., Yao, L., Cai, W., Li, X., J. Cryst. Growth, 2006, 290, 296.

76. H. Na, K. Woo, K. Lim and H. S. Jang, Nanoscale, 2013, 5, 4242

77. Park, C.-M., Hwa, Y., Sung, N.-E., Sohn, H.-J. J. Mater. Chem., 2010, 20, 1097.

78. Rajan, A. S., Sampath, S., Shukla, A. K., Energy Environ. Sci., 2014, 7, 1110.

79. Ding, M., Lu, C., Cao, L., Song, J., Ni, Y., Xu, Z., J. Mater. Sci., 2013, 48, 4989.

80. Kim, S. Y., Woo, K., Lim, K., Lee, K., Jang, H. S., Nanoscale, 2013, 5, 9255.

81. Moon, B. K., Jeong, J. H., Yi S.-s., Kim, S. C., Choi, H., Kim, J. H., Opt. Mater., 2006, 28, 676.

82. Melo, E. F., Santana, N. C., Alves, K. G. B., Sa, G. F., 'Melo, C. P., Rodrigues, M. O., Junior, S. A., J. Mater. Chem. C, 2013, 1, 7574. 


\section{Anexos}

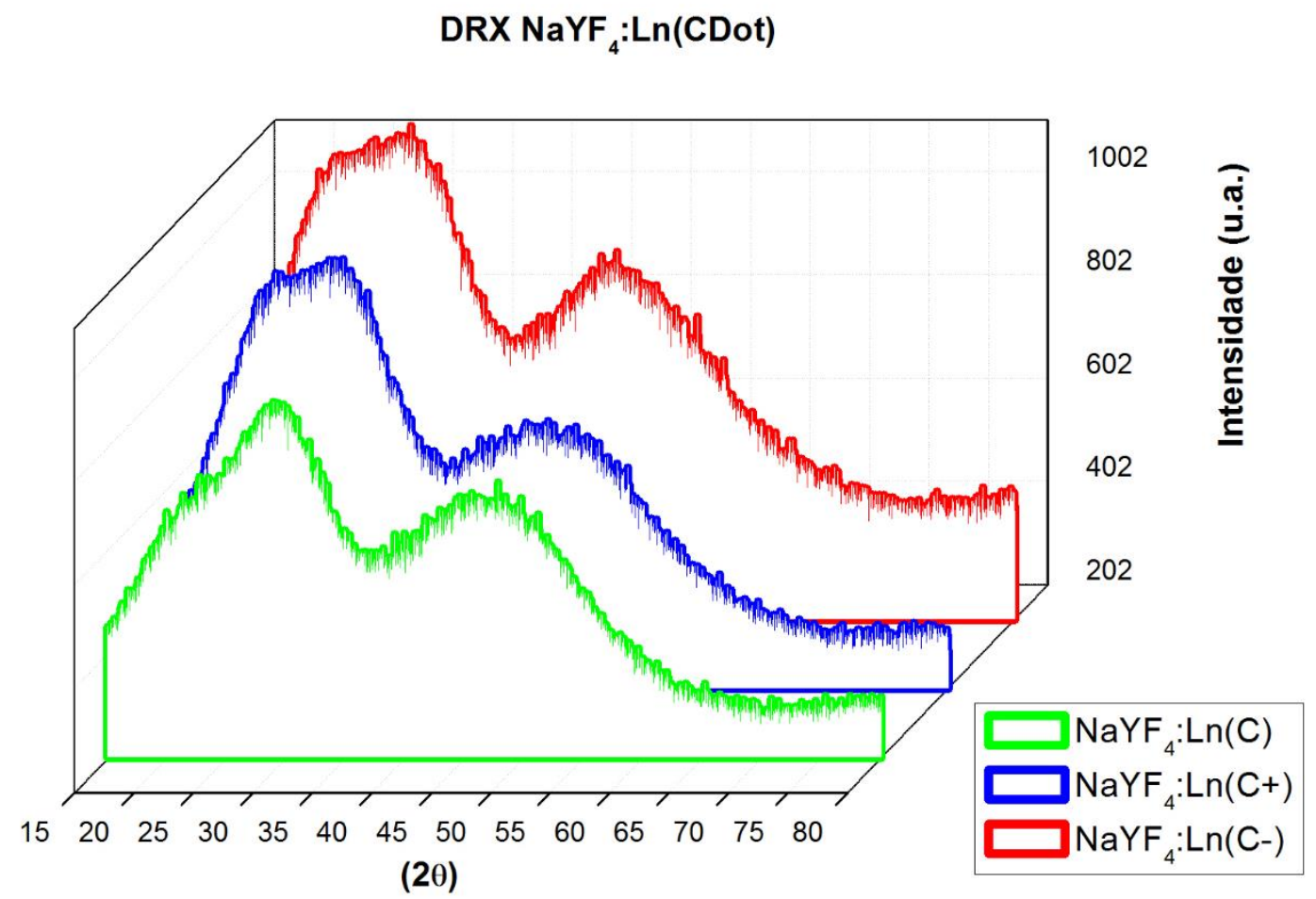

Figura 37 - Difratograma de Raio-X de pó dos compósitos sintetizados por coprecipitação. 


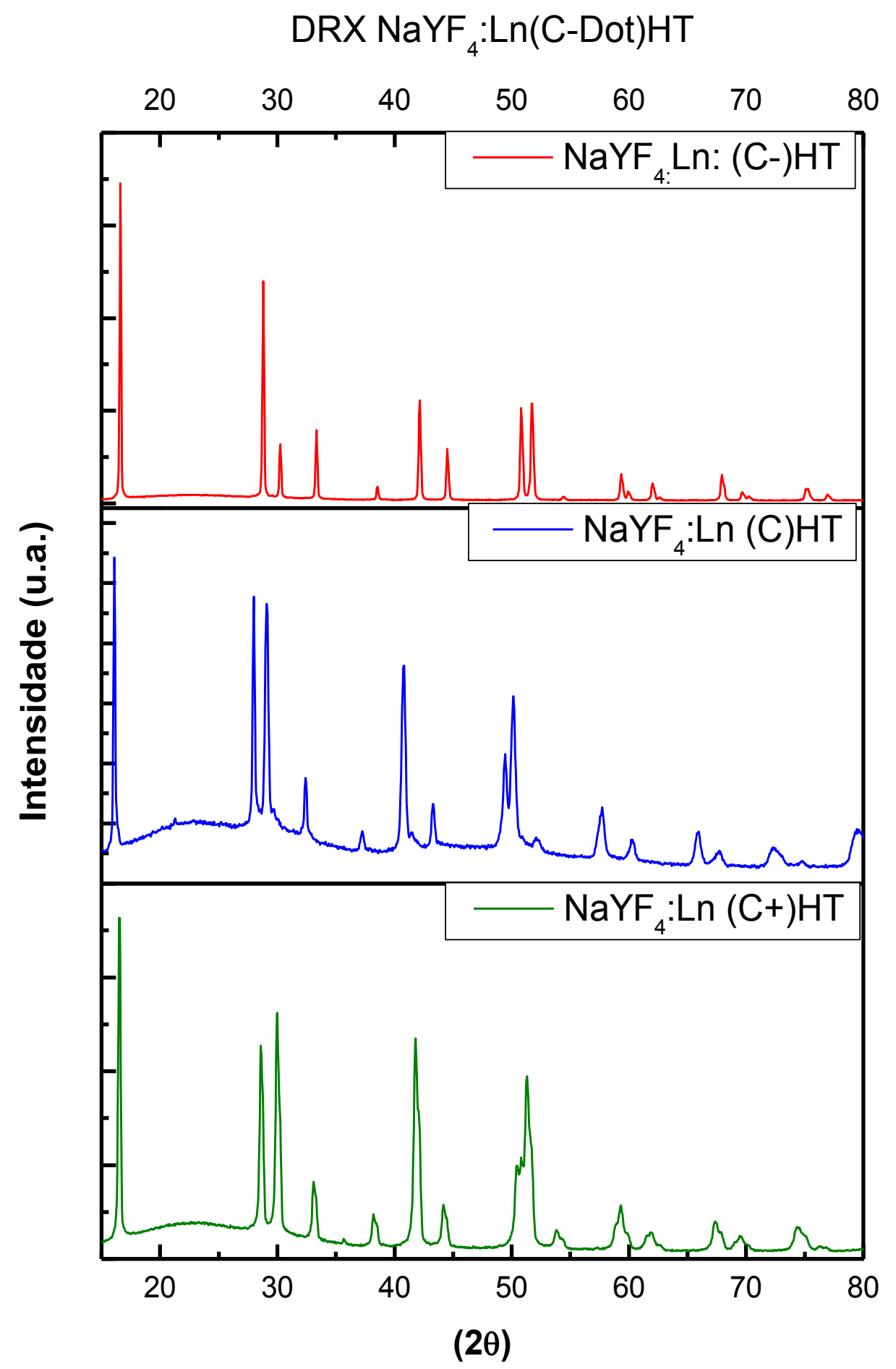

Figura 38 - Difratograma de Raio-X de pó dos compósitos sintetizados por via hidrotermal 

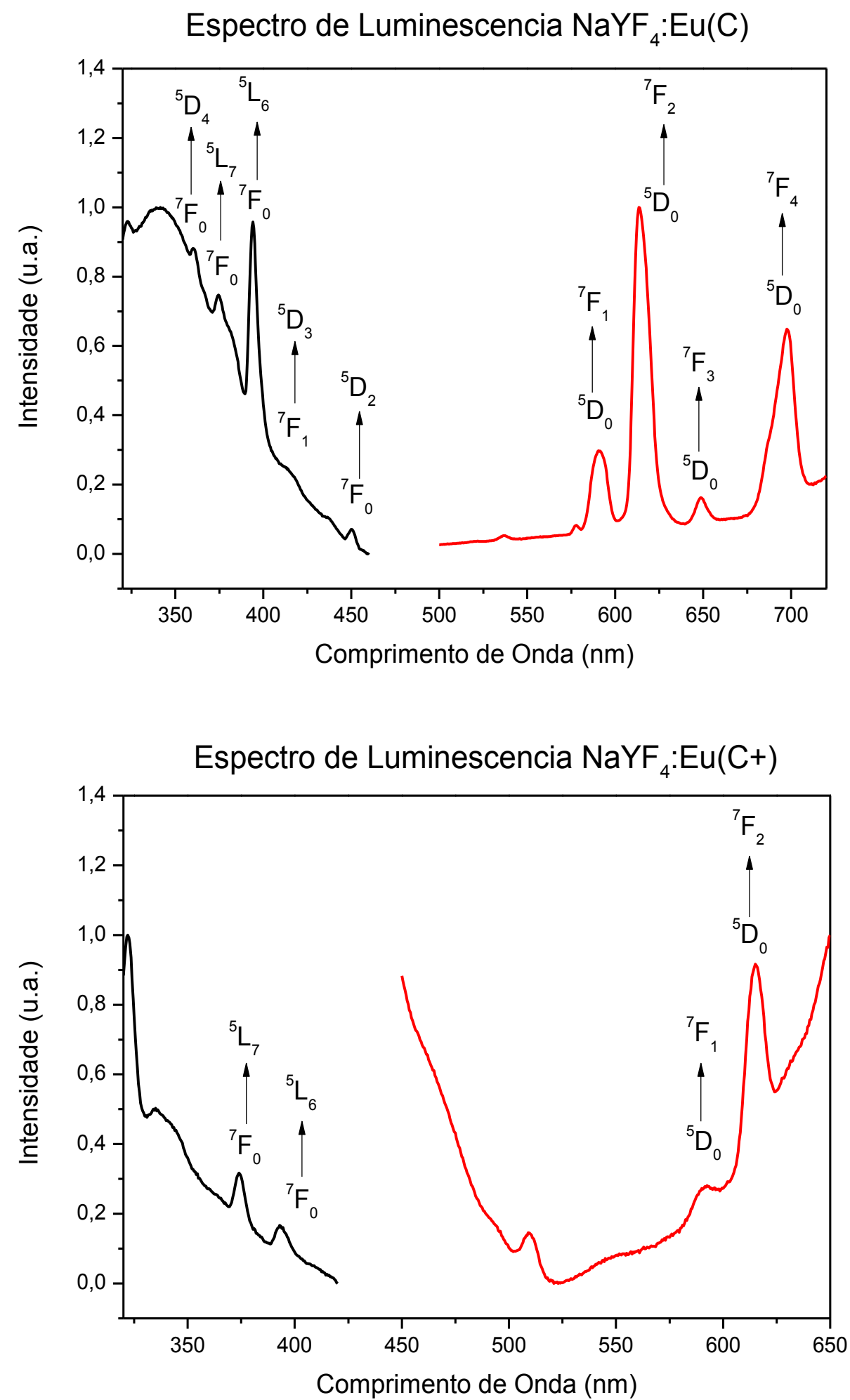

Figura 39 - Espectros de Luminescência dos compósitos NaYF $\mathrm{F}_{4} \mathrm{Eu}(\mathrm{C})$ e $\left(C_{+}\right) ;(-)$Excitação e (-) Emissão 

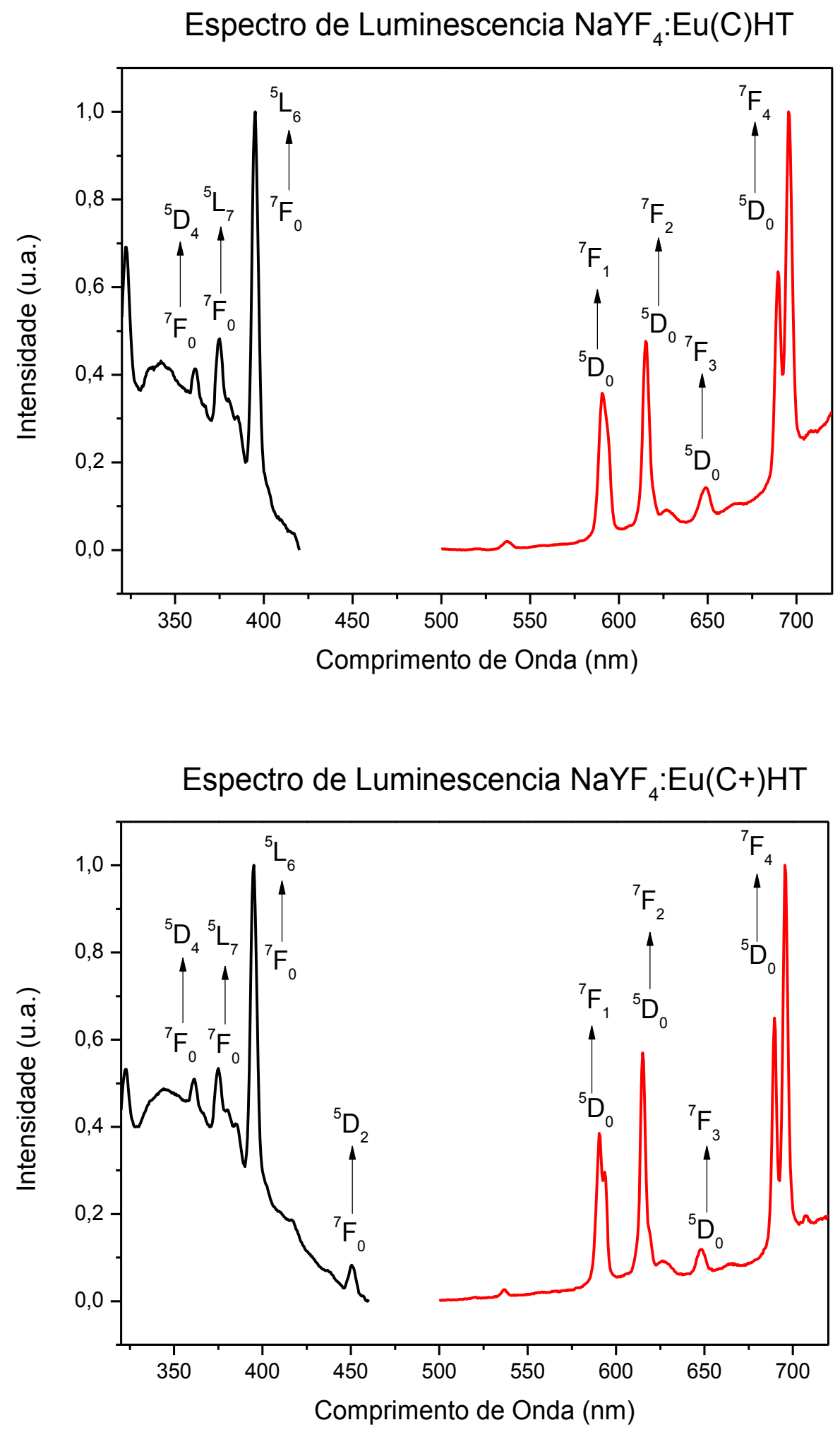

Figura 40 - Espectros de Luminescência dos compósitos NaYF 4 :Eu(C)HT e (C+)HT; (-) Excitação e (-) Emissão 
Espectro de Luminescencia $\mathrm{NaYF}_{4}: \mathrm{Tb}(\mathrm{C})$

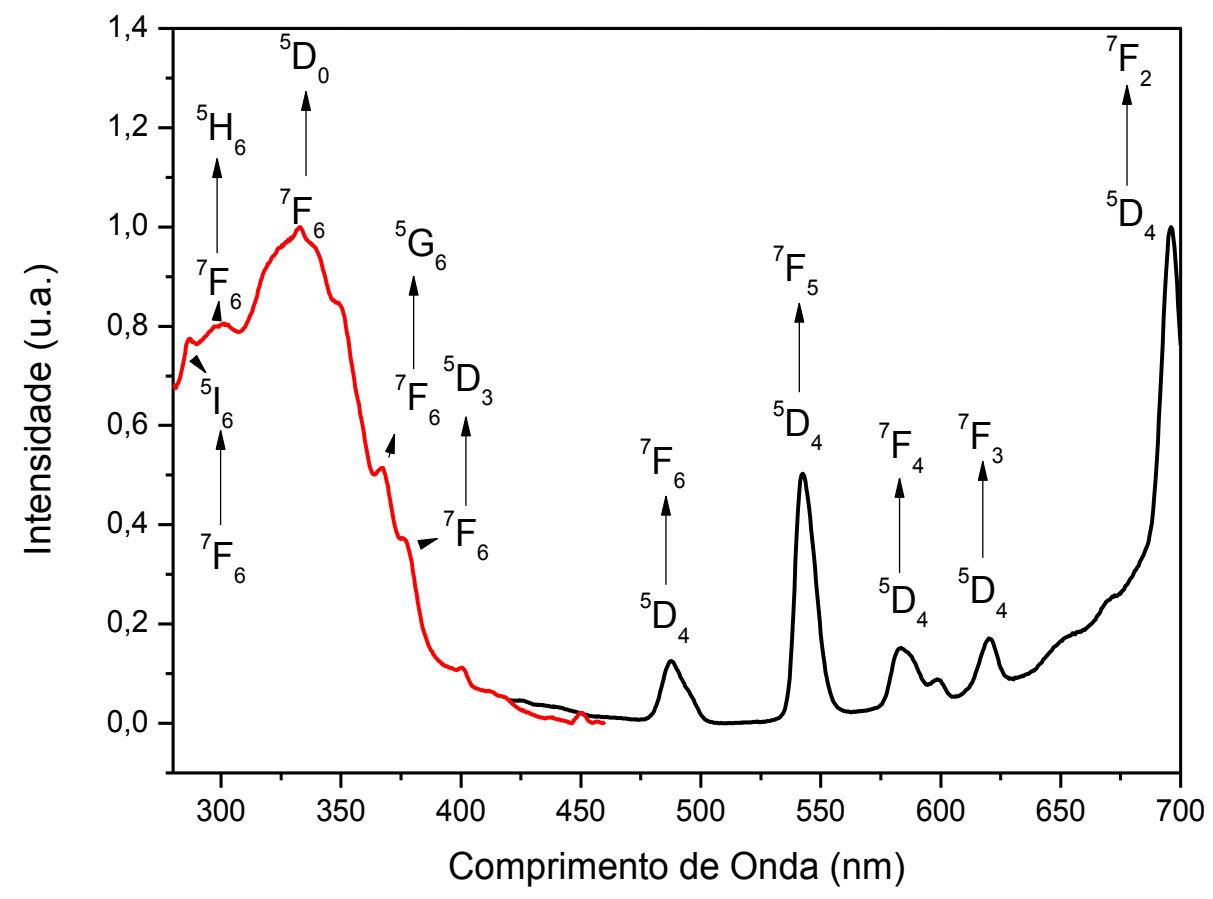

Espectro de Luminescencia $\mathrm{NaYF}_{4}: \mathrm{Tb}(\mathrm{C}+)$

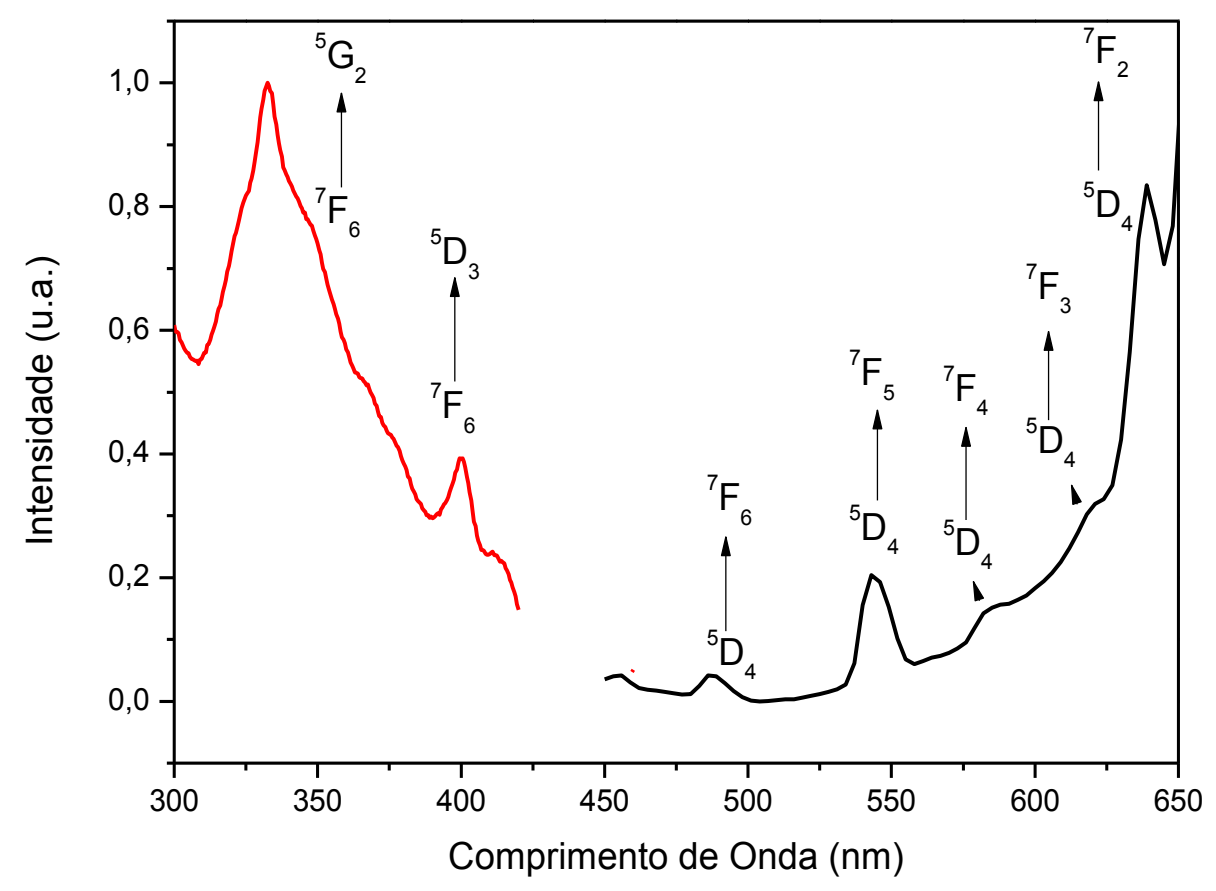

Figura 41 - Espectros de Luminescência dos compósitos $\mathrm{NaYF}_{4}: \mathrm{Tb}(C)$ e (C+); (-) Excitação e (-) Emissão 

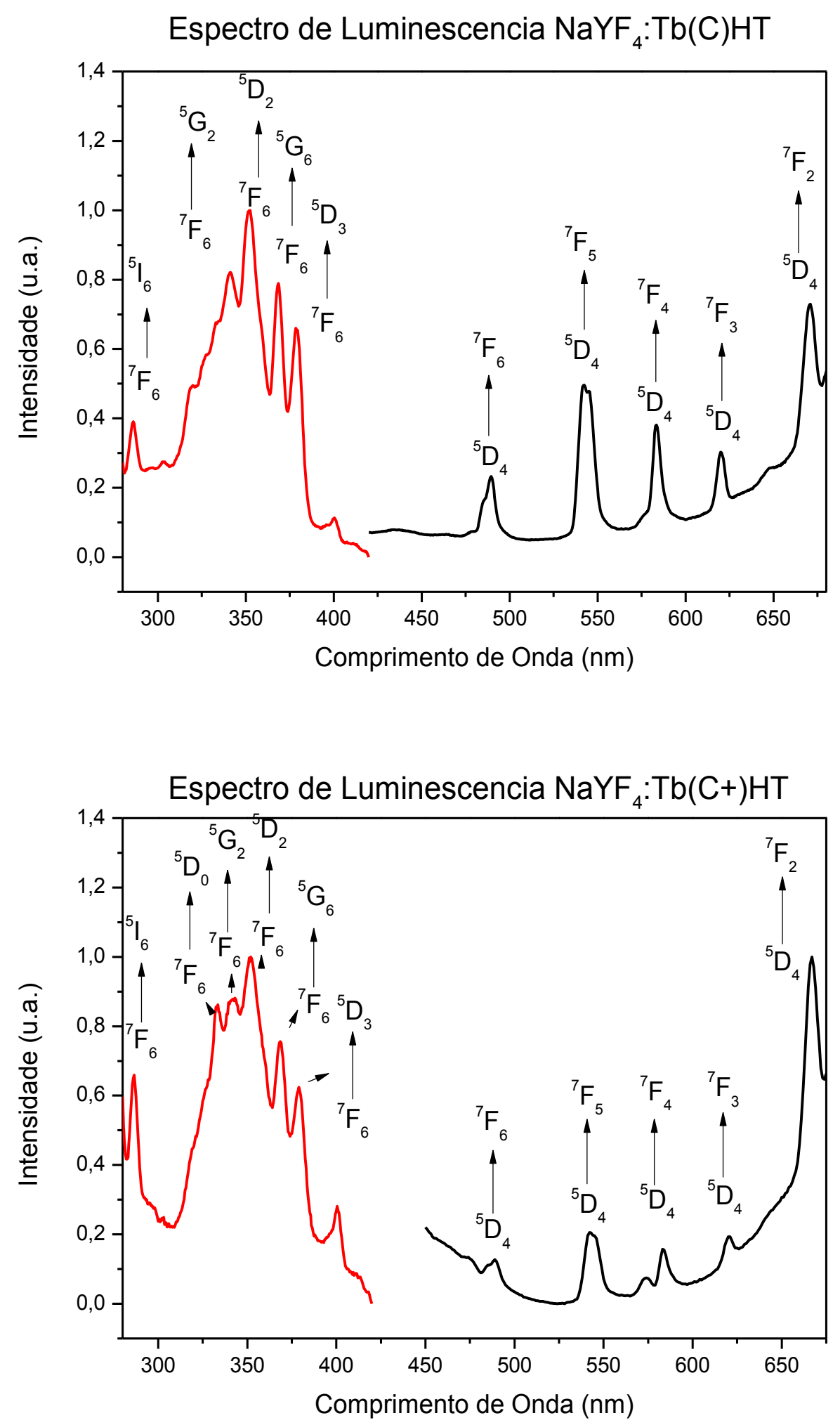

Figura 42 - Espectros de Luminescência dos compósitos $\mathrm{NaYF}_{4}: \mathrm{Tb}(\mathrm{C}) \mathrm{HT}$ e $(\mathrm{C}+) \mathrm{HT}$; (-) Excitação e (-) Emissão 



Figura 43 - Tempos de vida dos nanocristais $\mathrm{NaYF}_{4}: \mathrm{Eu}$ e NaYF :Tb 

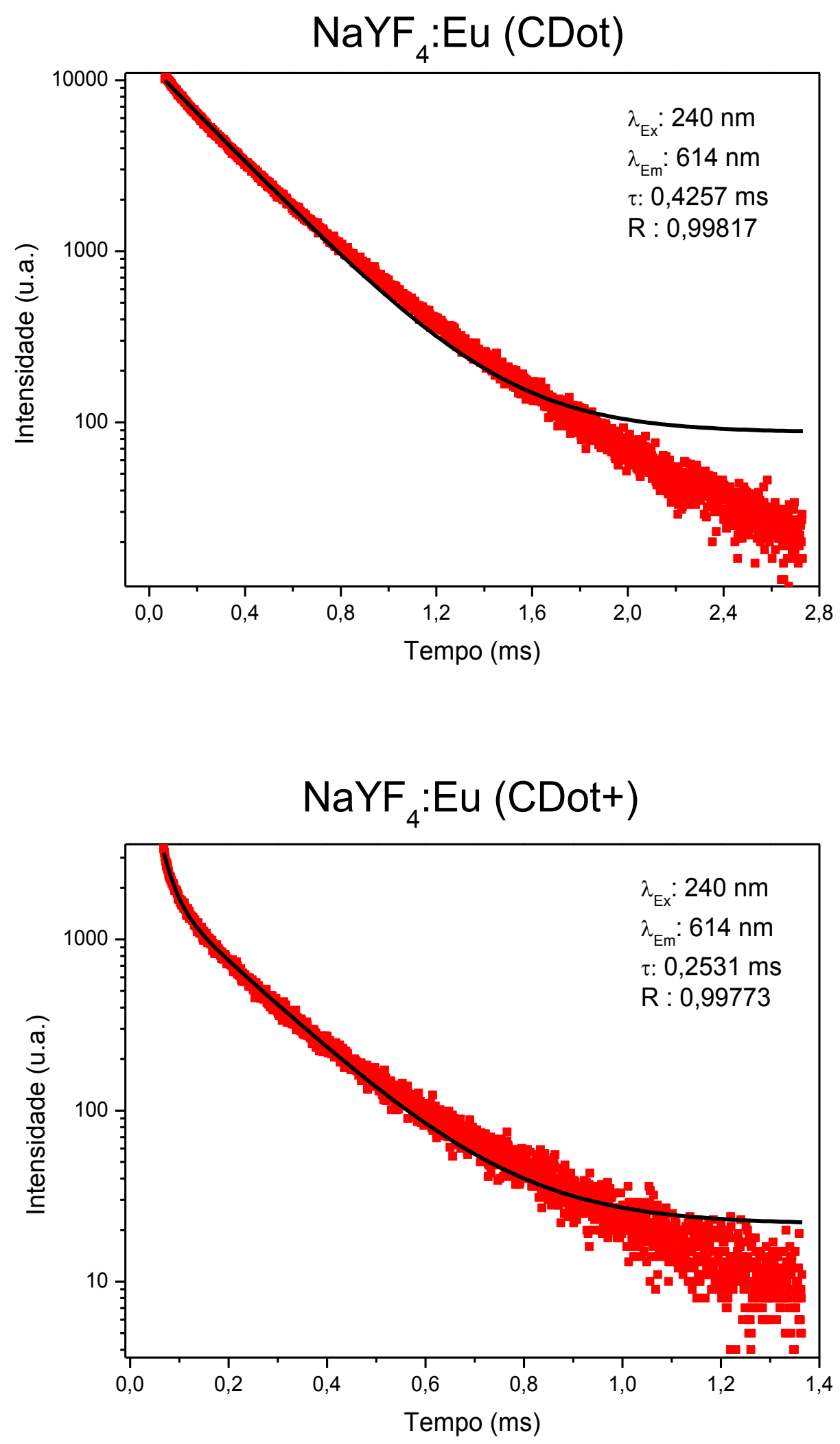

Figura 44 - Gráfico de Tempos de Vida dos compósitos NaYF $4: E u(C)$ e (C+). 

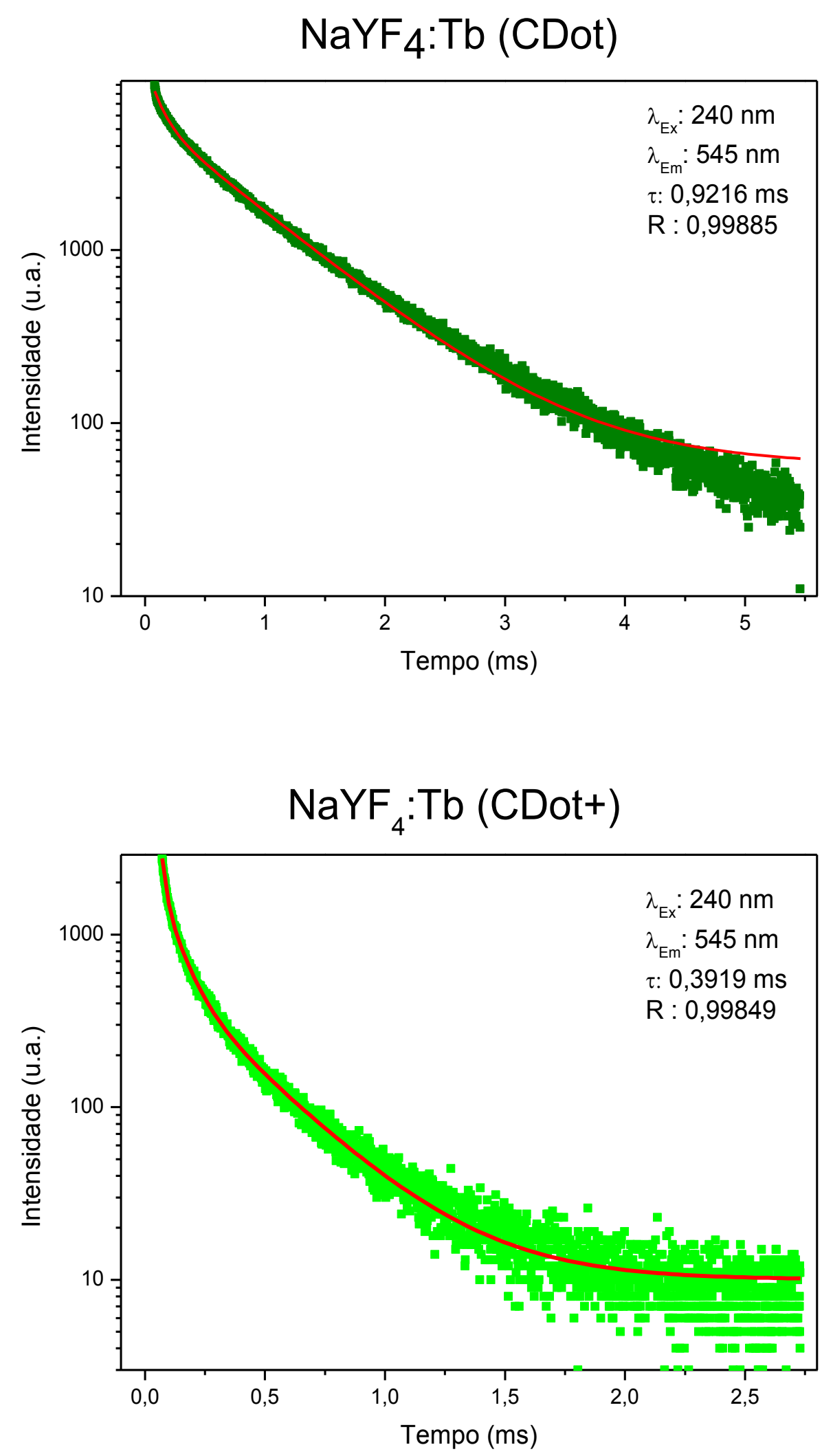

Figura 45 - Gráficos de Tempos de Vida das Espécies $\mathrm{NaYF}_{4}: \mathrm{Tb}(C)$ e (C+). 